\title{
The best of both worlds? Studies on healthy indulgences and their effects on food intake control
}

Citation for published version (APA):

Belei, N. V. T. (2012). The best of both worlds? Studies on healthy indulgences and their effects on food intake control. [Doctoral Thesis, Maastricht University]. Datawyse / Universitaire Pers Maastricht. https://doi.org/10.26481/dis.20120705nb

Document status and date:

Published: 01/01/2012

DOI:

10.26481/dis.20120705nb

Document Version:

Publisher's PDF, also known as Version of record

\section{Please check the document version of this publication:}

- A submitted manuscript is the version of the article upon submission and before peer-review. There can be important differences between the submitted version and the official published version of record.

People interested in the research are advised to contact the author for the final version of the publication, or visit the DOI to the publisher's website.

- The final author version and the galley proof are versions of the publication after peer review.

- The final published version features the final layout of the paper including the volume, issue and page numbers.

Link to publication

\footnotetext{
General rights rights.

- You may freely distribute the URL identifying the publication in the public portal. please follow below link for the End User Agreement:

www.umlib.nl/taverne-license

Take down policy

If you believe that this document breaches copyright please contact us at:

repository@maastrichtuniversity.nl

providing details and we will investigate your claim.
}

Copyright and moral rights for the publications made accessible in the public portal are retained by the authors and/or other copyright owners and it is a condition of accessing publications that users recognise and abide by the legal requirements associated with these

- Users may download and print one copy of any publication from the public portal for the purpose of private study or research.

- You may not further distribute the material or use it for any profit-making activity or commercial gain

If the publication is distributed under the terms of Article $25 \mathrm{fa}$ of the Dutch Copyright Act, indicated by the "Taverne" license above, 


\section{The Best of Both Worlds?}

Studies on Healthy Indulgences and Their Effects on Food Intake Control 
(C) 2012, Nina Belei, Maastricht

All rights reserved. No part of this publication may be reprinted or utilized in any form or by any electronic, mechanical, or other means, now known or hereafter invented, including photocopying and recording or in any information storage retrieval system, without written permission of the copyright owner.

Cover Design: Nina Belei

Printed by: Datawyse, Maastricht, The Netherlands

ISBN 9789461591609 


\title{
The Best of Both Worlds?
}

\author{
Studies on Healthy Indulgences and \\ Their Effects on Food Intake Control
}

\section{PROEFSCHRIFT}

Ter verkrijging van de graad van doctor aan de Universiteit Maastricht,

op gezag van de Rector Magnificus, Prof. mr. G. P. M. F. Mols volgens het besluit van het College van Decanen, in het openbaar te verdedigen

op donderdag 5 juli 2012 om 10:00 uur

door

Nina Vanessa Therese Belei

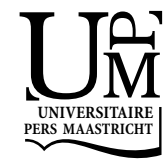




\section{Promotor}

Prof. dr. J. G. A. (Jos) Lemmink

\section{Copromotor}

Prof. dr. S. (Suresh) Ramanathan, Texas A\&M University

\section{Beoordelingscommissie}

Prof. dr. J. C. (Ko) de Ruyter (voorzitter)

Prof. dr. M. (Mien) Segers

Prof. dr. J.C.M. (Hans) van Trijp, Wageningen University 
"To eat is a necessity, but to eat intelligently is an art." La Rochefoucauld 


\section{ACKNOWLEDGEMENTS}

"Two little mice fell in a bucket of cream. The first mouse quickly gave up and drowned. The second mouse, wouldn't quit. [S] he struggled so hard that eventually [s] he churned that cream into butter and crawled out. [Ladies and] gentlemen, as of this moment, I am that second mouse."

(Adapted from Frank Abagnale Sr. in "Catch Me If You Can”)

The journey of writing a dissertation opens up great opportunities to grow and develop both on a professional, as well as on a personal level, yet at the same time one is faced with many obstacles, phases of feeling insecure and lacking self-confidence, and situations in which one has to decide whether to give up [and drown], or continue to believe in oneself and working even harder on turning "that cream into butter". The process of completing this manuscript has involved all of the above and more. It has taken me to my limits several times, but then, with the support, care, and guidance of many special people, I was able to discover the great highs involved with doing cool research and to pull myself out of the lows. Working together with very inspiring people and experiencing that perseverance and faith in one's capabilities and hard work will eventually pay off, has not only broadened my horizon, but has made me learn a lot about myself. Today, I would like to express my gratitude to all those who have accompanied me on this path, who have shared the best and worst moments of my Ph.D. with me, and without whom this doctoral dissertation would never have been possible.

First and foremost, I would like to thank my advisors Professor Dr. Jos Lemmink and Professor Dr. Suresh Ramanathan for their invaluable guidance and continuous support. Jos, you gave me the chance to start the journey of writing a dissertation by offering me a PhD position in the Department of Marketing \& Supply Chain Management at Maastricht University. Although your role as the dean of the School of Business and Economics has kept your days filled with meetings and business trips, you always had an open door for me and I knew I could count on your support at all times. You always believed in me and my ideas, especially when times were rough and I started over with a new topic after my second Ph.D. year. Your incessant support in everything I came to discuss with you not only gave me the opportunity to a 
wonderful and productive stay at Northwestern University (Evanston, IL, USA), but enabled me to grow professionally and to successfully finish what I started. Thank you so much for everything!

Suresh, although you have only joined my way during the second half of my Ph.D. journey, it feels like you have been there from the start. Thank god you are such a spontaneous person, making you come and visit me in Maastricht for a day after we met at the Marketing Science conference in 2010. Our shared research interests together with the lucky circumstance of me spending seven months in Chicago soon after, resulted in an immensely productive, satisfying, and fun collaboration. You have taken on the role as my mentor, always believing in me and my skills and never getting tired of discussing new research ideas and conceptual and methodological research challenges with me. You have been a great source of inspiration and I feel truly blessed for having had such a wonderful, smart, experienced, and motivating mentor on my side. You made me bring out the very best of me and bore with me also when I was facing difficult times. There is just one thing I can say to you: YAI (not what you think)! Thank you!

A very special word of thanks goes to my great friend, former Ph.D. fellow, and today's paranymph Dr. Claudia Jasmand. Indeed, no way without you, Claudi! We became fast friends when we started our Ph.D. journey together on the very same day and since then, we have literally shared and mastered every imaginable situation a doctoral student can possibly encounter. You have been my greatest source of research inspiration and your incredible eye for detail together with your ability to see the big picture has helped me boosting the quality of my work and to turn a vague (but tempting ;-)) idea into a concrete and interesting research question. Most importantly, however, you never stopped motivating and believing in me and our endless discussions (in places like cars, purple-lines, supermarkets, labs, offices, hallways, coffee corners, patios, German and US apartments, cinemas, cafes and bars) on research issues in particular and the challenges and joys of life in general, have made me enjoy this journey and my time in Maastricht so incredibly much more. Thank you so much for your wonderful friendship and loyalty and you know what? I am sure that there is more to come! 
I would also like to express my gratitude to my co-authors and former colleagues Dr. Kelly Geyskens and Dr. Caroline Goukens. Kelly and Caroline, I have learned so much from working with you and I am indebted for the time and effort you have put into our project from the very beginning, for your insightful comments and feedback, and for teaching me to discover and appreciate the relevance and potential of my work within the field of consumer behaviour. Moreover, you have encouraged me to "aim for the stars" and to follow my research guts, for which I am extremely grateful. It has been a great experience to work with you and to bring to life new and "tempting" research projects. Thank you so much for all your support throughout the way; without you, this would have been impossible!

I owe sincere and earnest thankfulness also to Professor Dr. Brian Sternthal, Professor Dr. Nidhi Agrawal, and Professor Dr. Miguel Brendl from Northwestern University, IL, USA. They have made my stay as a visiting scholar in the US possible and being part of the Kellogg School of Management Marketing Group has been the most amazing experience. Brian, you are one of the smartest, insightful, and most generous people I have ever met. I feel truly honoured for having gotten the chance not only to meet you, but also to work with you and, most importantly, to learn from you. Your willingness to share your knowledge and your invaluable feedback on my research has not only significantly improved my work, but has considerably sharpened my ability to think "academic". I very much look forward to continue working with and learning from you in the future. Many thanks for everything you have done for me and for encouraging me to "think big, but pack light!"

I would also like to thank the three members of my assessment committee, Professor Dr. Ko de Ruyter, Professor Dr. Mien Segers, and Professor Dr. Hans van Trijp, for the time and effort they spent on reading my dissertation. A special 'thank you' goes to Professor Dr. Ko de Ruyter, my former boss and Head of Department of Marketing \& Supply Chain Management at Maastricht University. Ko, I am extremely grateful for your support during the difficult time when I started over with a new dissertation topic after my second Ph.D. year. Thank you for believing in me and for letting me find my own research way. I hope that the completion of this manuscript shows you that your support for my decision at that time was indeed worthwhile. 
In addition, I would like to thank my former colleagues at Maastricht University as well as the people from the other universities I got in touch with over the years for the many great discussions on research, for sharing their teaching experiences, and for the interesting and fun breaks which facilitated knowledge exchange and helped building friendships. In particular, I thank Professor Dr. Piet Pauwels, Dr. Vera Blazevic, Prof. Dr. Gaby Odekerken-Schröder, Jan Pelser, Linda Lichel, Simon Bartczek, Charlotte Rolef, Rudi Baethge, Dr. Clemens Köhler, Dr. Daniela Osterrieder, Robert Merrin, Paulo Saraiva, Dr. Ingrid Beckers, Roger Pruppers, and Gwen Noteborn for being great colleagues, confederates in dealing with difficult students, or simply chat-buddies when there was a need to talk. Special thanks also goes to Dr. Elisabeth Brüggen, Dr. Els Breugelmans, Dr. Lieven Quintens, Dr. Bram Foubert, Dr. Evelyn Vanpoucke, Professor Dr. Allard van Riel, the BEElab team, Simon Gurung, and everybody else who supported me with my data collection processes.

The final words of thanks are reserved for my great friends outside the academic world and my wonderful family. Gustel, thank you so much for opening up your heart and life for Noah and for becoming his "Zweitmami" for so many years. Without you I wouldn't know how I would have managed. Petra, thank you for sharing the ups and downs with me on our many walks and runs through the fields around Horbach (often at 5:45am) and for taking care of Noah and Charu whenever I had "emergency" situations and peaks related to my work. Steffi, thank you for being a great friend also when we hardly see each other anymore and for never stopping to trying to reach me even if that implies that you have to talk to the $\mathrm{AB}$ most of the time first. Hopefully, we can improve the frequency of seeing each other in the future. Jan, thank you for supporting for me and my family during the very difficult times in 2009/2010 and for giving me the strength and security I needed to deal with the situation at that time. I am happy that I can finally show you the finished version of my "Diplomarbeit". Pia, thank you for the great times we had in Ankara, Stockholm, Aachen, Jacksonville, and Chicago; next time we will rock Boone.

My biggest and most sincere 'thank you' goes to my parents, my sister Anika, and my wonderful husband Peter (my paranymph). Mami, Papi, and Ani, thank you so much for your continuous support, for giving me the opportunity to follow my dreams, 
and for always being there for me when I needed you. Knowing that you love me for who I am and knowing that you would back up even my most extreme decisions has made me the person I am today. Mami and Papi, just in case you are not aware of it: a million thanks for CL62 and the long time I was able to spend there; this has significantly contributed to finishing up my dissertation in time. Finally, from all my heart, I want to thank my wonderful husband Peter for his endless support, his enduring patience, his deep love, and for always being my biggest protector and motivator. Pidi, I have never met a person who had more faith in me and my abilities and who has showed me so much love on a daily basis for more than 13 years now. I am literally searching for words to express what you mean to me and how incredibly thankful I am for having you in my life. I truly think that without you, I wouldn't be that second mouse looking down at the bucket filled with butter realizing: it is actually FULL! I love you!

Nina Belei Aachen, May 2012 


\section{TABLE OF CONTENTS}

CHAPTER 1 ..................................................................................... 1

1.1 Research Background .................................................................................... 3

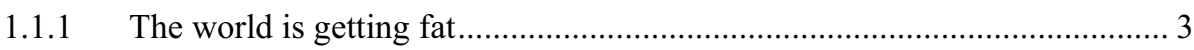

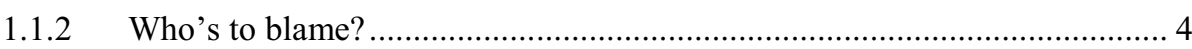

1.1.3 The Rise of Healthy Indulgences........................................................... 7

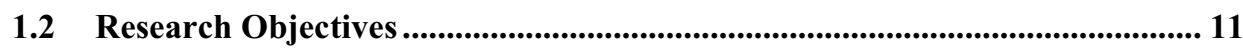

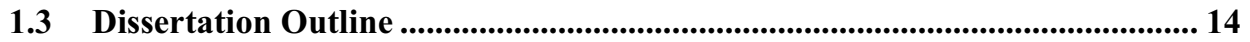

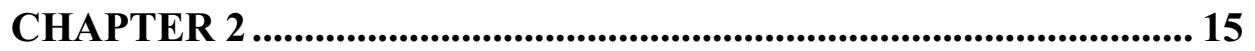

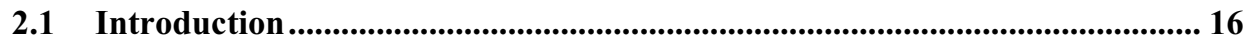

2.2 Conceptual Background ........................................................................................... 18

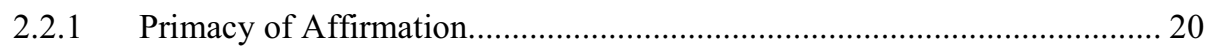

2.3 Experiment 1 - Pilot Study .................................................................................... 25

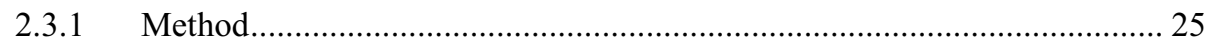

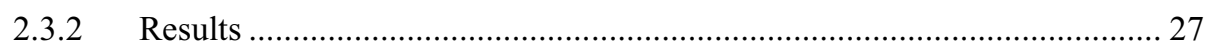

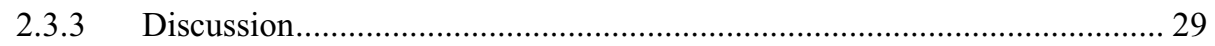

2.4 Experiment 2a......................................................................................................... 30

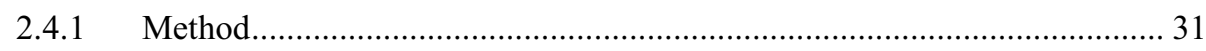

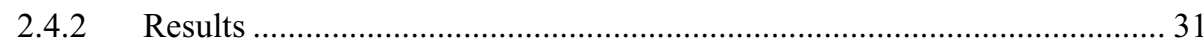

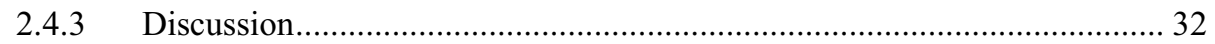

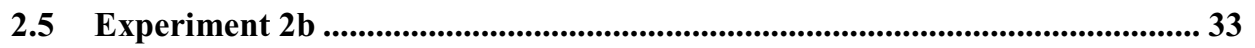

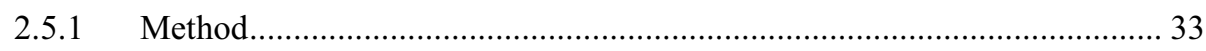

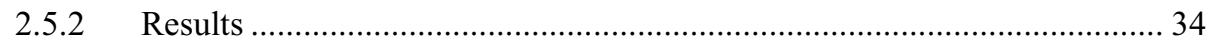

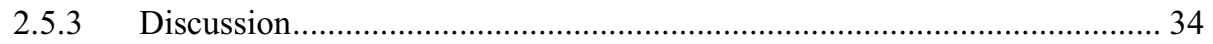

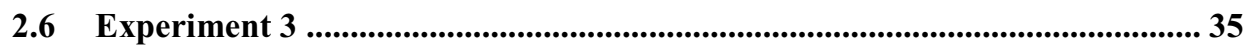

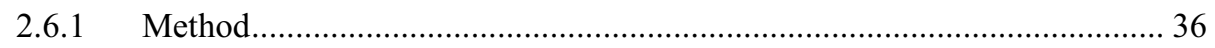




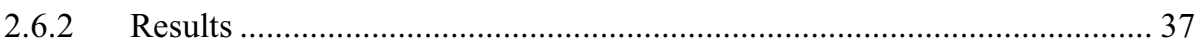

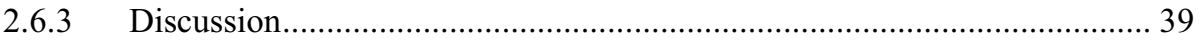

$2.7 \quad$ Experiment 4 ........................................................................................................ 41

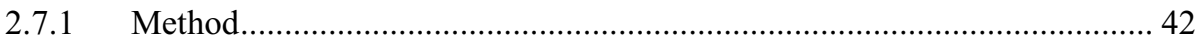

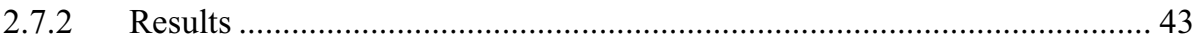

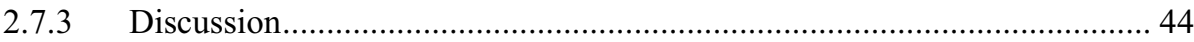

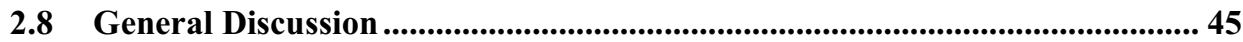

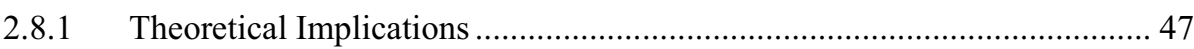

2.8.2 Implications for Marketers and Public Policy Makers............................. 49

2.8.3 Limitations and Future Research ..................................................... 51

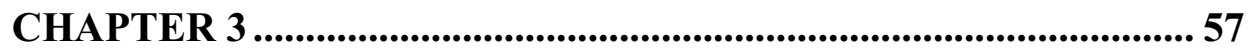

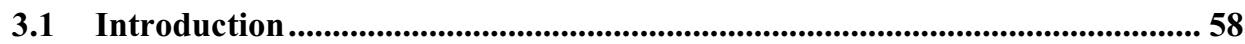

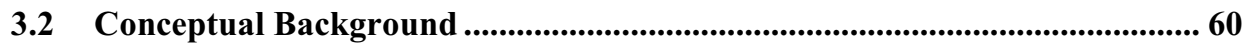

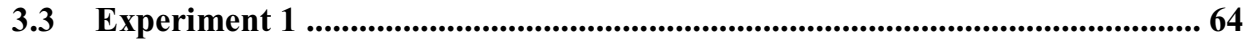

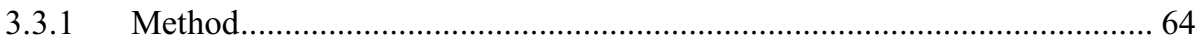

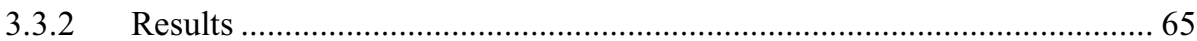

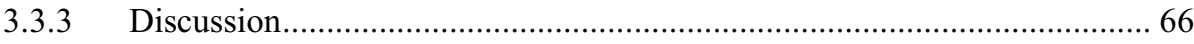

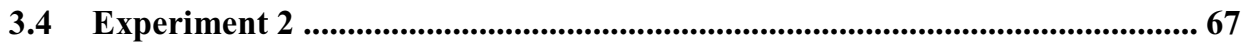

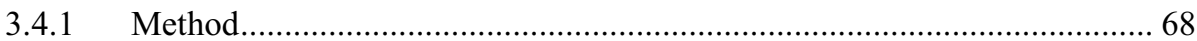

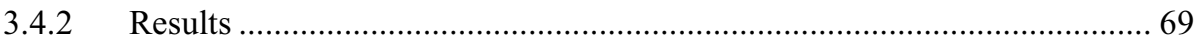

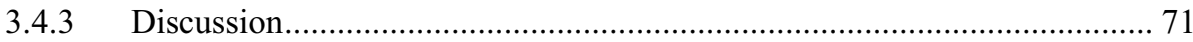

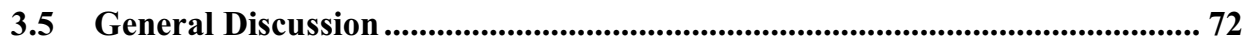

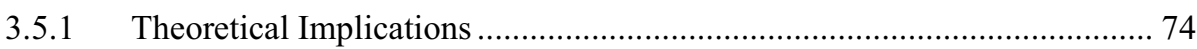

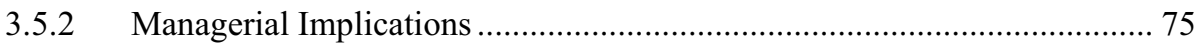

3.5.3 Limitations and Future Research .......................................................... 77

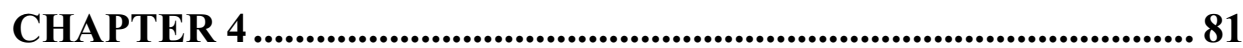

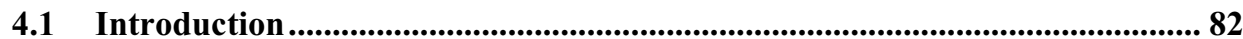

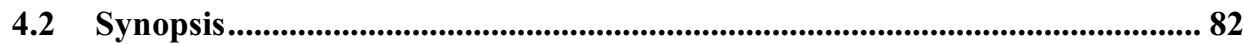




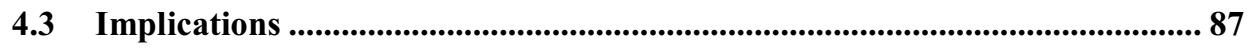

4.4 Suggestions for Future Research ........................................................................ 89

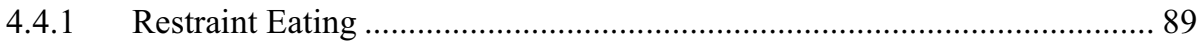

4.4.2 The Role of Need for Cognitive Closure ................................................. 92

4.4.3 Subtle Health Cues, Presentation Format, and Size................................... 94

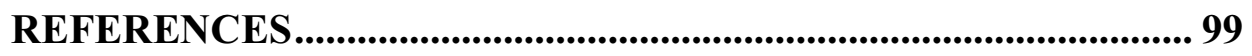

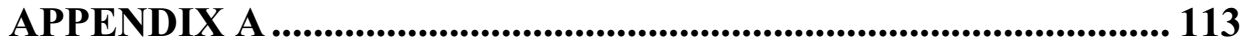

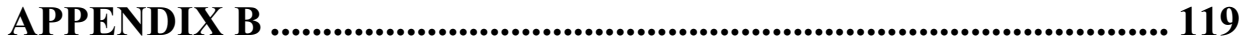

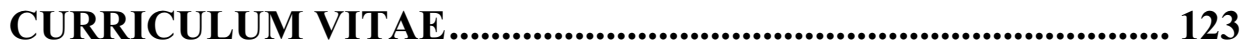





\section{CHAPTER 1}

\section{Introduction}

In this chapter, we introduce the general topic of this dissertation and discuss the scientific relevance of studying how healthy indulgences affect consumers' food intake control. We begin with a short discussion on the research background, in which we outline how societal changes, market forces, and psychological factors influence increasing waistlines among consumers on a global scale. Next, we introduce the concept of healthy indulgences and discuss the current state of knowledge regarding their effects on consumers' eating behaviour. This is followed by a summary of the objectives of the two sets of empirical investigations and a brief overview of the relevant theories used to develop our hypotheses. Finally, a short outline of the content of this dissertation is presented. 
"You notice it especially at the beach. With one out of two adults and one out of four children overweight, it's almost abnormal to be normal weight. Fewer manual jobs, more computers and television, parents afraid to let their kids outside to play without supervision, and increased dependence on cars all contribute to the fattening of

America. But that's only part of the equation. The food industry spends billions of dollars each year on advertising and promotion to create an environment that constantly pressures us to eat. And it's not hawking carrots and celery sticks".

Kelly Brownell

Director of the Yale Rudd Center for Food Policy \& Obesity, New Haven, USA 


\subsection{Research Background}

\subsubsection{The world is getting fat}

"Overweight", "Love Handles", "Fast Food Nation", "Super-Size Me", "Fat Planet", "The Pressure to Eat", "Junk food", "Convenience"; these and similar headlines, titles, and buzzwords are rampant online, in newspapers, in magazines, in TV shows, and recently even entire movies are made on the topic of increasing waistlines and more obese nations. The potential negative effects on health resulting from unhealthy eating patterns such as abnormal or excessive fat accumulation have become a serious and global health threat (WHO 2011). Numerous studies and statistics illustrate the prevalence of an increasing number of people being overweight not only in developed countries with a high socioeconomic status (e.g., Europe and the United States of America), but increasingly also in countries which are predominantly associated with people being underweight (e.g., developing countries like Brazil and Columbia). The World Health Organization, for example, estimates that in 2008, about 1.5 billion adults were overweight, with over 500 million men and women being obese ${ }^{1}$ (WHO 2011). Compared to 1980, the number of people classified as overweight has more than doubled and it is assumed that nowadays, the number of people being overweight exceeds that of people being underweight (Caballero 2007).

Until recently, experts have been reluctant to acknowledge rapidly increasing waistlines as a serious societal issue given that worldwide more than 800 million people are still suffering from hunger and malnutrition (Food and Agriculture Organization 2002). Yet, considering the significant health and economic consequences of people being overweight, the negative effects related to unhealthy eating patterns are now recognized as a serious global health problem (WHO 2008). Illnesses such as heart diseases, type 2 diabetes, high blood pressure, and cancer are only a few of the many overweight-related health consequences with significant economic impact. Medical costs accompanying overweight include direct costs such as diagnostic and treatment

\footnotetext{
${ }^{1}$ The international measure used by the World Health Organization (WHO) to categorize people into being overweight or obese is the body-mass index (BMI), which is calculated as a person's weight in kilograms divided by the square of his height in meters $(\mathrm{kg} / \mathrm{m} 2)$. A BMI of larger than or equal to 25 is considered as overweight, a BMI of larger than or equal to 30 reflects obesity (WHO 2011).
} 
services, as well as indirect costs related to the value of income lost from reduced productivity (e.g., bed days), and future income losses caused by premature death (CDC 2011; Wolf and Colditz 1998).

\subsubsection{Who's to blame?}

An important question pertains to which factors have, and currently are, contributing to the escalating global epidemic of people being overweight. Considered a predominantly social and environmental disease (WHO 2011), it is argued that two main factors stimulate people to gain weight on a continuous basis (Chernev 2011). Following the notion of "we are what we eat", the quality of the food that is consumed determines a significant extent of how much weight is gained. Recent market trends in the food industry have created an "obesogenic environment" characterized by a multitude of unhealthy, easily accessible food temptations and hence enormous increases in the consumption of fattening snacks (Critser 2003; Nestle 2002). Such market forces involve

- larger serving/package sizes (Nielsen and Popkin 2003, Wansink 1996),

- increased flavor variety (Raynor and Epstein 2001),

- vast availability of ready-to-eat meals,

- 24/7 fast-food restaurants located at almost every corner in urban environments, and

- lower prices of energy-dense, high-calorie foods relative to nutritious, lowcalorie foods.

The observation that it costs more to eat healthy is especially worrisome. In a study in which prices per calorie of 372 foods sold at regular US-supermarkets were compared, Monsivais and Dewnowski (2007) concluded that energy-dense food costs on average $\$ 1.76$ per 1000 calories, while low-energy food costs on average $\$ 18.16$ per 1000 calories. Not only is high-energy food significantly less expensive than nutritious alternatives, but people are also much more likely to overeat junk food as it tastes good and larger quantities are needed to feel satiated (Consumer Reports on Health 2006). While nutritionists identify the large variety and availability of junk food as the culprit behind globally increasing waistlines, modern lifestyles also play a major role (Center 
for Consumer Freedom 2007). Nowadays, people engage in less and less physical activity compared to previous generations; a trend that is driven largely by technological innovations (Cutler, Glaeser, and Shapiro 2003). Sedentary work, heavy reliance on cars and elevators, and computer games and television as the key "activity" during leisure time all fuel an imbalance of calories-in versus calories-out.

Next to societal changes and strong market forces, a number of psychological factors have been identified as contributing to unhealthy eating patterns as well. A considerable body of evidence in the literature indicates that while consumers may have the motivation to pursue a healthy diet, they fall prey to several decision errors and biases permeating food-related thoughts and actions (Chernev 2011; Wansink 1996). For example, research has shown that people stereotype foods according to a good/bad dichotomy of vices and virtues (Chernev 2011; Wertenbroch 1998). While virtues typically comprise foods considered as beneficial for health, innocuous for waistlines, but inferior with respect to taste (e.g., fruits, vegetables, and whole grain products), vices comprise foods typically perceived as detrimental for health, offensive for waistlines, but superior with respect to taste (e.g., fast-food, sweets and bakery products, chocolates, crackers). Given the instant pleasure associated with consuming vices, they are also referred to as indulgent foods (Chernev 2011). Although a "good" food / "bad" food categorization simplifies consumers' decision making and helps them to cognitively organize the environment, it also leads to more extreme evaluations, fewer attention to quantity, misperceptions regarding taste and calorie content, as well as overreliance on single aspects of the food when making judgments (Polivy et al. 1986; Schuldt and Schwarz 2010; Wansink and Chandon 2006). Next to this stereotyping bias, other biases that have been documented in the food context include

- the fallacy that adding a healthy option to a meal helps losing weight (balancing bias; Chernev 2011a; Chernev and Gal 2010),

- the belief that the best available option in a choice set is a good choice even when it is not (comparison bias, Chernev 2011), and

- the fact that people are easily influenced by the way food options are presented (framing bias, Levin and Gaeth 1988; see Chernev 2011 for a comprehensive discussion on these biases). 
In light of the previously described irrational forces and the many tempting food options available in the market, it is not surprising that consumers often fail at attempts to control their food intake and their efforts to make healthy food choices. A substantial amount of self-control is necessary to resist short-term impulses (e.g., towards indulgent foods) in order to achieve long-term goals or desired end states (e.g., a healthy, fit, and slim body). Yet, these short-term cravings are often stronger than one's willpower to pursue a long-term goal (e.g., Hoch and Loewenstein 1991; Loewenstein 1996; Metcalfe and Michel 1999), and hence the immediate desire for a tempting food prevents people from staying focused on the more important, yet also more difficult to achieve long-term goal of being healthy. Other factors facilitating selfcontrol failure include unsuccessful attempts in monitoring one's behaviours, depletion of resources necessary to regulate behaviour, or experiencing states of emotional distress (Baumeister 2002). Interestingly, research has shown that even the self-control process itself might limit peoples' ability to regulate behaviour, in that cognitive efforts directed at 'not thinking about food' likely result in a pre-occupation with food, making it more salient in the mind (e.g., Heatherton, Polivy and Herman 1990; Ogden 1995; Ward and Mann 2000).

Despite the difficulties accompanying a responsible approach to eating, it is clear that people have to eat and that abstinence is therefore not an option (Fishbach and Myrseth forthcoming). Especially in increasingly stressful times and more demanding work environments do people need indulgent moments to pamper and reward themselves. Indeed, food has been found to have reinforcing and rewarding value for individuals, which is especially the case for hedonic (i.e., pleasure-related) food (e.g., Epstein and Leddy 2006). Moreover, food is "social" in that it acts as a bonding agent bringing together family, friends, and sometimes even random people when they gather for lunch, dinner or special occasions (Hale 2010). The importance of food in people's lives becomes further apparent in times of economic downturns, in which food is the last consumers are willing to abridge (Hale 2010). Consumers thus do not want to cut back on their consumption of foods, least of all indulgent foods, but rather demand more healthy alternatives that they can consume without regulating themselves and without experiencing feelings of guilt. 


\subsubsection{The Rise of Healthy Indulgences}

The previous discussion emphasizes the important role of food in people's daily lives and suggests that the rising problem of increasing waistlines is reflective of a complex blend of several factors. While some of these factors are related to environmental market forces and societal developments, others pertain to psychological aspects making it difficult for consumers to behave rationally with respect to food intake. Overall, public policy makers are left with questions as to what can be done to combat the fattening of entire nations and how individuals can be nudged to follow more healthy diets and not over-consume indulgent foods.

Guided by the notion that indulgent foods stimulate failures of self-control and thus overconsumption, health organizations have suggested the dissemination of more wholesome food alternatives (e.g., WHO 2011). In light of these signals and a high sensitivity to consumers' increasing demand for guilt-free pleasures (Willmer 2007), the food industry has responded by making available healthier alternatives to inherently unhealthy foods. Such foods are often referred to as healthy indulgences ${ }^{2}$ and typically feature front-of package claims such as "extra antioxidants", "with calcium", "low-fat", or "reduced sugar", thereby making the foods appear less threatening to consumers" health and diet-related goals. We will refer to such nutrition-based claims as health claims as they communicate a health benefit either by stressing the presence or increased amount of attributes perceived as beneficial for one's health (e.g., antioxidants, vitamins) or by highlighting the absence or reduced amount of attributes perceived as unfavorable for one's health (e.g., fat, cholesterol). Typical examples of products in the healthy indulgence space are provided in Figure 1. Consider, for instance, the recent introduction of $7 \mathrm{Up}{ }^{\circledR}$ Mixed Berry Antioxidants, which puts a healthy spin on the original soda option by highlighting the presence of antioxidants. Likewise, think about Old Dutch's ${ }^{\circledR}$ low-sodium potato chips or the option to consume a chocolate muffin or cookie containing an extra amount of vitamins (VitaMuffin ${ }^{\circledR}$ ).

\footnotetext{
${ }^{2}$ We would like to emphasize that by using the term "healthy indulgences" we do not want to imply that such foods should be considered as actually healthy. Rather, we adopt this term from the current debate on unhealthy foods which, by the use of health claims, portray themselves as healthier relative to their conventional counterparts.
} 
These and similar variants of inherently unhealthy foods claiming to provide a health benefits are increasingly prominent on today's supermarket shelves.

Ideally, such 'better-for-you' options of indulgent foods should help consumers with their diets in that they allow for substitution of regular, high-energy indulgences with alternatives containing reduced amounts of "bad" ingredients (e.g., cholesterol, fat, sugar) or increased amounts of "good" ingredients (e.g., vitamins, calcium, antioxidants). As most consumers may not be able to completely avoid consuming indulgent foods, one might argue that people are at least consuming variants that have less harmful consequences for their bodies.

The increasing prevalence of healthy indulgences designed to satisfy people's cravings for everyday treats with a healthy twist thus seems to provide benefits for all parties involved: Consumers no longer have to cut back on indulgence, but instead can engage in satisfying, yet smart-snacking consumption behaviors; manufacturers are able to increase their market shares while providing real value to consumers; and the society at large seems to benefit from healthier eating patterns potentially reducing the growing problems related to obesity. 


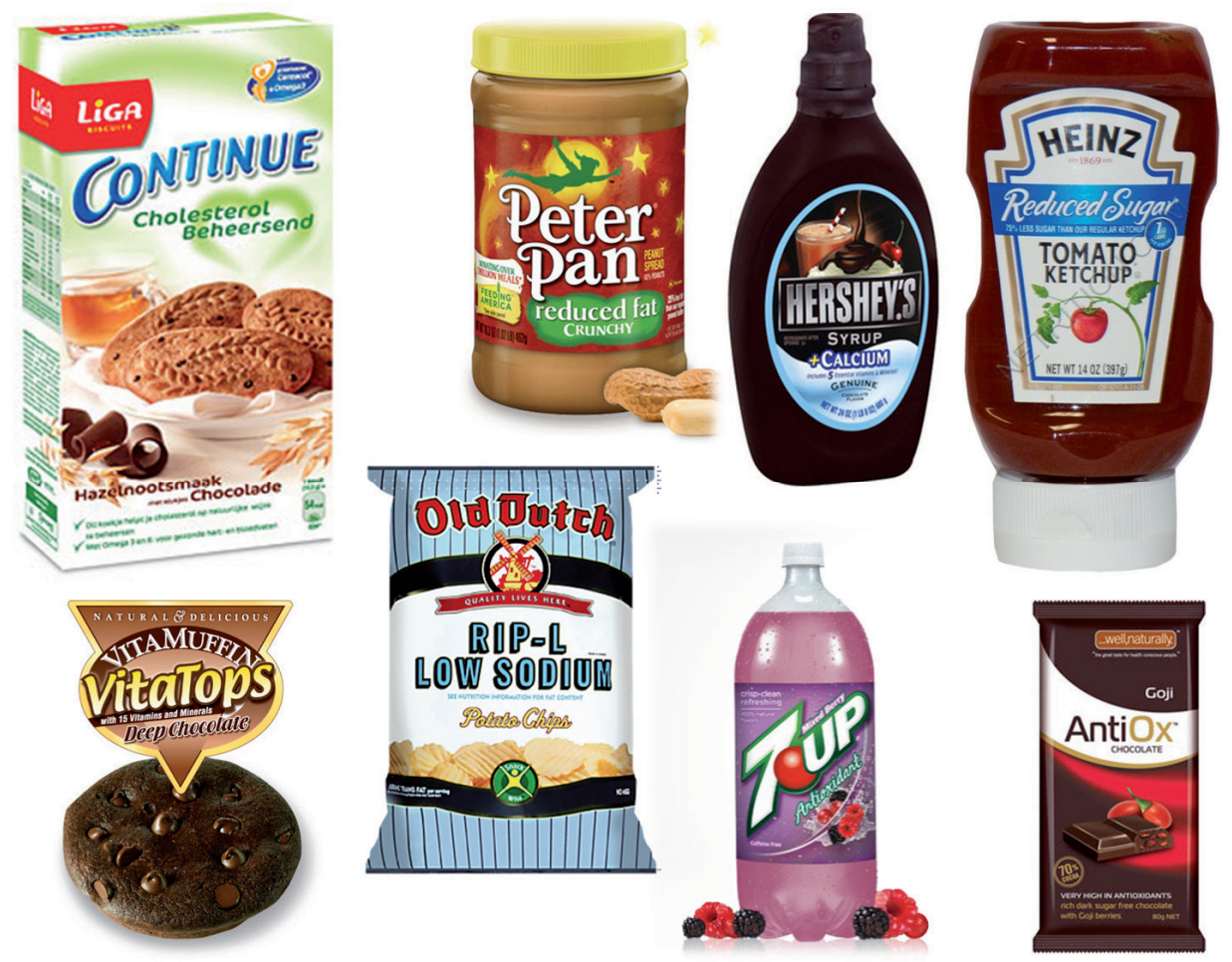

Figure 1: Examples of Healthy Indulgences

Yet, despite the growing interest in, and availability of, healthy indulgences in the food landscape, we know surprisingly little about their effects on actual food intake. Recent research has emphasized the need to look at how people process nutrition information (e.g., Grunert and Wills 2007), as there is evidence that nutrition labeling may not be all that beneficial to consumers as is commonly believed. Specifically, recent findings in the literature suggest that health-related claims such as "low-fat" attached to indulgences stimulate rather than inhibit food intake because consumers falsely infer the food to have fewer calories, making its consumption easier to justify (Wansink and Chandon 2006). Such inappropriate overgeneralizations of attributes of the food that are not substantively related to the attribute the claim actually emphasizes (Polivy et al. 1986; Schuldt and Schwarz 2010; Wansink and Chandon 2006) likely translate into increased food intake, as they implicitly provide consumers with a license to eat (Wansink and Chandon 2006). Note, that although there is emerging theoretical evidence that overgeneralizations of nutrition-based health claims might stimulate 
overconsumption, the only study to demonstrate this effect is that by Wansink and Chandon (2006), albeit only in the specific context of low-fat health claims. Whether this effect can be generalized to other health claims as well remains unclear, but it appears reasonable to expect all indulgences that are framed as healthy to stimulate food intake instead of triggering self-control as they are easier to justify to oneself.

In contrast to the view that health claims function as consumption-stimulating cues, an alternative perspective is presented by research demonstrating an inverse relationship between functional and hedonic stimuli. Specifically, the literature on the effects of hedonic (e.g., fun, tasty) versus functional (e.g., safe, nourishing) attributes on stimuli perception, preference, and choice suggests that consumers should eat less of unhealthy food carrying a health claim because they (unwittingly) subscribe to the "unhealthy = tasty" intuition (Raghunathan, Walker Naylor, and Hoyer 2006). This would imply that the healthier a food gets the less tasty and hence less attractive it is perceived. To the best of our knowledge, however, there are no studies that test these predictions within a broader set of health claims in the context of indulgent foods, hence strongly amplifying the relevance of a more thorough examination of the topic for academics, marketers and public policy makers alike.

In light of these inconsistencies in consumer behavior literature as to how health claims affect consumption of the indulgences they are attached to, this dissertation sets out to investigate the effects of healthy indulgences on food intake control. More specifically, we seek to answer the following question:

\section{When and why do people over-consume versus regulate food intake in response to health claims attached to indulgent foods?}

We address this question through two sets of empirical investigations. The following section summarizes the objectives of each empirical investigation and gives an overview of the relevant theories used to develop our hypotheses. It concludes with a brief outline of the content of this dissertation. 


\subsection{Research Objectives}

The primary objective of this dissertation resides in providing a comprehensive understanding of whether, when, and why exposure to health claims attached to indulgent foods stimulates versus reduces food intake control. Hence, our focus is on measuring actual consumption in response to healthy indulgences rather than settling for self-reported intentions to consume the respective foods. Thereby, we will address the call for research investigating the behavioral consequences following exposure to nutrition labeling in general, and health claims in particular (e.g., Grunert and Wills 2007).

Manuscript I (chapter 2) focuses on the direct effects of health claims in influencing consumption of indulgences bearing the claims. Intrigued by the worrisome finding of increased food intake following exposure to low-fat health claims (Wansink and Chandon 2006), we investigate whether we can generalize these effects to other health claims as well. Drawing on the literature on functional versus hedonic attributes (Raghunathan et al. 2006) we suggest that health claims featuring such attributes may affect the direction of food intake differently. As noted by Grunert and Wills (2007), exposure to stimuli has consistently been shown to result in subconscious activation of relevant schemata the recipient is familiar with. However, up to now, none of the studies covered in their review of literature on consumer responses to food nutrition labels has addressed this issue. Drawing on research documenting primacy of affirmation (Jung, Malaviya, and Sternthal 2004), we suggest that the type of attributes stressed in health claims affect subconscious activation of relevant concepts and goals, in turn determining whether consumption of the foods carrying the claims increases versus decreases relative to foods that feature no such claims. Across five experimental studies we demonstrate that in contrast to common wisdom, not all health claims are created equal in that functional versus hedonic health claims attached to indulgent foods lead to opposite consumption patterns, thereby affecting consumers' ability to control their food intake quite differently. In particular, we show that functional health claims (e.g., "extra calcium", "low cholesterol") lead to decreased consumption of the food bearing the claim as they trigger high levels of health-goal accessibility, which, together with simultaneously accessible indulgence goals attached to the indulgence itself, result 
in goal conflict. This conflict induces an aversive state, resulting in reduced consumption of the indulgence. Hedonic health claims (e.g., "low-fat", "reduced sugar"), on the other hand, direct attention to the hedonic qualities of the food, thereby rendering a health goal temporary less accessible. Such increased focus on the pleasure dimension of the food together with very low accessible health goals results in much lower conflict between health and indulgence goals. This low level of goal conflict together with an accentuated hedonic orientation towards the food stimulates increased consumption of the indulgence. However, importantly, we demonstrate that when a conflict is created externally (e.g., by means of priming), this increased consumption is blocked.

Manuscript II (chapter 3) focuses on the indirect effects of health claims in influencing consumers' responses to regular food category members. Specifically, and building on the finding of functional health claims triggering high levels of goal conflict resulting in decreased consumption of the food causing the conflict (chapter 2), we examine how the presence of conflict-inducing healthy indulgences in a given product category affects consumption of regular category members not causing the experienced conflict. We draw on theories provided in the literature on spillover effects (e.g., Dahlen and Lange 2006; Lei, Dawar, and Lemmink 2008; Scott and Tybout 1981) and on recent insights regarding the affective and behavioral consequences of goal conflict (Bailis et al. 2011) to investigate to what extent conflict-induced states of aversion can be subject to spillover effects. Across two experimental studies we provide evidence that a brief exposure to conflict-inducing healthy indulgences results in reduced food intake of regular category members (i.e., indulgences not claiming to be healthy). We argue that this decreased consumption of regular category members is the result of a spillover of negative states of aversion as a direct consequence of experienced goal conflict. This, in itself, is intriguing, in that the negative affective state (i.e., aversion) was evoked by essentially positive health information (i.e., a claim featuring the presence of antioxidants). Moreover, within our second experiment we investigate whether and how consumers' perceptions regarding regular category members' healthiness are affected by spillover of states of aversion. Our results show that rather than being negatively affected by aversion, participants' healthiness perception of the regular category member that was consumed increased. This finding appears to suggest that an aversion- 
independent process of health association transfer from the brand presented in the first task (i.e., the healthy indulgence) to the unknown brand consumed in the second task of the experiment was at work. Together, the two experiments in the second manuscript provide evidence for a two-fold spillover effect involving both transfers of health associations as well as transfers of negative affective states.

Combined, the results of our empirical investigations help resolving the inconsistencies in consumer behavior literature regarding when and why self-control with food intake is likely to fail versus likely to be enhanced upon exposure to more wholesome alternatives of inherently unhealthy, yet indulgent foods. Thereby, our work contributes a piece to the overall puzzle of understanding the dynamics of consumers' self-regulatory processes in the context of food temptations and, importantly, the conditions under which self-control is enhanced or reduced by health-related environmental cues.

Chapter 4 concludes this dissertation by summarizing the key findings of our empirical investigations and by discussing the resulting implications. We end this chapter by offering some general directions for future research in the domain of food consumption, which we hope will further advance our understanding of whether, when, and why health-related environmental cues stimulate versus reduce food intake control. 


\subsection{Dissertation Outline}

Table 1 provides an overview of the chapters with respect to their objectives, their theoretical focus, the research designs, as well as the analysis strategies employed to investigate the respective research objectives.

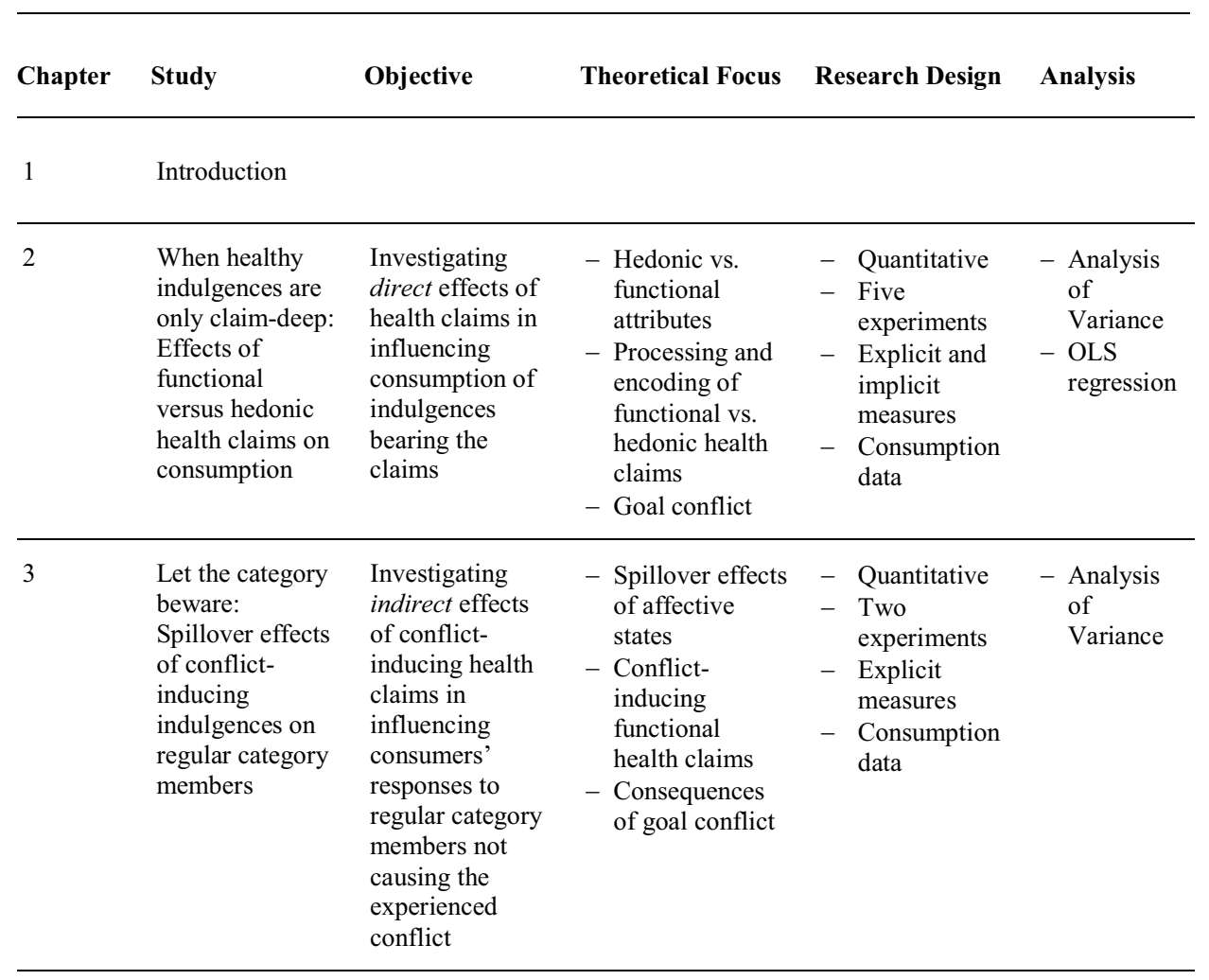




\title{
CHAPTER 2
}

\section{When Healthy Indulgences are only Claim-Deep: Effects of Functional versus Hedonic Health Claims on Consumption}

\begin{abstract}
Marketers commonly assume that health claims attached to otherwise unhealthy food stimulate consumption because such claims offer easy justification for consuming the indulgence. Five experiments demonstrate that not all health claims are created equal and provide support for the hypothesis. Specifically, we content that it is important to distinguish between two different types of health claims (functional versus hedonic health claims) and suggest that the nature of the food attributes the claims emphasize, namely, functional versus hedonic, determines the extent of consumption of the indulgence. Results show that health claims featuring functional attributes (e.g., "extra antioxidants") trigger high levels of health-goal accessibility, which, together with simultaneously accessible indulgence goals attached to the indulgence, result in goal conflict. This conflict leads to reduced consumption of the food. In contrast, claims featuring hedonic attributes (e.g., "low-fat") appear to accentuate the pleasure dimension of the food instead of rendering health goals more accessible, which results in very low levels of goal conflict and increased consumption of the food. Implications for the food industry and public policy makers, as well as suggestions for future research are discussed.
\end{abstract}

This chapter is based on: Belei, Nina, Kelly Geyskens, Caroline Goukens, Suresh Ramanathan and Jos Lemmink (2012), "The Best of Both Worlds? Effects of Attribute-Induced Goal Conflict on Consumption of Healthy Indulgences," forthcoming in the Journal of Marketing Research. 


\subsection{Introduction}

Food-producing companies have long recognized the value of offering snacks that tout the healthiness of the products in a bid to overcome the reluctance consumers have towards unhealthy foods in their attempts to live a healthy, well-balanced life. Alarmed by approximately 1.5 billion overweight people (WHO 2011), health organizations advocate greater availability of more wholesome food alternatives and consumers themselves demand food that combines "the best of both worlds": scrumptious food with a healthy twist that takes away the guilt (Today's Dietitian 2008). Thus, it is not surprising that the food industry has increased its focus on providing consumers with a range of so-called healthy indulgences. A chocolate bar with extra antioxidants (Hershey's ${ }^{\circledR}$ ), a vanilla muffin enriched with vitamins (VitaMuffin $\left.{ }^{\circledR}\right)$, creamy omega-3 peanut butter (Jif $\left.{ }^{\circledR}\right)$, low-sodium buttered popcorn (JollyTime ${ }^{\circledR}$ ), low-fat potato chips (Lay’s $\left.{ }^{\circledR}\right)$, and reduced-sugar cookies (ChipsAhoy ${ }^{\circledR}$ ) are only some of the many examples of indulgences claiming to provide a health benefit. In fact, healthy snacks now outpace traditional snacks by a ratio of 3:1 (Today's Dietitian 2008), offering great opportunities for the food and beverage industry.

Conceptually, healthy indulgences share two important characteristics. First, they represent an "improved" version of foods generally perceived as unhealthy, consumed primarily for reasons of taste, pleasure, and indulgence. Second, they all carry a claim or label either explicitly or implicitly suggesting the food is a healthier (and thus "better-for-you") alternative relative to a conventional version. Typically, such claims either stress the presence (or increased amount) of food attributes perceived as beneficial for one's health (e.g., vitamins, calcium, antioxidants), or the absence (or decreased amount) of attributes regarded as detrimental to one's health (e.g., sugar, fat, cholesterol). Prior research suggests that consumers may increase their consumption of such healthy indulgences because they reduce guilt and are easy to justify (Okada 2005; Wansink and Chandon 2006). Consumers' tendency to overgeneralize health claims often results in misleading inferences on, for example, the amount of calories contained in the food and thus in overestimation of the appropriate amount to eat (Wansink 2004; Wansink and Chandon 2006). Yet, despite the growing prevalence of healthy indulgences in the market, surprisingly little research focuses on the different types of 
health claims attached to indulgences and their effects on food intake. To the best of our knowledge, the only study to demonstrate the consumption effects associated with health claims is that of Wansink and Chandon (2006), who focused on low-fat claims showing that such claims led to increased consumption of such snacks arguably because of guilt reduction and ease-of-justification.

The key question addressed in this research is whether all health claims are created equal, thus leading to the same increase in food intake. Specifically, we examine whether the nature of the health claim attached to an indulgence affects consumption of the indulgence. We will compare health claims referring to a functional attribute (e.g., "antioxidants", "cholesterol") to health claims referring to a hedonic attribute (e.g., "fat", "sugar"), as prior research has been agnostic about the nature of the attributes health claims emphasize. We draw on research demonstrating an inverse relationship between hedonic (e.g., fun, enjoyable) and functional (e.g., nourishing, healthy) attributes (Raghunathan et al. 2006) and research documenting primacy of affirmation (Jung et al. 2004), to propose that seemingly similar health claims result in opposite consumption patterns depending on whether the attribute the claim emphasizes is functional or hedonic. Thus, when a consumer is given chocolate and is told that the chocolate is either high in antioxidants (i.e., a functional attribute) or low in fat (i.e., a hedonic attribute), we expect respectively decreased versus increased consumption relative to the consumption of a conventional chocolate not making a health claim.

Across five experiments, we provide evidence that only health claims stressing functional attributes (hereafter referred to as functional health claims) help control the consumed amount by triggering high levels of health-goal accessibility. Because a hedonic indulgence goal is salient as well given the product category (i.e., tempting food such as chocolate), stressing a functional attribute results in high conflict between the opposing health and indulgence goal. This aversive state leads to reduced consumption of the indulgence. In contrast, claims featuring hedonic attributes (hereafter referred to as hedonic health claims) appear to direct attention to the hedonic qualities of the food instead of enhancing accessibility of health-related goals. Such increased focus on the pleasure dimension of the food together with very low accessible 
health goals results in very low levels of goal conflict and increased consumption of the indulgence.

\subsection{Conceptual Background}

In their attempts to combine a healthy lifestyle with the pleasures of indulgences, consumers are increasingly looking for products that offer both a superior taste and health benefits. The growing availability of healthy indulgences designed to satisfy people's cravings for everyday treats with less accompanying feelings of guilt seems to provide an optimal solution. Consumers no longer have to cut back on indulgence, but instead can engage in satisfying, yet smart-snacking consumption behaviors; manufacturers are able to increase their market shares while providing real value to consumers; and the society at large seems to benefit from healthier eating patterns potentially reducing the growing problems related to obesity.

Unfortunately, the promising picture painted here is far from accurate. Emerging evidence suggests that healthy indulgences may not be all that beneficial to consumers. It has been shown that people often use information-processing heuristics that provide them with easier to justify decisions, allowing avoidance of potential negative emotions (Payne and Bettman 2000). The use of heuristics implies that only a subset of relevant information is processed, which increases the probability of systematic decision errors. Such ease-of-justification processing has been documented for situations involving decisions whether to indulge in, or refrain from, unhealthy, yet tempting food. For example, research has demonstrated people's tendency to overgeneralize the benefits associated with nutrition-based claims, resulting in erroneous inferences about attributes of the product that are not substantively related to the attribute the claim actually emphasizes (Polivy at al. 1986; Schuldt and Schwarz 2010; Wansink and Chandon 2006). Such inappropriate generalizations can have important implications regarding how a food is perceived by consumers. Andrews, Netemeyer, and Burton (1998), for example, found that consumers perceive food promoted as "no cholesterol" and "healthy" (e.g., margarine) as containing lower levels of fat. Recent research by Schuldt and Schwarz (2010) demonstrated that cookies claiming to be "organic" are judged by consumers to contain fewer calories. As a 
consequence, health claims attached to inherently unhealthy, energy-dense foods might provide consumers with an implicit license to eat, which would ultimately be reflected in over-consumption of such foods.

Despite the general agreement in the literature that consumers tend to overgeneralize nutrient-based food claims, few studies have tested the behavioral implications of such over-generalization. Wansink and Chandon (2006) were the first to point out that low-fat claims have a countervailing effect as they increase overall consumption by up to $50 \%$, arguably because low-fat food induces consumers to falsely infer the food also contains fewer calories, thus making it more acceptable to eat. Combining these findings with the fact that consumers have a tendency to overgeneralize other nutrition-based labels resulting in misleading health halos (e.g., Chandon and Wansink 2007), one might conclude that all health claims attached to indulgent foods would provide similar ease of justification. That is, one might expect all indulgences that are framed as healthy to stimulate food intake instead of triggering self-control.

In contrast to the view that health claims function as consumption-stimulating cues, an alternative perspective could be provided based on research demonstrating that consumers subscribe to the "unhealthy = tasty" intuition (Raghunathan et al. 2006). According to this view, an increasing degree of functionality (e.g., safe, healthy) is simultaneously associated with a decrease in hedonic potential (e.g., fun, pleasure), thus suggesting that the hedonic and functional potential of stimuli are negatively correlated. For example, Raghunathan (2007) showed that participants evaluated a car that was portrayed as being "fun to drive" and "attractive" to be less safe than when it was portrayed as "unattractive" and "less enjoyable to drive". In another study, the author presented participants with a picture taken by either a "fun" camera colored in an attractive light blue, or by a "regular" camera colored in a neutral silver tone. Participants had to rate the quality of the picture taken by the camera (e.g., quality of color, quality of resolution) and results showed that the picture taken by the fun camera was evaluated as being inferior in terms of quality relative to the regular camera. Transferring the logic of an inverse relationship between functional and hedonic stimuli to the context of food, the healthier a food is portrayed, the less enjoyable it is 
perceived. This would imply that one should perceive any inherently unhealthy food making health claims as relatively poor on taste compared to a standard option and hence as less attractive. Consequently, and in contrast to the view proposed by an easeof-justification mechanism, one might predict decreased consumption of healthy indulgences.

\subsubsection{Primacy of Affirmation}

In addition to the literature on the processing of nutrition-based claims and the negative correlation between hedonic and functional attributes, the work on the encoding of specific product descriptions involving tags (e.g., negations) is of critical concern for our analysis. Recent research has documented the phenomenon of primacy of affirmation (e.g., Jung et al. 2004; Mayo, Schul, and Burnstein 2004). According to this principle, when product benefits are expressed as negations (e.g., "not difficult to use", where 'not' is the negator tag and 'difficult to use' is the affirmation), cognitive resources are initially allocated to the affirmation, inducing elaboration of schemata closely related to the affirmation, but not of the overall meaning of the negation. Only if additional resources are available will the negator be processed as well. For example, Mayo et al. (2004) showed that after being presented with the statement "Tom is not a tidy person", participants' response times in a lexical decision task to statements congruent with the affirmation ("Tom's clothes are folded neatly") were faster than to statements congruent with the negation ("Tom forgets where he left his car keys"). The authors argued that in order to process a negation, one first has to process the core supposition (i.e., the affirmation "Tom is a tidy person") before one can negate it (e.g., "Not(Tom is a tidy person)"). Given that the core supposition is processed as a cognitive unit whose consideration activates associations or schemata that are congruent with the core, but not with the negation, the authors referred to this process as the schema-plus-tag model (see Mayo et al. (2004) for a review). Thus, ironically, a product described as "not easy to use" is typically evaluated more favorably compared to a product described as "not difficult to use" (Jung et al. 2004). Interestingly, the finding that the affirmation is more salient than the tag and therefore used for making 
judgments, occurred even if a directed search of memory indicated that the negation was accurately processed ${ }^{3}$.

In the context of healthy indulgences, health claims used to portray the health benefits of foods typically involve tags (e.g., "low", "extra") and affirmations ("fat", "vitamins"), even though only some of them are framed as negations. Transferring the notion of primacy of affirmation to health claims would suggest that the affirmations rather than the tags are processed. For example, Jung et al. (2004) noted that a linguistic construction like "not fattening" (or "low-fat") is likely to result in increased elaboration on the affirmation "fattening" instead of the negator "not". They suggested that such elaboration on fat is likely to activate schemata related to the core supposition and may thus call to mind images of scrumptious fast food, delicious desserts, or tasty, sauceladen entrees. This argument receives support by research demonstrating that people expect better taste when potato chips are labeled as " $25 \%$ fat" rather than " $75 \%$ lean" (Wertenbroch 1998), as well as research showing that the more fatty and thus unhealthy a food is portrayed, the more enjoyment of the food is inferred (Raghunathan et al. 2006). Hence, primacy of the affirmation "fat" likely directs attention to the pleasure associated with consuming the food instead of enhancing associations that are congruent with the overall meaning of the negation (i.e., low-fat is healthy).

Building on the previous discussion and taking into account the well documented finding that tempting food activates appetitive and hence indulgencerelated goals of food enjoyment (Dhar and Simonson 1999; Fedoroff, Polivy, and Herman 2003; Raghunathan et al. 2006; Shiv and Fedorikhin 1999; Tepper and Trail 1998), we anticipate that exposure to indulgences making hedonic health claims will accentuate a hedonic orientation towards the food, rendering health goals less accessible. Such heightened attention to food enjoyment likely stimulates increasing

\footnotetext{
${ }^{3}$ Jung et al. (2004) showed that primacy of affirmation holds especially in a situation of moderate resource availability. They employed three levels of resource availability (low, moderate, and high) and showed that when resources are substantial (e.g., low cognitive load), product evaluations were consistent with the negation; when resources were limited (e.g., high cognitive load), evaluations were not influenced by the negation; and when resources were moderate (e.g., neither high nor low load), product evaluations were consistent with the affirmations alone. These results suggest that only in the extreme cases of particularly low or high resource availability are affirmations not granted primacy, whereas in situations in which a moderate level of resources is available, the negator tag becomes dissociated from the affirmation when making a judgment (e.g., Mayo et al. 2004).
} 
food intake. As such, the primacy of affirmation account appears to provide an alternative explanation for the finding of increased consumption of low-fat indulgences, thereby presenting a contrast with the previously discussed ease-of-justification view (Wansink and Chandon 2006). Recall that according to simple ease-of-justification, the entire claim would be processed and used as a heuristic to infer benefits of the product which are not substantively related to the attribute the claim actually emphasizes.

A related issue emerging from the previous discussion regards the question of what happens when health claims emphasize attributes which are actually associated with the concept of health, and thus rather functional than hedonic in nature. An example would be a health claim stressing the increased amount of antioxidants (e.g., "extra antioxidants"). Here, the affirmation "antioxidants" should be processed rather than the tag "extra", and associated schemata related to the core supposition should become highly accessible. Given the strong associative linkage between antioxidants and health, it is thus likely that the concept of "health" (rather than that of "indulgence" in the case of low-fat claims) becomes highly accessible in consumers' minds ${ }^{4}$. In fact, a vast amount of health claims appears to highlight functional attributes (e.g., antioxidants, cholesterol, vitamins, calcium, sodium) rather than attributes more hedonic in nature and strongly linked to concepts such as taste and pleasure (e.g., fat, sugar). A better understanding of the effects of the different types of health claims is thus crucial to predict how consumers respond to such claims, especially when there is reason to expect opposite consumption patterns.

In light of the primacy of affirmation account suggesting increased accessibility of health-related concepts and goals when the core supposition refers to a functional, health-related attribute, and considering the fact that exposure to indulgent food triggers indulgence-related goals (e.g., Fedoroff, Polivy, and Herman 2003), it is likely that functional health claims result in a situation of conflict between the competing health and indulgence goals. Given that goal conflict and the resulting emotional ambivalence are aversive states which consumers usually try to resolve

\footnotetext{
${ }^{4}$ Note that one could argue that the affirmation 'antioxidants' by itself might be processes as a negation, such that 'anti' would represent the tag and 'oxidants' the affirmation. Yet, regardless of whether 'antioxidants' or 'oxidants' comprise the affirmation, both are functional in nature with associations strongly related to health.
} 
(Ramanathan and Williams 2007), we posit that functional health claims will lead to decreased consumption of the food associated with such conflict. Evidence of decreased consumption evoked by functional health claims would lend some comfort to public policy makers in that not all health claims necessarily have detrimental effects for consumers, as it would show that indulgences making functional health claims potentially enhance consumers' self-control with food intake. For food manufacturers, on the other hand, decreased consumption of indulgences making functional health claims would imply a 'backfire' effect, as the desired consumption increase would be reversed.

In sum, we present a more nuanced perspective than is offered by previous literature on nutrition-based claims to predict when and why people over-consume versus regulate food intake in response to health claims. We suggest that the extent of consumption of indulgences framed as healthy depends on the nature of the attribute the claims emphasize. Building on research documenting primacy of affirmation (e.g., Jung et al. 2004), we expect consumers to process the attributes stressed in health claims (i.e., the affirmations) rather than the claim as a whole. Given that attributes highlighted in health claims differ in their functional versus hedonic nature triggering either healthrelated or indulgence-related concepts or goals, the following formal hypotheses are derived:

\section{$H_{1}$ : Differential effects of attribute type on goal accessibility and goal conflict}

(a) Functional health claims attached to indulgences trigger high levels of health goal accessibility, which, together with already accessible indulgence goals triggered by the indulgence itself, create high levels of goal conflict.

(b) Hedonic health claims attached to indulgences render a health goal temporary less accessible, resulting in very low levels of goal conflict. 


\section{$\mathrm{H}_{2}$ : Differential effects of attribute type on consumption}

(a) Functional health claims attached to indulgences lead to decreased consumption of the healthy indulgence relative to an indulgence without such a claim.

(b) Hedonic health claims attached to indulgences lead to increased consumption of the healthy indulgence relative to an indulgence without such a claim.

We tested these predictions in five experimental studies. In a pilot study (experiment 1), we show that seemingly similar health claims attached to unhealthy food result in different consumption patterns. Claims emphasizing a functional food attribute (e.g., antioxidants) induce a significant decrease in consumption compared to a control condition, whereas claims highlighting a hedonic food attribute (e.g., fat) trigger a significant increase in consumption. Experiment $2 a$ and $2 b$ test the robustness of this phenomenon, with experiment $2 \mathrm{a}$ ruling out an alternative framing or loss-aversion explanation and experiment $2 \mathrm{~b}$ demonstrating increased consumption irrespective of whether a hedonic claim allows for construal of the indulgence as more (low-fat) or less (high-fat) healthy. Experiment 3 demonstrates that functional versus hedonic food attributes indeed elicit different levels of health-goal accessibility, whereas indulgence goals are equally accessible across conditions. Specifically, we find a significant linear trend in health goal accessibility across conditions, with very high levels of health goal accessibility for functional health claims attached to indulgences, very low levels of health goal accessibility for hedonic health claims attached to indulgences, and health goal accessibility for indulgences not making health claims falling in between. Together with highly accessible indulgence goals triggered by the hedonic nature of the food itself, functional health claims therefore create a situation of high goal conflict, which is likely resolved by avoiding the object causing the conflict. The very low levels of health goal accessibility following exposure to hedonic health claims combined with accessible indulgence goals, on the other hand, result in very low levels of goal conflict, which is likely the result of an increased hedonic orientation towards the food. In a final experiment (experiment 4), we manipulate health/indulgence goal accessibility by means of priming, providing additional evidence that food situations triggering a 
conflict between functional and indulgence goals help consumers to control their food intake. In particular, we show that the consumption-increasing effect induced by hedonic health claims can be blocked if a conflict is created by an external activation of a health goal.

\subsection{Experiment 1 - Pilot Study}

The objective of our pilot study was to test our hypothesis that not all health claims are created equal. Specifically, we sought to provide evidence that health claims differing in the nature of the attributes emphasized in the claim (i.e., hedonic vs. functional) have differential effects on consumption of this food.

\subsubsection{Method}

Participants. One hundred and nine undergraduate students (58 men, 51 women) from a medium-sized Dutch University participated in the experiment in exchange for course credit. Of the participants, the majority was Dutch $(50.5 \%)$ and German (30.1\%), with an average age of 22 years.

Design and procedure. We randomly assigned participants to one of three conditions ("antioxidants", "low-fat", or "control"). In the functional-attribute condition, participants evaluated a chocolate product package that featured the following health-related claim: "Extra antioxidants - Health from the cacao bean." In the hedonic-attribute condition, participants evaluated a chocolate package with a lowfat label. In the control condition participants evaluated a version of the package for which we had removed all health-related cues (see Appendix A). We selected "antioxidants" as a representative of a functional food attribute because the claim is increasingly prominent on various food packages and can be classified as stressing functional rather than hedonic benefits regarding one's health. We selected "fat" as a representative of a hedonic attribute for our health-claim manipulation because of the preeminence of low-fat health claims in the food market and because of the word's association with food enjoyment (Raghunathan et al. 2006, Wertenbroch 1998). Furthermore, a pretest $(\mathrm{N}=47)$ showed that both health claims are perceived as equally believable $(\mathrm{t}(45)=-.12$, NS) and convincing $(\mathrm{t}(45)=.66, \mathrm{NS})$. 
On entering the cubicles, participants found a laminated, colored picture of the respective product package, approximately matching the size of the original product. In a paper-and-pencil questionnaire, participants completed a battery of 15 questions pertaining to the attractiveness of the chocolate package (e.g., "The design of the package's front side is appealing," "The information on the package's front side is credible"). After participants completed the package evaluation task, we removed the materials from the cubicles and we invited all participants to taste the chocolate they had seen on the product package. To increase the variance in food intake, we used chocolate pearls (about $1 \mathrm{~g}$ each) instead of the brand's regular seashell shapes (about 11 g each). We informed participants that presenting relatively small portions of the food in such taste tests was common, so the company had provided chocolate pearls, which were the same as the seashells, just smaller and more convenient to test. We placed two transparent bowls of chocolate (one with dark chocolate pearls $(700 \mathrm{~g})$ and another with milk chocolate pearls $(700 \mathrm{~g}))$ in front of the participants and they evaluated the product on several seven-point "agree-disagree" items relating to their taste, color, and structure. By providing them with two types of chocolate, we increased the chance that most participants would like the test product. Towards the end of the questionnaire, we collected data on estimated calorie content and purchase intention.

After completing the taste test and following a short filler task, participants responded to a brief personality questionnaire designed to assess individual differences in health concern (Wansink and Chandon 2007), their self-reported ability to control food intake, and demographics. In particular, to measure to what extent participants were concerned about healthy eating, we used a five item scale including three items adopted from Chandon and Wansink (2007). Participants had to indicate their agreement on a seven-point scale anchored at $1=$ strongly disagree and $7=$ strongly agree: "Eating healthy is important to me", "I watch how much I eat", "I pay attention to calorie information", "I think of myself as a person who is concerned about healthy food", "I am very concerned about the health-related consequences of what I eat". Selfcontrol was measured with a four item scale to which participants had to indicate their agreement also on a seven-point scale anchored at $1=$ strongly disagree and $7=$ strongly agree: "I am good at resisting temptation", "I display a lot of self-control when 
it comes to eating", "I have a lot of experience controlling my eating behavior", "I tend to engage in indulgent eating more than I should (reverse coded)".

\subsubsection{Results}

After the taste test and unbeknownst to the participants, the experimenter weighed how many grams of the chocolate pearls had been consumed by each participant. We created a summated variable for the consumption of the milk and dark chocolate pearls. An ANOVA of the health-claim manipulation on the quantity consumed revealed a significant main effect $(\mathrm{F}(2,106)=11.37, p<.05)$. In line with our expectations and previous research on the effects of low-fat claims (Wansink and Chandon 2006), participants in the hedonic-attribute condition consumed significantly more chocolate than participants in the control condition $\left(\mathrm{M}_{\text {Hedonic }}=28.31, \mathrm{SD}=14.49\right.$; $\left.\mathrm{M}_{\text {Control }}=20.46, \mathrm{SD}=16.52 ; \mathrm{F}(1,106)=6.27, p<.05\right)$. More importantly, in comparison with the control condition, participants in the functional-attribute condition consumed significantly fewer chocolate pearls $\left(\mathrm{M}_{\text {Functional }}=13.45, \mathrm{SD}=7.61 ; \mathrm{F}(1,106)\right.$ $=4.43, p<.05)$.

One could argue that the antioxidant claim making the chocolate appear healthier also made the chocolate appear less tasty (Raghunathan et al. 2006). However, this effect should then also have held for the low-fat claim, which is not borne out by the increased consumption in this case. To test whether the health claims influenced the taste perceptions of the chocolate, we conducted an additional ANOVA, which revealed no significant differences in the perceived taste of the chocolates across the three conditions $(\mathrm{F}(2,106)<1)$. An overview of the consumption findings is provided in Figure 2. 


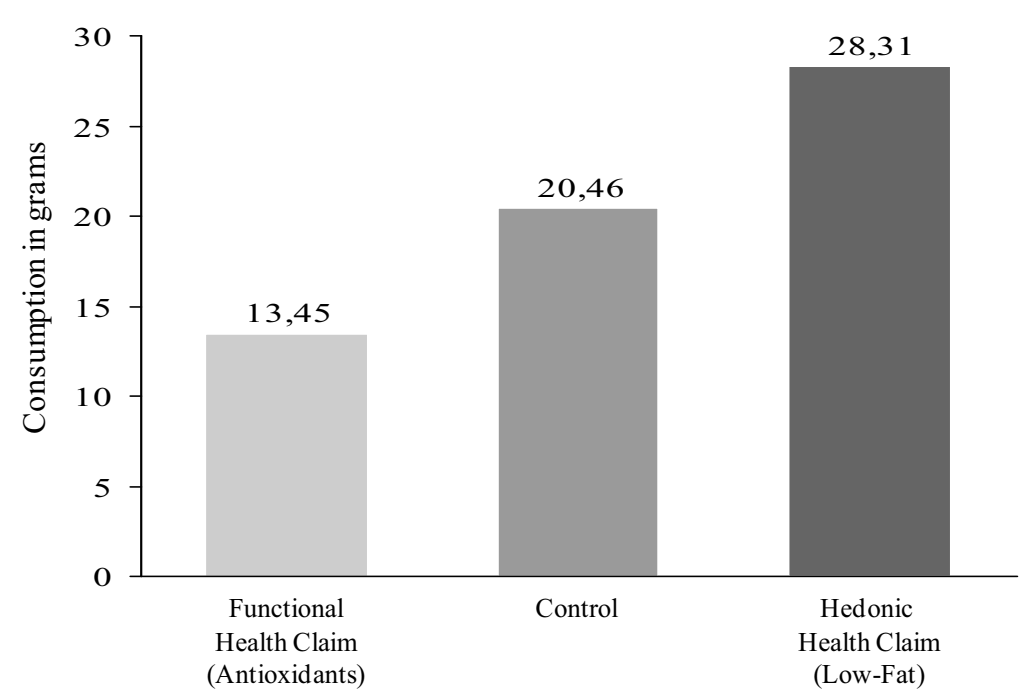

Figure 2: Chocolate Consumption across Conditions

Additional Analyses. To examine potential moderating effects of individual differences in health concern or self-control on consumption, we first assessed the reliability of both scales using Cronbach's alpha (health concern: $\alpha=.82$; self-control: $\alpha$ $=.71)$. Second, we verified the unidimensionality of the scales $(61.5 \%$ of the variance was extracted by a single principal component of the health concern scale; $54.4 \%$ of the variance was extracted by a single principal component of the self-control scale), before we averaged responses on each scale to create two summated variables. We then meancentered the continuous variables 'health concern' and 'self-control' and recoded our condition variable into two dummy variables (dummy_low-fat: $1=$ low-fat, all other $=$ 0 ; dummy_antioxidants: $1=$ antioxidants, all other $=0$ ). Next, we computed four interaction terms and subjected all variables to a regression analysis with consumption as dependent variable. Results revealed significant main effects of the two dummy variables (dummy_low-fat: $\beta=7.39, p<.05$; dummy_antioxidants: $\beta=-7.15, p<.05$ ), whereas all other effects were non-significant. These results imply that neither the selfreported ability to control food intake nor individual differences in health concern affected the results obtained above.

An ANOVA on estimated calorie perceptions across conditions revealed no differences between the functional, the hedonic, and the control condition $(F(2,106)=$ 
1.12 , NS), suggesting that the presence of the health claims did not result in immediate overgeneralizations of benefits associated with the product that are not explicitly mentioned in the claim. Further, we tested for differences in purchase intentions across conditions to examine whether participants were more likely to purchase healthy indulgences than conventional indulgences. The results of an additional ANOVA revealed no differences in people's intention to purchase the chocolate across conditions $(\mathrm{F}(2,106)<1)$. Specifically, a grand mean of $4.23(\mathrm{SE}=.16)$ suggests that participants were neither especially willing nor unwilling to buy the respective chocolates. This finding implies that the addition of a health claim neither enhanced nor decreased participants' intentions to purchase the indulgence, irrespective of the observed differences in consumption across conditions. Finally, controlling for potential gender effects did not reveal a significant effect $(\mathrm{F}(1,103)=1.55$; NS), suggesting that men and women did not respond differently to our health manipulations.

\subsubsection{Discussion}

The results of our pilot study provide initial support for our hypothesized effects of health claims on actual food consumption. While all health claims attached to unhealthy foods may make the indulgences be seen as easy to justify, which should hence stimulate increased consumption, our results show that ostensibly similar health claims can lead to very different consumption patterns: a functional health claim appears to decreases consumption, whereas a hedonic health claim increases consumption relative to a control condition. The finding of equal calorie estimations across conditions is interesting, in that it appears to run counter to the notion of overgeneralization (e.g., Schuldt and Schwarz 2010) and ease-of-justification (e.g., Wansink and Chandon 2006), especially suggested for hedonic low-fat claims. Yet, a closer look into the studies conducted by Wansink and Chandon (2006) reveals inconclusive results for absolute calorie estimations of low-fat versus regular food labels. In their study 1, absolute calorie estimates were not influenced by nutrition label, whereas in their second study, low-fat food was perceived as containing fewer calories than a regular version; consistent significant effects were only found for estimated calorie consumption (i.e., participants generally underestimated the amount of calories they consumed, and this effect was more pronounced for low-fat nutrition labels than 
for regular labels). That is, rather than claiming that the non-significant differences in calorie estimations in our study provide evidence that overgeneralizations did not occur, we follow the argument of Schuldt (2011), who refers to the well-documented phenomenon that consumers have difficulties with estimating absolute calorie content (see also Berman and Lavizzo-Mourey 2008; Livingstone and Black 2003). As such, consumers' absolute calorie estimations should not be overrated in drawing conclusions as to whether overgeneralizations from one attribute to other related attributes actually occurred.

Despite the conformity of the direction of consumption following different types of health claims with our prediction, the design of experiment 1 did not account for an alternative framing explanation, suggesting that the opposite consumption effects were driven by the specific wording of the claims. In particular, the low-fat claim highlights the reduced amount of a negative attribute (fat), whereas the antioxidants claim stresses the increased amount of a positive attribute (antioxidants). Research has indicated that the absence of negative attributes is likely more desirable than the presence of positive attributes (e.g., Kahneman and Tversky 1979), implying that a lossaversion type explanation might hold instead of our proposed nature of attribute explanation. We tested this alternative explanation in experiment $2 \mathrm{a}$, which was identical to the pilot study except that we added a condition allowing us to disentangle which of the two explanations is driving our effects. Furthermore, replicating the different consumption effects identified for functional versus hedonic health claims would demonstrate the robustness of the phenomenon, thus lending credibility to our claim that not all health claims are created equal.

\subsection{Experiment 2a}

The aim of the second experiment was to test the alternative explanation that the opposite consumption effects were driven by the framing of the individual health claims. Therefore, we ran a replication study with an additional condition using a claim that stressed the reduced amount of a negative functional attribute (i.e., lowcholesterol). The primacy of affirmation account would suggest that only the affirmations "antioxidants", "fat", and "cholesterol" should be processed and the nature 
of the attributes (functional versus hedonic) is expected to determine which schemata are accessed, which, in turn, determine direction of consumption.

\subsubsection{Method}

Participants. Ninety-seven students (64 men, 33 women) from a medium-sized Dutch University participated in the experiment in exchange for course credit. The majority of the participants were German (46.4\%) and Dutch (21.6\%), with an average age of 22 years.

Design and procedure. The design and procedure of the second experiment was identical to experiment 1 , except that we added a condition with a health claim highlighting the reduced amount of a negative functional attribute (i.e., lowcholesterol). We expected the low-cholesterol condition to result in similar consumption patterns as the low-fat condition if a framing or loss-aversion explanation would hold, whereas we expected the low-cholesterol condition to reveal consumption patterns similar to the antioxidants condition if the nature of the attributes determines the direction of influence.

\subsubsection{Results}

The results of an ANOVA of the health claim manipulation on the quantity consumed revealed a significant main effect $(\mathrm{F}(3,93)=9.85, p<.05)$ and showed that, compared to the control condition, consumption increased when we exposed participants to the hedonic low-fat health claim $\left(\mathrm{M}_{\text {Low-Fat }}=31.28, \mathrm{SD}=27.25 ; \mathrm{M}_{\text {Control }}=\right.$ 21.82, $\mathrm{SD}=10.44 ; \mathrm{F}(1,93)=4.56, p<.05)$ and decreased when we exposed them to the functional antioxidants health claim $\left(\mathrm{M}_{\text {Antioxidants }}=11.53, \mathrm{SD}=7.91 ; \mathrm{F}(1,93)=5.61\right.$, $p<.05)$. Most importantly, exposure to the low-cholesterol claim decreased consumption of the chocolate to a similar extent as we found with the antioxidant claim $\left(\mathrm{M}_{\text {Low-Cholesterol }}=11.02, \mathrm{SD}=5.55 ; \mathrm{F}(1,93)=6.29, p<.05\right)$, with the difference between the antioxidant and the low-cholesterol claim not being significant $(F(1,93)<1)$. Testing for differences in taste perceptions across conditions revealed a significant main effect $(\mathrm{F}(3,93)=4.09 ; p<.05)$, with participants in the low-cholesterol condition indicating less liking of the taste of the chocolate compared to the other conditions. 
Controlling for taste perceptions in the analysis on consumption, however, did not change the pattern of results (i.e., all significant effects remained and no non-significant effects became significant). Further, including gender in the analysis did not reveal a significant effect $(F(1,89)<1)$, and, similar to experiment 1 , no differences in estimated calories across conditions were identified $(\mathrm{F}(3,93)<1)$. An overview of the consumption findings is provided in Figure 3.

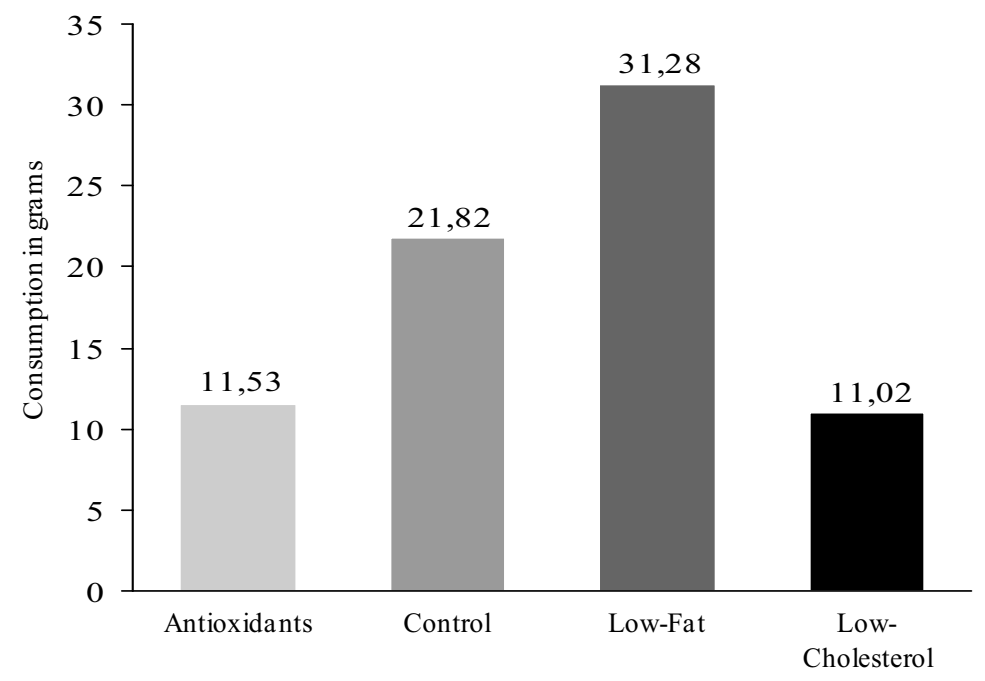

Figure 3: Chocolate Consumption across Conditions

\subsubsection{Discussion}

The findings of experiment 2a rule out a framing explanation as well as the related idea of loss-aversion, which would suggest that the absence of negative attributes is more desirable than the presence of positive attributes. We continue with experiment $2 \mathrm{~b}$ designed to compare claims stressing the reduced amount of a hedonic attribute to claims stressing an increased amount of a hedonic attribute, thereby potentially allowing for a construal of an indulgence as either more or less healthy. If people indeed ignore tags such as "low" and "high" and instead access concepts and schemata related to the hedonic affirmation, then it shouldn't matter whether the intended meanings of the claims make the indulgence more (e.g., low-fat) or less (e.g., 
high-fat) healthy. Consequently, we would expect to see increased consumption in both cases relative to a control condition.

\subsection{Experiment 2b}

The aim of experiment $2 \mathrm{~b}$ was to test whether purely hedonic claims such as "high-fat" would stimulate similar consumption increase of indulgences as we already demonstrated for hedonic health claims such as "low-fat". Thus, we expected purely hedonic claims, which, theoretically, make indulgences more difficult to justify, resulting in increased consumption relative to a control group, if the primacy of affirmation triggers a focus on the hedonic qualities of the food, making healthiness irrelevant.

\subsubsection{Method}

Participants. One-hundred and fifty-six students (105 men, 51 women) from a medium-sized Dutch University participated in the experiment in exchange for course credit. From the participants, the majority was German $(58.3 \%)$ and Dutch $(22.4 \%)$, with an average age of 21 years.

Design and Procedure. Upon arriving at the lab, we randomly assigned participants to either a low-fat, a high-fat, or a control condition and informed them that they would be contributing to a pudding evaluation study. We selected the claim "extracreamy" as a representative of the "high-fat" claim to best resemble current real-life industry developments. In particular, food manufacturers have recently introduced a number of indulgences focusing on their enhanced fat and calorie content and thus ultimately on superior taste. Milk shakes such as Mars ${ }^{\circledR}$ Thick Shake, M\&M's ${ }^{\circledR}$ Super Thick Shake, or Betty Crocker's ${ }^{\circledR}$ Rich \& Creamy ice cream might be considered the opposite of healthy, but the "non-plus-ultra" in terms of food enjoyment.

We provided chocolate pudding in large, transparent cups $(500 \mathrm{ml})$ on which we affixed a label reading either "low-fat," "extra-creamy," or "regular." In contrast to experiments 1 and $2 \mathrm{a}$, participants started immediately with the taste test instead of first completing a package evaluation task, as we provided the product-claim manipulations in the form of a sticker on the pudding cups. We used similar questions for the taste test 
questionnaire as we used before, but adjusted them to fit to pudding. Unbeknownst to the participants, we measured how much pudding they consumed by comparing the preand post-weights of the filled cups.

\subsubsection{Results}

An ANOVA on the quantity consumed with the product claim manipulation as a between-subject factor and hunger as a covariate revealed a significant main effect of product claim $(\mathrm{F}(2,153)=4.32, p<.05)$, with participants in the hedonic health claim condition and in the purely hedonic claim condition consuming significantly more of the pudding than those in the control condition (hedonic health claim vs. control: $\mathrm{M}=$ $115.81, \mathrm{SE}=11.43$ vs. $\mathrm{M}=72.72, \mathrm{SE}=11.72 ; \mathrm{F}(1,153)=7.02, p<.05$; purely hedonic claim vs. control: $\mathrm{M}=113.14, \mathrm{SE}=11.44$ vs. $\mathrm{M}=72.72, \mathrm{SE}=11.72 ; \mathrm{F}(1,153)=6.21$, $p<.05)$. The difference between the two treatment groups was not significant $(\mathrm{F}(1,153)$ $<1)$. Thus, in line with our prediction, a claim emphasizing a hedonic food attribute appears to result in increased food intake, regardless of whether the intended meaning of the claim allows for an interpretation of the food as more or less healthy.

Controlling for potential gender effects did not have an effect on the results $(\mathrm{F}(1,149)=2.58$; NS) and a subsequent ANOVA on taste perceptions with productclaim manipulation and gender as between-subject factors and hunger as a covariate neither revealed differences in perceived taste across conditions $(F(2,153)<1)$ nor between gender $(\mathrm{F}(1,150)<1)$.

\subsubsection{Discussion}

In line with our expectations, the results of experiment $2 b$ demonstrate once more the consumption-increasing effects of hedonic attributes emphasized in claims. Specifically, we showed that regardless of whether the claims allow for an interpretation of the indulgence as more or less healthy, participants consumed more of the foods when a hedonic attribute was present than when it was absent (i.e., in the control condition). Would the claims be processed in their entirety (i.e., triggering schemata congruent with the intended meanings of the claims rather than giving primacy to the affirmations), consumption of the high-fat pudding (i.e., the extra-creamy version) 
would be expected to be significantly lower than that of the low-fat pudding, because high-fat is much more difficult to justify than low-fat. Thus, if ease-of-justification would be the process underlying hedonic health claims, then one would expect to see reversed effects with purely hedonic claims.

Together, the results of experiment $2 \mathrm{a}$ and $2 \mathrm{~b}$ lend additional support to the primacy of affirmation account (Jung et al. 2004) in that people appear to elaborate on the affirmation (e.g., cholesterol, fat) rather than on the tag (e.g., low, high), thereby making the functional versus hedonic nature of the attribute the key determinant for how much of the food an individual eventually consumes ${ }^{5}$. Thus far, our results provide consistent support for our hypotheses of decreased consumption in the case of functional health claims $\left(\mathrm{H}_{2 \mathrm{a}}\right)$ and increased consumption in the case of hedonic health claims $\left(\mathrm{H}_{2 \mathrm{~b}}\right)$. However, none of the experiments provided insights into the suggested goal activation processes underlying these behavioral effects. We therefore continue with experiment 3 , in which we investigate accessibility of health and indulgence goals upon exposure to indulgences making functional, hedonic, or no health claims.

\subsection{Experiment 3}

The objective of experiment 3 was to provide insight into the underlying processes involved with the identified consumption patterns. Recall that we anticipated differences in health goal accessibility for functional versus hedonic health claims, with functional health claims triggering high levels of health goal accessibility and hedonic health claims rendering health goals less accessible given an increased hedonic orientation towards the food. Furthermore, we argued that the hedonic nature of the food itself results in accessible hedonic food enjoyment goals (i.e., indulgence goals), independent of the presence of health claims. This suggests that for functional health claims, simultaneous health- and indulgence goal accessibility would create high levels of conflict between the two competing goals. For hedonic health claims, on the other hand, an accentuated focus on the pleasure associated with consuming the food reflected

\footnotetext{
${ }^{5}$ We argue that since we did not manipulate resource availability (i.e., we did not explicitly put participants under high or low cognitive load), we assume moderate resource availability in all conditions. This argument is supported by the fact that participants were allocated randomly to the conditions, ensuring that potentially different levels of resource availability were evenly distributed across conditions.
} 
in accessible indulgence goals and low levels of health goal accessibility would constitute low levels of conflict. We used a lexical decision task to test for differences in goal accessibility in which faster recognition of target words (health and indulgencerelated words) signified the activation of the goals (Fishbach, Friedman, and Kruglanski 2003; Geyskens et al. 2008).

\subsubsection{Method}

Participants. Sixty-three students (21 men, 42 women) from a medium-sized Dutch University participated in the experiment in exchange for course credit. From the participants, the majority was German (49.2\%) and Dutch (34.9\%), with an average age of 24 years.

Design and procedure. We randomly assigned participants to one of three conditions ("antioxidants," "low-fat," or "control") in which they performed the same package evaluation task as in experiment 1 and experiment 2a. An important point of difference with the previous experiments was that this time, we removed the line "Health from the cacao bean" in the functional health claim condition to control for any confounding effects triggered by the word 'health' itself. Hence, the adjusted package in the functional health claim condition now only featured the claim "extra antioxidants" (see Appendix A). In addition, we collected measures on processing fluency via three items assessing whether the package of chocolate was easy to process $(1=$ difficult to process, $7=$ easy to process $)$, eye-catching $(1=$ not at all eye-catching, $7=$ very eyecatching), and attractive ( $1=$ not at all attractive, $7=$ very attractive) (Labroo and Lee 2006). Measuring processing fluency allowed us to test an alternative explanation, namely, that the increase in consumption of low-fat food is the result of a fit between the type of claim and the nature of the food (i.e., hedonic attribute/hedonic food), whereas the decrease in consumption of antioxidant-enriched chocolate might be the result of a lack of fit between the two (i.e., functional attribute/hedonic food).

After removing all materials, participants were prepared for the lexical decision task. Following a two-second warning screen, including a fixation cross, a stimulus word appeared on the computer screen in front of the participants. They responded as quickly and accurately as possible by pressing a key to indicate whether the stimulus 
was a word (left-shift key) or a non-word (right-shift key). Response times in milliseconds and accuracy were recorded. After a trial round of 10 trials ( 5 neutral and 5 pseudo-words), participants saw a total of 66 letter strings presented at random: 34 nonwords, 16 neutral words unrelated to health or indulgence, 8 target health words (healthy, vitamins, exercise, sports, vegetable, vigorous, nutrition, fruit), and 8 indulgence-related words (desire, wanting, pleasure, tasty, sweet, delicious, enjoyable, indulging). We counterbalanced the order of the health and indulgence words between participants to control for possible spillover effects.

\subsubsection{Results}

To prepare the data for analysis, we used only correct responses (Fazio 1990) and removed response latencies greater than or lower than three standard deviations from the means $(8 \%)$. We averaged response times to the target and neutral words and log-transformed the summated variables. For ease of interpretation, however, we report the means of the response times in milliseconds. We created a dummy variable indicative of the order in which the target words appeared; yet, testing for order showed no significant effects, and we therefore dropped this variable from further analyses.

To test the effects of the functional and the hedonic health claim manipulation on response times to the health and indulgence words, a Reaction Time (within; neutral, health, indulgence) $\mathrm{x}$ Health Claim (between; control, low-fat, antioxidants) mixed ANOVA was conducted. The results revealed a significant interaction effect $(F(2,60)=$ $3.70, p<.05)$. Planned contrasts showed that, in line with our predictions on indulgence goal accessibility, no differences in reaction times to indulgence words were observed across conditions $(F(2,60)<1)$, suggesting similar accessible indulgence goals in the functional (i.e., antioxidants) health claim condition $\left(\mathrm{M}_{\text {Antioxidants }}=633.96\right)$, the control condition $\left(\mathrm{M}_{\text {Control }}=638.95\right)$, and the hedonic (i.e., low-fat) health claim condition $\left(\mathrm{M}_{\text {Low-Fat }}=658,06\right)$. No differences were found for response times to the neutral words across conditions $(\mathrm{F}(2,60)<1)$.

Consistent with our hypothesis on health goal accessibility, planned contrasts showed that the functional claim made a health goal relatively more accessible compared to the hedonic claim $\left(\mathrm{M}_{\text {Antioxidants }}=638.72, \mathrm{SD}=73.79, \mathrm{M}_{\text {Low-Fat }}=703.25, \mathrm{SD}\right.$ 
$=102.29 ; \mathrm{F}(1,60)=10.85, p<.05)$, while we found a marginally significant difference compared to the control condition $\left(\mathrm{M}_{\text {Control }}=662.35, \mathrm{SD}=80.38 ; \mathrm{F}(1,60)=3.10, p<\right.$ .10). This suggests that the health goal was facilitated in the antioxidants claim condition. Zooming in on the antioxidants claim condition, we can see that the health words $(F(1,60)=3.51, p<.07)$ and indulgence words $(F(1,60)=4.89, p<.05)$ were activated to an equal extent in comparison to the neutral words, indicating experienced goal conflict in this functional health claim condition.

Although the activation of the health goal did not differ between the low-fat claim and the control condition $(F(1,60)=1.10 ; \mathrm{NS})$, further analyses revealed that the ordering (functional health claim $<$ control $<$ hedonic health claim) was significant as indicated by a significant linear trend of health goal accessibility across conditions $(\mathrm{t}(59)=1.90, p<.05)$. No quadratic trend was observed $(\mathrm{t}(59)=.96, p=.68)$. Zooming in on the low-fat claim condition, we can indeed see that participants responded significantly slower to the health words than to the neutral words $(\mathrm{F}(1,60)=5.26, p<$ $.05)$ and the indulgence words $(\mathrm{F}(1,60)=10.91, p<.05)$. This suggests that the health goal was inhibited and, consequently, very low to no goal conflict was experienced. Moreover, in the control condition, no differences were found for response times between the indulgence, health, and neutral words $(F(1,60)<1)$. Together, these findings show that there is low conflict between the health and indulgence goal in regular circumstances (i.e. the control condition), which is even less present in the lowfat condition.

To further explore differences in degree of goal conflict across conditions, we calculated individual difference scores for each participant. Specifically, we subtracted from the average reaction times to health words each participant's average reaction time to indulgence words. Lower scores indicate relatively high levels of goal conflict whereas higher scores reflect relatively low levels of goal conflict. Results revealed a marginally significant linear trend of goal conflict across conditions $(\mathrm{t}(60)=1.35, p=$ .06), with highest goal conflict experienced by participants in the functional health claim condition $(\mathrm{M}=4.75, \mathrm{SD}=56.60)$, lowest goal conflict experienced by participants in the hedonic health claim condition $(\mathrm{M}=45.19, \mathrm{SD}=78.59)$, and control 
participants falling in between $(\mathrm{M}=23.40, \mathrm{SD}=62.95)$. These results are presented in Figure 4.

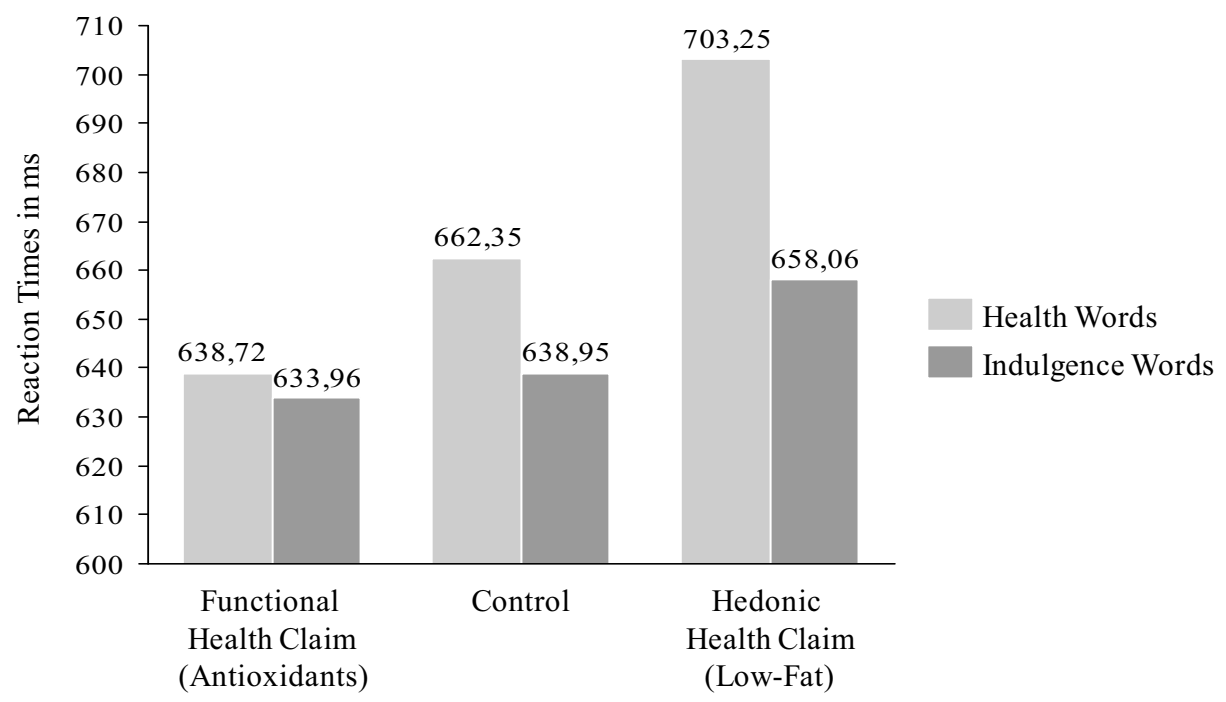

Figure 4: Reaction Times to Health and Indulgence Words across Conditions

Confound Check. The reliability of the fit/ease of processing measure was assessed using Cronbach's alpha $(\alpha=.79)$. Next, we verified the unidimensionality of the scale $(72.8 \%$ of the variance was extracted by a single principal component) before we averaged responses on the scale to create a summated variable. A subsequent ANOVA on ease of processing across the three conditions showed no significant differences between conditions $(\mathrm{F}(2,60)<1)$, ruling out an alternative fit explanation as discussed above.

\subsubsection{Discussion}

The results of the lexical decision task provide some interesting insights into the accessibility of health and indulgence-related goals upon exposure to indulgences making functional, hedonic, or no health claims. While we find similar indulgence goal accessibilities across all conditions, only the functional health claim simultaneously triggered high levels of health-goal accessibility, suggesting high temporary conflict between health and indulgence goals. In line with the notion of primacy of affirmation 
(Jung et al. 2004), the affirmation appears to be making concepts closely related to the core supposition salient. That is, given the health-related nature of the attribute constituting the affirmation of the functional health claim, the activation of health goals is likely. In addition, the hedonic nature of the food itself simultaneously activates indulgent food enjoyment goals, which compete with the accessible health goals, creating a situation of goal conflict. Researchers have suggested that high experienced goal conflict is likely to result in emotional ambivalence and aversive states (Ramanathan and Williams 2007; Rook 1987), which people typically try to resolve by dissociating themselves from the object(s) causing the aversive states. As such, the finding of high experienced goal conflict in the functional health claim condition supports our first hypothesis $\left(\mathrm{H}_{1 \mathrm{a}}\right)$ and provides an explanation for the decreased consumption patterns identified in experiment 1 and $2 \mathrm{a}\left(\mathrm{H}_{2 \mathrm{a}}\right)$.

The finding of very low accessible health goals in the hedonic health claim condition is interesting, in that it runs counter to the intuition that health claims uniformly trigger health-related concepts and goals. Our data strongly suggest that rather than increased levels of health goal accessibility, hedonic health claims render health goals temporarily less accessible $\left(\mathrm{H}_{1 b}\right)$, which is likely the result of an affirmation-induced hedonic orientation towards the food. Together with accessible indulgence goals, this creates a situation of very low levels of goal conflict, easing the way for a sole focus on the pleasure associated with consuming the food.

At this point, one might argue that accentuated hedonic orientations towards food triggered by hedonic health claims should be reflected in more accessible indulgence goals relative to a control group. While the finding of equal accessibility of indulgence goals across all conditions supports the notion of tempting food activating appetitive and hence indulgence-related goals of food enjoyment (Dhar and Simonson 1999; Fedoroff, Polivy, and Herman 2003; Raghunathan et al. 2006; Shiv and Fedorikhin 1999; Tepper and Trail 1998), it does not provide explicit proof for an increased focus on the pleasure associated with consuming the food. We argue that the similar accessibility of an indulgence goal in the hedonic health claim condition relative to the functional claim or the control condition might be the result of a ceiling effect. Such a ceiling effect makes it impossible to detect significant differences between 
different levels of already activated goals in a lexical decision task. In light of the consistent behavioral effects regarding hedonic health claims observed in the previous experiments (especially the finding of increased consumption following a high-fat claim; experiment 2b) and taking into account the finding of very low levels of accessible health goals in favor of accessible indulgence goals in the hedonic health claim condition in the present experiment, we hold on to our belief that the nature of the affirmation receiving primacy determines direction of consumption, which, when being hedonic, stimulates food intake.

Additionally, one might argue that the observed very low level of goal conflict in the hedonic health claim condition supports an ease-of-justification mechanism instead of an accentuated hedonic orientation towards the food. Recall that an ease-ofjustification process would predict that people would process the intended meaning of a health claim rather than just the affirmation alone. That is, in general, exposure to healthy indulgences should make people construe the food either as "healthy" or as "less unhealthy", which should thus be reflected in at least some accessibility of healthrelated goals. In the hedonic health claim condition of the present experiment, however, accessibility of health goals was lowest, pointing towards health goal inhibition in favor of a focus on the pleasure associated with consuming the food rather than health goal activation.

\subsection{Experiment 4}

Up to now, we demonstrated that functional health claims lead to decreased consumption (experiment 1 and $2 \mathrm{a}$ ) and create conflict by the simultaneous activation of a health and an indulgence goal (experiment 3). On the other hand, hedonic health claims lead to increased consumption (experiment 1 and $2 \mathrm{a}$ and $2 \mathrm{~b}$ ) with very low levels of health goal accessibility easing the way for a sole focus on the pleasure associated with consuming the food. A logical next step would be to conduct a study that measures both goal activation and consumption, and to investigate whether the behavioral effects are driven by this differential goal activation. However, as Spencer, Zanna, and Fong (2005) argue, measuring the activation of the underlying concept can prime the concept for all the participants and, thereby, prevent the observation of the behavioral effect. We 
therefore opted to manipulate the level of health/indulgence goal activation instead of measuring them.

Following our argumentation, one would predict the consumption increase in the hedonic health claim condition to be blocked if a conflict is created by an explicit external activation of the health goal. In our final experiment, we therefore examined how the activation of a health versus indulgence goal prior to the claim exposure influences the above-found results. We applied a priming technique, resulting in three conditions: a control condition without health or indulgence goal activation (neutral prime), a condition with health goal activation (health prime), and a condition with indulgence goal activation (indulgence prime). The aim of priming is to activate a concept in long-term memory (usually below the awareness threshold) by exposing participants to words related to that concept (Bargh and Chartrand 1999). With this priming technique, we simulated the activation of the health/indulgence goal.

\subsubsection{Method}

Design and procedure. One hundred forty-nine undergraduate students participated in partial fulfillment of a course requirement and were randomly assigned to one of the six cells of a 2 (claim: hedonic versus functional) $\times 3$ (prime: control versus indulgence versus health) design.

Participants first received a "language test" that primed them with neutral, health, or indulgence words. The language test was a scrambled sentences task (Bargh and Chartrand 2000). Each sentence consisted of five words and participants were instructed to construct a grammatically correct four-word sentence. In the health goal activation condition, 8 of the 20 sentences in the test contained a word that was related to health (e.g., vitamins, healthy). In the indulgence goal activation condition, these sentences contained a word that was related to indulgence (e.g., indulge, pleasure). The words were chosen in a way that ensured that the health-related/indulgence-related words would be used in the sentence composition. In the neutral prime condition the goal-related words were replaced by neutral words.

Subsequently, participants were asked to evaluate a chocolate product package, identical to the one used in experiment 1 . This package featured either a claim 
highlighting the presence of antioxidants (functional attribute condition), a claim focusing on its low-fat content (hedonic attribute condition), or no claim (control condition). All participants completed a battery of 15 questions pertaining to the attractiveness of the chocolate package (e.g., "The design of the package's front side is appealing"). Later, and similar to experiment 1, we invited all participants to taste the chocolate they had seen on the product package. Again, we used the chocolate pearls instead of the brand's regular seashell shapes. We placed one transparent bowl filled with a mixture of milk and dark chocolate pearls $(700 \mathrm{~g})$ in front of the participants and asked them to evaluate the product on several seven-point "agree-disagree" items relating to their taste, color, and structure.

\subsubsection{Results}

After the taste test and unbeknownst to the participants, the experimenter weighed how many grams of the chocolate pearls had been consumed. We created a summated variable for the consumption of the milk and dark chocolate pearls. An ANOVA testing the effects of the prime (neutral vs. health vs. indulgence) and health claim (functional vs. hedonic attribute) on the consumed quantity of chocolate pearls (in grams) revealed a significant main effect of the health claim $(\mathrm{F}(1,143)=10.59, p<$ $.05)$. Furthermore, a planned interaction contrast marginally supported our prediction that differences in consumption between functional and hedonic health claims would be substantially different in the health prime condition compared to the neutral and indulgence prime conditions $(\mathrm{F}(1,143)=3.54, p<.07)$. Replicating the results of study 1 , participants in the neutral prime condition consumed more chocolate pearls in the hedonic-attribute claim condition $\left(\mathrm{M}_{\text {Low-Fat }}=26.63, \mathrm{SD}=23.6\right)$ than those in the functional-attribute claim condition $\left(\mathrm{M}_{\text {Antioxidants }}=14.28, \mathrm{SD}=11.11 ; \mathrm{F}(1,143)=5.92\right.$, $p<.05)$. Participants primed with the indulgence goal showed the same consumption pattern, with participants in the hedonic-attribute claim condition $\left(\mathrm{M}_{\text {Low-Fat }}=26.92, \mathrm{SD}\right.$ $=22.12$ ) consuming more chocolate pearls than those in the functional-attribute claim condition $\left(\mathrm{M}_{\text {Antioxidants }}=14.37, \mathrm{SD}=12.12 ; \mathrm{F}(1,143)=8.07, p<.01\right)$. Interestingly and in line with our prediction, the consumption increase in the hedonic-attribute claim condition was blocked when participants were primed with health. More specifically, participants in the health prime conditions ate an equal amount in the hedonic-attribute 
condition $\left(\mathrm{M}_{\text {Low-Fat }}=15.70, \mathrm{SD}=13.36\right)$ compared to the functional-attribute condition $\left(\mathrm{M}_{\text {Antioxidants }}=14.24, \mathrm{SD}=13.15 ; \mathrm{F}(1,143)<1\right)$. An overview of the findings is presented in Figure 5.

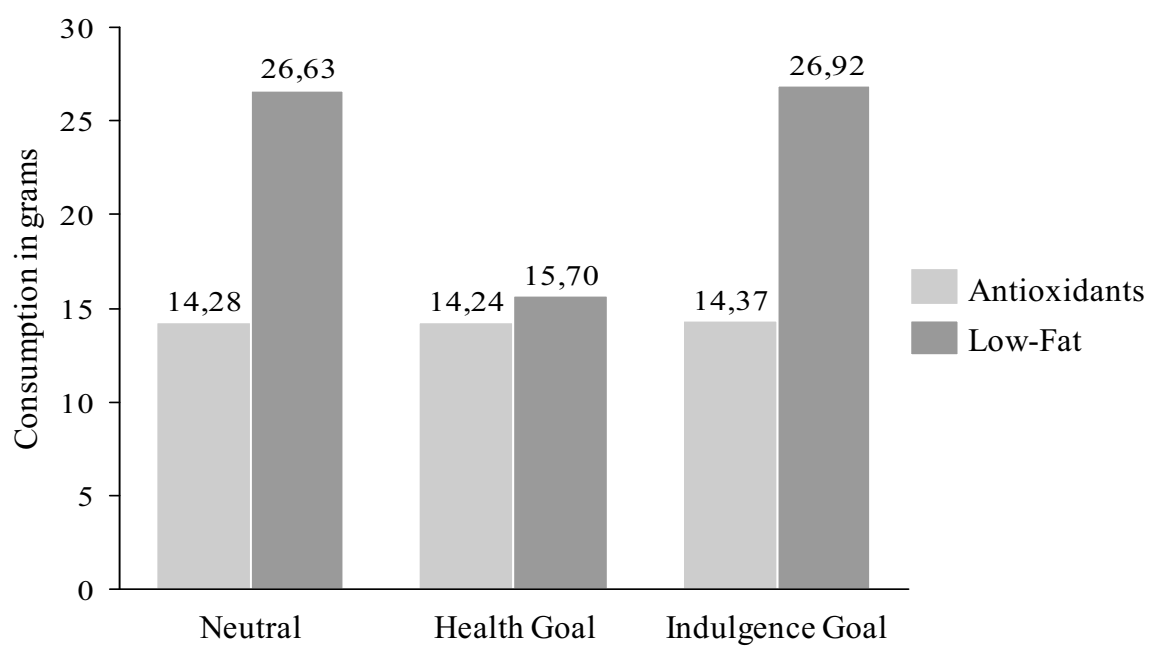

Figure 5: The Interaction of Health Claim by Prime on Consumed Amount of Chocolate

\subsubsection{Discussion}

The findings of experiment 4 , in which we explicitly manipulated goal activation, are consistent with our reasoning that food situations triggering a conflict between indulgence and health goals help consumers to control their food intake. Priming individuals with a hedonic indulgence goal does not alter the previously found effect of health claims on consumption. Tempting, unhealthy food by itself triggers high levels of indulgence-related goal accessibility (e.g., Fedoroff et al. 2003), so the prime has only limited effect. On the other hand, priming individuals with a health goal changes the previously found consumption-increasing effect of hedonic health claims. Hedonic health claims do not trigger a health goal and hence no conflict with the indulgence goal arises. However, when a health goal is primed, a conflict arises by which we see a similar decrease in consumption as in the case of functional health claims. 
These findings thus provide additional evidence for our reasoning that the previously found decreased consumption effects of functional health claims can be explained by the conflict caused by the simultaneous activation of an indulgence goal and a health goal. Furthermore, the results of this study also show that consumption enhancing effects of hedonic health claims can be blocked by explicitly creating conflict. This would imply that any cue in the marketing environment reminding the consumer of health concerns can protect them from the consumption-enhancing effects of hedonic health claims attached to indulgent foods.

\subsection{General Discussion}

Healthy indulgences appear to provide a solution to consumers' attempts to combine a healthy lifestyle with the pleasures of indulgences. However, recent research has suggested a negative effect of presenting inherently unhealthy food as healthier, as consumers tend to overgeneralize the benefits associated with such foods, leading them to consume significantly more of the healthy indulgence (e.g., low-fat M\&Ms) than they would of the conventional version (e.g., regular M\&Ms). The current research examined whether we can generalize the consumption-increasing effects established for low-fat health claims (Wansink and Chandon 2006) to other health claims as well. Our results provide converging evidence that not all health claims are created equal in that they lead to opposite consumption patterns depending on whether the food attributes the claims stress are of a hedonic versus functional nature.

In a pilot study (experiment 1), we provided evidence for the phenomenon that health claims emphasizing hedonic food attributes induce a significant increase in consumption compared to a control condition, whereas claims highlighting functional food attributes result in a significant decrease in consumption. Experiment $2 \mathrm{a}$ replicated the results of experiment 1 and ruled out an alternative framing or loss-aversion explanation. Focusing on the behavioral effects of claims stressing hedonic attributes, experiment $2 \mathrm{~b}$ demonstrated increased consumption irrespective of whether such claims allow for construal of the indulgence as more (low-fat) or less (high-fat) healthy, thereby providing additional support for our proposed framework. Building on the notion of primacy of affirmation (Jung et al. 2004), we have argued that people process 
the affirmations rather than the claims as a whole, which makes the hedonic versus functional nature of the affirmations a key determinant for the direction of influence. Specifically, when the attribute a claim emphasizes (i.e., the affirmation) is of functional, health-related nature, the activation of health goals is likely. Together with highly accessible indulgence goals triggered by the hedonic nature of the food itself, the two competing accessible goals create a situation of goal conflict, which is resolved by consuming less of the food causing the conflict. When the attribute a claim emphasizes is of hedonic nature, concepts congruent with the hedonic affirmation (e.g., food enjoyment) are likely to become salient rather than concepts congruent with the intended meaning of the claim (e.g., health). Consequently, this accentuated hedonic orientation towards the food stimulates increased food intake of the indulgence. Experiment 3 provided support for the suggested different levels of health goal activation evoked by functional versus hedonic health claims and demonstrated high conflict between health and indulgence goals in the case of functional health claims. The very low levels of health goal accessibility following exposure to hedonic health claims combined with highly accessible indulgence goals, on the other hand, result in very low levels of goal conflict, which we believe is the result of an increased hedonic orientation towards the food. Our final experiment 4 further corroborates our theoretical framework by showing that food situations triggering goal conflict help consumers to control their food intake. In particular, we show that the consumption-increasing effect induced by hedonic health claims can be blocked if a conflict is created by an external activation of a health goal.

One might be tempted to argue that an alternative explanation for our finding of increased consumption following exposure to hedonic health claims is provided by the theory of vicarious goal fulfillment (Wilcox et al. 2009). According to this perspective, the mere opportunity to fulfill a long-term health goal (e.g., provided by the presence of a healthy food option in a choice set) results in health-goal fulfillment, leading people to behave in line with an alternative (short-term) indulgence goal. In our context, one might argue that the observed low accessibility of health goals in the hedonic health claim condition is indicative for health goal fulfillment, which, in turn, licenses consumers to indulge. Although intuitively appealing, two arguments speak against this explanation. First, if hedonic health claims such as "low-fat" provide consumers with a 
license to indulge, then "high-fat" claims should result in the opposite effect, acting similar to a "stop" sign regarding food intake. That is, one would expect lower consumption following exposure to high-fat claims (e.g., extra-creamy) relative to a control group, and certainly lower consumption relative to a group having been exposed to a low-fat claim. Our finding of similar increasing consumption in both the low-fat and the high-fat condition of experiment $2 \mathrm{~b}$ runs counter to this perspective, instead supporting the notion that consumers ignore the tags "low" and "high" while giving primacy to the affirmation "fat". Given that "fat" evokes schemata related to hedonic food enjoyment goals (e.g., Raghunathan et al. 2006), such claims thus trigger increased food intake relative to a control group. Second, our finding of decreased consumption following exposure to functional health claims is in conflict with this perspective as well. By and large, indulgences featuring functional health claims communicate health benefits to the consumer and should thus - if the theory of vicarious goal fulfillment holds - easily fulfill long-term health goals. The finding of highly accessible health goals in the functional health claim condition (experiment 3), together with the repeated demonstration of reduced food intake, do not support this view.

\subsubsection{Theoretical Implications}

The findings obtained in the present research contribute to the literature in several important ways. First, the conceptual framework this research proposes calls into question the conjecture that health claims generally and automatically result in overgeneralizations of the benefits of the unhealthy foods to which they are attached (e.g., Andrews et al. 1998; Wansink and Chandon 2006). Prior research has suggested that indulgences that are framed as healthy through the addition of a health claim are easier to justify than a conventional version, thereby providing consumers with an implicit license to indulge. However, the only study demonstrating the behavioral implications of this notion in the context of healthy indulgences is that of Wansink and Chandon (2006). The authors provided evidence that indulgences labeled as lower in fat result in increased consumption relative to an indulgence not making this claim, yet the generalizability of the underlying process to other types of health claims remained open. 
To the best of our knowledge, the present study is the first to explore in more detail consumption effects of different types of health claims, identifying the nature of the attributes a claim emphasizes as a key determinant for whether consumption of the food carrying the claim increases or decreases relative to a control group. While we replicate the detrimental consumption-increasing effects of hedonic low-fat health claims, the most intriguing finding of our research pertains to the fact that health claims featuring functional attributes consistently resulted in decreased food intake. Demonstrating the important role of attributes differing in their hedonic versus functional nature in enhancing or reducing consumers' abilities to control their food intake contributes to extant models of self-control. For example, we argue that the primacy granted to the processing of hedonic attributes stressed in health claims makes concepts of food enjoyment highly salient, and that this hedonic orientation towards food stimulates increased consumption (i.e., self-control loss). Prior literature on selfcontrol has posited that factors that draw attention to immediate, near-future outcomes (e.g., the pleasure associated with consuming the indulgence; Fujita et al. 2006), as well as factors that enhance an activation of the "hot", impulsive system (e.g., attention to the appetitive qualities of a food; Metcalfe and Mischel 1999), are likely to weaken potential self-control efforts. Our findings corroborate these insights in that the presence of hedonic attributes and their resulting focus on food enjoyment reflects centered attention on immediate gratifications, and the consequential increased food intake thus is in line with these models' predictions of self-control failure. In a similar vein, our finding of activated health-related concepts and goals in the case of functional health claims relates to prior literature's suggestion that factors drawing attention to more distant future outcomes (e.g., leading a healthy lifestyle; Fujita et al. 2006), or factors that enhance activation of the "cool", rational system (e.g., construal of temptations as goal-threatening objects; Metcalfe and Mischel 1999), likely result in enhanced selfcontrol efforts. We find that functional health claims indeed trigger decreased consumption and hence increased self-control, albeit we propose that not the presence of the functional cue alone, but the resulting strong experienced goal conflict drives these consumption effects. Our framework, therefore, adds to existing literature on selfcontrol by illustrating the importance of distinguishing between functional and hedonic 
attributes in the context of healthy indulgences and by showing when experienced goal conflict leads to more controlled eating patterns.

Our research thus answers the call for more in-depth research on different types of nutrition claims and their effects on food intake (Grunert and Wills 2007; Wansink and Chandon 2006), identifying conditions under which consumption of tempting foods carrying different types of claims increases or decreases (e.g., Finkelstein and Fishbach 2010). Given the relevance of our findings to society as a whole and to food manufacturers in particular, we strongly encourage future research to test the generalizability of our proposed theory to other types of nutrition claims involving different food product categories.

Our results also extend the work on the schema-plus-tag model (Jung et al. 2004; Mayo et al. 2004) by showing that this principle appears to hold in the specific context of nutrition-based claims involving tags and affirmations. Next to demonstrating that affirmations differing in their hedonic versus functional nature result in opposite consumption patterns, we showed that the notion of primacy of affirmation appears to be extendable beyond the specific case of negations to other types of linguistic instructions involving tags. For example, we documented behavioral consequences in line with the notion of primacy of affirmation for an indulgence emphasizing an increased amount of antioxidants, as well as for an indulgence claiming to be high in fat. Thus, the findings presented here illuminate the broader applicability of the schemaplus-tag model (Mayo et al. 2004) and call for more research testing the principle in other consumption domains.

In sum, our research offers new insights into how healthy indulgences influence how much individuals end up consuming of the alleged "smart-snacking" alternatives, thereby enhancing our understanding of the specific conditions in which people over-consume versus regulate food-intake in response to health claims. The important implications of our findings will be discussed below.

\subsubsection{Implications for Marketers and Public Policy Makers}

Our findings have broad relevance to the food industry, and suggest that the nature of attributes emphasized in health claims can have significant effects on 
consumption. In particular, our findings imply important negative repercussions of the currently popular strategy of offering healthier alternatives of inherently unhealthy foods, when the attributes the claims stress are of functional nature. Functional food attributes emphasized in health claims enhance consumers' self-control concerning food intake, which reverses the desired consumption increase food manufacturers seek. In contrast, and in line with previous findings by Wansink and Chandon (2006), exposure to healthy indulgences featuring hedonic food attributes leads to increased consumption. Food manufacturers therefore might benefit from stressing hedonic food attributes in health claims such as fat and sugar. Alternatively, if a functional health claim is used, a strong emphasis on the taste of the indulgent food (e.g., in the form of a tag line such as "great taste"), in combination with, for example, a graphical design of the package making the functional claim less prominent than the emphasis on the taste dimension might mitigate the effects the functional health claim has on consumption of the healthy indulgence. The question then, however, is whether it makes sense for food manufacturers to use functional health claims at all, as they likely result in reduced food intake and also do not appear to enhance consumers' willingness to purchase the foods. Given the broad and apparently drastic implications of our findings, before giving any strategic recommendations as to whether or not functional health claims should be used, more research is needed testing the applicability of our findings in a real-life setting.

For public policy makers, a different picture emerges. Specifically, our findings might provide some comfort that not all marketing efforts aimed at promoting more wholesome alternatives of unhealthy, tempting food necessarily have negative consequences regarding consumers' eating patterns. Although we replicate the detrimental effects of low-fat references on food intake, we also demonstrate the power of health claims featuring functional food attributes in triggering more controlled consumption, ultimately leading to more health-conscious eating behaviors for unhealthy foods. Moreover, documenting that the consumption-increasing effect of hedonic health claims can be blocked by externally creating goal conflict emphasizes the importance of combining indulgence cues with health cues in supporting consumers' self-control efforts in the context of food intake. Thus, our findings suggest that consumers might be better off if healthy indulgences are reframed in functional terms. For example, low-fat foods may be described in terms of cholesterol or hydrogenated 
oils, which is likely not to have negative effects on consumers' purchase intention as our data has shown.

Together, the research presented here illuminates the potential of healthy indulgences to become a double-edged sword, in that they stimulate both favorable and unfavorable consumption patterns depending on the attributes emphasized in the claims and, more importantly, depending on which perspective one uses to interpret the findings (e.g., that of the food industry or that of society as a whole). Clearly, our findings suggest that in the long-run, we, as consumers, would likely benefit most from consuming indulgences featuring functional health claims.

\subsubsection{Limitations and Future Research}

Despite the intriguing and novel findings presented here, the present research is not without limitations and hence the results should be interpreted accordingly. First, it is important to acknowledge that we did not include an explicit measure resembling a manipulation check of the two different types of health claims used in the experiments, ensuring that the claims differed in their hedonic versus functional nature. Although we took great care in classifying a currently prominent set of health claims into being either functional or hedonic in the attributes they emphasize (e.g., we relied on literature suggesting that, for example, "fat" is predominantly perceived as hedonic (Raghunathan et al. 2006; Wertenbroch 1998), whereas "cholesterol", "vitamins" and "antioxidants" are rather regarded as functional in nature (Zou and Hobbs 2006)), it would be important to verify this classification in future research to improve the reliability of the findings. Alternatively, and to further enhance the validity of our proposed theory, it would be ideal if one could use a food attribute which is ambiguous in terms of its functional or hedonic potential and manipulate this dimension in an experiment. One potential candidate for such a procedure might be "calories". It is not clear whether calories are perceived as more hedonic in nature, thus evoking concepts related to taste and food enjoyment, or whether they are predominantly regarded as functional in nature, thus triggering health and dietary thoughts and concerns. If a mindset manipulation making people construe stimuli as either functional or hedonic precedes consumption of an indulgence labeled as either "high" or "low" in calories, we would 
expect the tags "high" and "low" to exert no influence, but the hedonic mindset to result in increased consumption, whereas the functional mindset should lead to decreased consumption.

Second, it is important to keep in mind that the samples used in the experiments consisted primarily of university students in their early 20's. Although a homogeneous sample guarantees a high degree of control over external factors (Lynch 1982), the sole usage of students in food research might not be representative of the population the respective food products are targeted to in the 'real' world. Therefore, we encourage future research to test whether our findings are generalizable across different age groups and across people with diverse educational backgrounds. In a similar vein, while our findings are robust across experiments conducted in the controlled environments of university labs, future research should test to what extent our findings hold in real consumption settings.

Third, although the current research illustrates the importance of distinguishing between functional and hedonic attributes in health claims, more research on potential boundary conditions for our proposed framework is needed. For example, whereas we focused on foods clearly classified as indulgences valued predominantly for their hedonic qualities, an interesting question is whether our findings extend to foods ambiguous with respect to their hedonic versus functional potential (e.g., muesli bar, pretzels). The established conflict between health and indulgence goals in case of functional health claims seems to depend to a large extent on the hedonic potential of the food itself, and the effects identified in the present research might get eliminated or reversed for foods more ambiguous in nature. Another interesting research direction would be to vary the level of the attributes the claims emphasize. For example, what trends in consumption might we observe when the fat content increases from $0 \%$ to $1 \%$, $10 \%$, or $20 \%$, and similarly for the amount of calcium or antioxidants? Based on prior research that shows people process decisions featuring hedonic attributes differently from those featuring utilitarian attributes (Chitturi, Raghunathan, and Mahajan 2007), people might be less sensitive to varying levels of a hedonic attribute and more prone to making comparisons between levels of functional attributes. 
Moreover, it would be worthwhile to examine how consumption of indulgences making functional versus hedonic health claims affects choice in subsequent consumption episodes. The work of Dhar and Simonson (1999) on balancing and highlighting provides a useful starting point for this investigation. Note, that given the metacognitive nature of such decision strategies, awareness of a connection between the choices is necessary (Khan and Dhar 2006). For indulgences making hedonic health claims, the following predictions can be derived: The present research posited that a hedonic health claim results in an accentuated focus on indulgence-related concepts and goals. According to Dhar and Simonson (1999), consumers generally have a strong preference for achieving peak experiences in subsequent consumption episodes (achieved through highlighting), and are more likely to attain peak goal fulfillment when a subsequent consumption experience involves items different to those involved in the initial experience. If, however, the subsequent choice involves items very similar to the item consumed first, consumers tend to follow a balancing strategy because "the synergetic effect of multiple goal-consistent items no longer exists" (Dhar and Simonson 1999, p. 32). This implies that after consuming indulgent food making hedonic health claims, consumers are likely to choose, for example, an expensive pair of designer sunglasses over a moderately priced, unbranded pair of sunglasses, as sunglasses are clearly different from indulgent food. This strategy would reflect highlighting. In contrast, if the subsequent choice involves items very similar to those of the initial consumption episode (e.g., a choice between a chocolate bar and an apple, thus a choice between two types of foods), consumers are likely to select the apple over the indulgent chocolate bar, reflecting a balancing strategy. Finding evidence for balancing in this context would have important implications, as it would show that, for example, low-fat food can stimulate healthy food choices after all.

The situation is slightly different for indulgences making functional health claims. Dhar and Simonson (1999) found that consumers prefer balancing (over highlighting) in consumption episodes involving tradeoffs between two conflicting goals, especially for episodes involving items that are very similar to each other. They argue that when two goals are active, a total neglect of any goal may spoil the value derived from attaining a peak level on the other goal. Thus, when two competing goals are active (e.g., as is the case when consuming indulgences making functional health 
claims), extreme solutions typically involved with highlighting, are avoided. Consequently, after consuming indulgences triggering goal conflict (e.g., calciumenriched ice cream), a subsequent choice between a chocolate bar and an apple is likely to result in the chocolate bar being preferred, as consumers already exerted self-control in the initial consumption episode (i.e., consuming less of the object causing the conflict). Such a choice would reflect balancing and is related to the licensing effect proposed by Khan and Dhar (2006). These authors suggested that engaging in, or committing to act virtuously in a prior task can license subsequent preferences for indulgent (e.g., luxury) objects. Note, though, that a licensing effect as defined by Khan and Dhar (2006) does not require the subsequent choice to be diagnostic (i.e., consumers need not be aware of a connection between the initial task and the subsequent task). Hence, we speculate that an indulgent object would also be selected when the respective item is very different from the item in the initial consumption episode (e.g., choosing a pair of designer sunglasses after prior consumption of antioxidant chocolate). As such, it appears as if consumers only benefit from more virtuous consumption effects in the initial consumption episode $t_{1}$. Subsequent consumption episodes $\left(t_{2}\right)$ involving choices between vices and virtues (Wertenbroch 1998) or luxuries and necessities (Kivetz and Simonson 2002) are likely to result in more indulgent choices, regardless of whether the items are very similar to, or very different from, the object consumed in $t_{1}$. Future research could examine these predictions.

Finally, an interesting and important avenue for future research regards the question of whether and how regular members of the product categories in which healthy indulgences operate are affected by their presence. Specifically, considering the - from a manufacturer perspective - backfire effect of indulgences featuring functional health claims, it would be important to examine to what extent the presence of such goal conflict-inducing indulgences in a given product category influences consumers' responses to regular category members not making health claims. Given that category members are related to each other via consumers' associative networks (Meyers-Levy and Tybout 1989), it is conceivable that what consumers experience with one specific member "spills over" and affects their behavior towards other members. We will 
address this question in chapter 3 of this dissertation. Note, that this investigation once more encompasses behavior occurring in consumption episode $t_{1}$, in that we will examine how mere exposure to (rather than consumption of) an indulgence featuring a functional health claim affects consumption of a regular category member. 



\section{CHAPTER 3}

\section{Let the Category Beware: \\ Spillover Effects of Conflict-Inducing Indulgences on Regular Category Members}

This paper examines how the presence of conflict-inducing healthy indulgences (i.e., indulgences making functional health claims) in a given product category affects consumption of regular category members not causing the experienced conflict. Results of two experimental studies reveal that exposure to conflict-inducing healthy indulgences results in reduced food intake of regular category members. This finding suggests that an aversive state of experienced goal conflict evoked by an indulgence making a functional health claim can spill over to affect behavior towards objects that are related to the conflict origin via consumers' associative networks. Providing evidence of negative behavioral spillover effects evoked by initial positive health information offers important and valuable input for managers on how the use of functional health claims attached to indulgences might impact other product category members. 


\subsection{Introduction}

It is widely accepted that brands cannot be isolated from information about other brands to which they are related via consumers' networks of mental associations; inevitably, they all become subject to indirect effects (Lei et al. 2008). Such indirect effects are typically referred to as spillover effects involving an updating of one's beliefs not only about the information target (e.g., information: Nike uses child labor to produce its sports shoes; information target: Nike), but also about objects that are not directly implicated (e.g., spillover effect: Adidas and Puma use child labor to produce their sport shoes). Although spillover of associations and perceptions can either be positive (e.g., when successfully leveraging brand equity; Keller 1993) or negative (e.g., in the event of brand scandals and product-harm crises; e.g., Dawar and Pillutla 2000), the far-reaching consequences of spillover induced by negative information has prompted a focus in the literature on examining the conditions under which negative spillover effects occur. So has negative information-induced spillover of associations and perceptions been documented, for example, from one attribute to another of the same brand (Ahluwalia et al. 2001), from one product to another within the same brand family (e.g., Balachander and Ghose 2003; John, Loken and Joiner 1998), and from one brand in a given product category to other category members (e.g., Dahlen and Lange 2006; Roehm and Tybout 2006).

In light of the potentially devastating spillover effects of negative information to related brands and products, it is interesting to consider the recent introductions of healthy indulgences within hedonic product categories such as chocolates, ice creams, and other confectionary products. At a first glance, one may wonder how the presence of healthy indulgences among the many regular versions of indulgent foods in a given product category might pose a threat regarding negative spillover. Healthy indulgences primarily differentiate themselves from other category members by communicating specific health benefits to consumers. Such positively differentiating product information is typically conveyed either by means of functional or hedonic health claims. Although both types of claims emphasize positive information about a product and should thus not be considered as potential sources for negative spillover, functional health claims have been shown to trigger immediate negative reactions in the form of 
experienced goal conflict (cf. chapter 2 of this dissertation). Goal conflict and the resulting emotional ambivalence represent aversive states which consumers typically try to resolve by dissociating themselves from the object causing the conflict. In the context of functional health claims attached to indulgent foods, this results in reduced consumption of the conflict-inducing food (cf. chapter 2 of this dissertation).

Given the cognitive relatedness between brands operating in the same product categories (e.g., Meyers-Levy and Tybout 1989) and taking into account that especially reactions to external negative information in the form of updated associations and perceptions can spill over to related entities, it would be important to examine whether information-induced negative states of aversion can spill over as well, possibly resulting in reduced consumption of regular category members. Hence, this paper seeks to examine to what extent an aversive state of experienced goal conflict evoked by an indulgence making a functional health claim can spill over to affect consumption of regular category members related to the conflict origin via consumers' associative networks. By measuring consumption as a proxy for how experienced aversion affects behavior, we provide evidence in two experimental studies that exposure to conflictinducing healthy indulgences results in reduced food intake of regular category members.

Behavioral consumption-related evidence of spillover of negative affective states has important theoretical as well as managerial implications. From a theoretical perspective, our findings contribute to extant literature on spillover effects by showing that in addition to information-induced association transfers, also consumers' reactions to information in the form of negative affective states bear potential to spill over and affect behavior towards objects cognitively linked to the information source. We thus bring forward a previously neglected "grey zone" of potential spillover candidates, redirecting attention away from informational valence (e.g., negative versus positive information) to consumers' affective reactions to information irrespective of its valence. In particular, the negative behavioral effect of reduced food intake of regular category members is triggered by initial positive information (i.e., a functional health claim). Previous research on spillover effects has consistently demonstrated that positive (negative) information has a positive (negative) effect on related entities, leading to 
premature conclusions as to how related entities are affected by spillover effects. Our findings illustrate that regular category members not claiming to be healthy are affected negatively by the presence of healthy indulgences communicating positive, functional health benefits in a given product category. Reduced consumption of regular product category members after consumers have been exposed to an indulgence making a functional health claims thus forces brand managers and marketers to rethink to what extent initial positive marketing communication might result in a "backfire" effect for brands that are linked to the information origin via consumers' associative networks.

\subsection{Conceptual Background}

The phenomenon of spillover effects has become a topic of growing importance considering its pervasiveness in many marketing contexts. Generally conceptualized as the process of how information influences beliefs that are not directly addressed in a communication (e.g., Ahluwalia et al. 2001), spillover effects encompass transfer of associations and perceptions between entities that are cognitively related through networks of mental associations. Associative network theories (e.g., Collins and Loftus 1975; Keller 1993; Morrin 1999) conceptualize consumer knowledge about entities (e.g., brands), as consisting of nodes, which are linked to other cognitive entities through a variety of associations (e.g., attributes, claims, evaluations). These associative linkages can vary in strength and need not be symmetric (Lei et al. 2008), in that "the direction processed more frequently develops stronger relations" (Barsalou and Sewell, 1985, p. 650). Such cognitive relatedness between brands makes them responsive to what happens to brands to which they are connected in an associative network.

For spillover to occur, external information about one brand must activate the respective brand node in the associative network, and this activation must then spread to other related nodes to which the origin brand is connected. This process of retrieval of related nodes (i.e., destination nodes) is a function of the associative linkage-strength, implying that the stronger the linkages between two nodes, the more relevant and salient the new information becomes to the destination node. The magnitude of a subsequent updating of the destination node then reflects the strength of the spillover (see Lei et al. 2008 for a more detailed discussion). 
Ideally, spillover effects are capitalized upon by leveraging, for example, positive brand equity to spillover targets such as other products, subbrands, and brands within company-defined brand architectures (e.g., Aaker and Joachimsthaler 2000). The cognitive relatedness between brands thus can assist managers in reaching marketing objectives by creating synergy, clarity, and leverage (Aaker and Joachimsthaler 2000). Next to strong associative linkages between brands within the same brand architecture, relatedness can be established by a variety of other marketing means, such as similar advertising, proximate shelf location, or comparable product (package) designs (Lei et al. 2008). Consumers tend to group brands operating in the same product category as "hanging together" as they typically serve to fulfill the same consumer need(s) and are marketed in similar ways. Such grouping or categorization processes enable consumers to effortlessly understand what category members are about and allow for easy and quick generalizations of knowledge about brands they have encountered, to other, similar brands (e.g., Dahlen and Lange 2006; Medin and Smith 1984). Hence, in a perfect world, many opportunities for managers to benefit from strong linkages between brands exist.

Unfortunately, however, there is no such thing as a perfect world and the previously described relatedness comes not without risks. As outlined above, cognitive relatedness makes brands highly susceptible to suffering from negative events (e.g., negative publicity) happening to related brands. For example, information about traces of benzene in Perrier water (Kurzbard and Siomkos 1992), news about E.coli contaminated Taco Bell products (Dahlen and Lange 2006), or negative publicity about malfunctioning tires of Bridgestone/Firestone (Advertising Age 2000) all raise immediate concerns not only about the quality of the affected brands, but also about competitors' products offered in the same product category. The pervasive effects negative information about one brand or company can have on other brands or products within, and sometimes even across product categories, has been documented in several studies (e.g., Cleeren, van Heerde and Dekimpe 2010; Dahlen and Lange 2006; Roehm and Tybout 2006). Such research has been fueled by the general notion that negative information is typically given more weight in judgment formation than positive information (e.g., Kanouse and Hanson 1971; Lutz 1975; Wright 1974). As such, rather than only being concerned about communicating the right information about their own 
brand(s), marketers are well advised to keep an eye also on what is happening to, and the activities of, their competitors, as "brands are also in fact in the hands of [...] competitors" (Dahlen and Lange 2006, p. 393).

The previous discussion illustrates that entities which are related via consumers' networks of mental associations can be subject to spillover effects; with positive information likely resulting in positive association transfers and negative information likely resulting in negative association transfers. In light of the far-reaching managerial consequences of spillover induced by negative information and taking into account the theoretical notion of negatively valenced information weighing more than positive information in judgment formation (e.g., Skowronski and Carlston 1989), it is not surprising that much attention in the literature has been directed at examining the conditions under which negative spillover effects occur.

The increasing availability of healthy indulgences in the indulgent food landscape (Lopez-Walters and $\mathrm{Wu}$ 2007) creates an interesting context for the discussion on spillover effects. At a first glance, healthy indulgences are not posing a direct threat in terms of negative spillover to the members of the general product categories they are launched in. In effect, healthy indulgences all appear to communicate positive product information in the form of a health benefit. Thus, consumers can decide whether they would like to indulge in a standard indulgence or whether they would prefer the treat of the "healthy" alternative claiming to be, for instance, high in antioxidants or low in sugar. Importantly however, as chapter 2 shows, not all health claims are created equal in that health claims featuring functional attributes (e.g., antioxidants, vitamins, cholesterol, and sodium) evoke negative affective reactions of aversive states as a consequence of high experienced goal conflict. Hence, although the overall information communicated by functional health claims is positively valenced, it results in negative reactions of states of aversion, ultimately leading to avoidance behavior towards the food causing the experienced conflict. Considering that consumers' reactions to information in the form of an updating of their beliefs of the information target can spill over to related entities (Dahlen and Lange 2006; Lei et al. 2008; Roehm and Tybout 2006), it is of importance to investigate to what extent also reactions in the form of affective states can be potential candidates for 
spillover effects. In the specific case of functional health claims attached to indulgences, spillover of negative affective states would be the consequence of initially positively valenced information, which makes this case not only interesting to investigate, but also theoretically as well as managerially relevant.

To predict whether negative affective states of aversion bear potential to affect related category members not causing the currently experienced conflict, we draw on recent work by Bailis et al. (2011) who examined affective and behavioral traces of goal conflict with physical activity. The authors suggest that in the context of goal conflict, the emotional tone of one's pursuit of the goal typically attached to the object triggering the conflict is likely to become less positive in light of the presence of a competing goal. They showed that after experimentally creating goal conflict through a goal-priming procedure of a study goal for participants with a pre-dispositionally high goal to exercise, the emotional tone associated with the goal to exercise becomes less positive. This negative change in affect spreads through the associative network and negatively affects perceptions of, and behavior towards, exercise-related objects (i.e., the exerciserelated object of a sports water bottle was devalued and used fewer by participants). Applied to our context, it is conceivable that when conflict is aroused by exposure to an indulgence making a functional health claim, the negative affective state of aversion as a direct consequence of experienced goal conflict might spread through the network of mental associations, "rubbing off" on any indulgence-related object (e.g., regular category members) cognitively related to the object causing the state of aversion. Given that aversion typically results in avoidance behavior, the consumption of regular category members is likely to go down.

More formally, we expect to observe the following in the event of spillover of negative affective states of aversion:

$\mathrm{H}_{1}$ : Exposure to conflict-inducing healthy indulgences results in reduced consumption of regular category members not making health claims. 


\subsection{Experiment 1}

The objective of the first experiment was to test how exposure to a conflictinducing indulgence (i.e., an indulgence making a functional health claim) affects consumption of regular category members not making health claims. Finding evidence of reduced consumption of a regular category member for participants having been exposed to a conflict-inducing healthy indulgence relative to a control group would be indicative for spillover of conflict-induced states of aversion.

\subsubsection{Method}

Participants. Eighty-eight students (50 men, 38 women) from a medium-sized Dutch University participated in the experiment in exchange for course credit. From the participants, the majority was German (83.0\%), with an average age of 20 years.

Design and procedure. Upon entering the lab, we randomly assigned participants to one of three conditions ("treatment", "control", or "baseline control"). We informed participants that they would contribute to a general product evaluation study, in which they would first evaluate the design of a given product package and, secondly, participate in a blind chocolate taste test for a chocolate manufacturer that requested to remain anonymous. The instructions emphasized that both tasks were initiated by different companies and were thus independent. We used a different layout for the questionnaires in the two tasks to lend further credibility to the claim that the two chocolate products introduced in the two experimental tasks were produced by different manufacturers. In the "treatment" condition, participants evaluated a chocolate product package featuring a functional health claim identical to the stimulus material used for the manipulation of chocolate making functional health claims in chapter 2 of this dissertation. In the "control" condition, participants evaluated a version of the chocolate package for which we had removed all health-related cues. Hence, the package represented a regular version of the chocolate without any references to its healthiness. In addition to the control condition, we added a "baseline control" condition in which participants evaluated the package of a non-food product (i.e., a fabric refresher). This provided us with consumption data that was not influenced by prior evaluation of tempting food stimuli (here: chocolate) and thus enabled us to examine whether 
elaboration on the chocolate package itself triggered conflict (e.g., in the control condition). If that was the case, we expected to find differences in the amount consumed between the control and the baseline control group.

Upon entering the experimental cubicles, participants found a laminated, colored picture of the respective product package (chocolate or fabric refresher), approximately matching the size of the original product. In a paper-and-pencil questionnaire, participants completed a battery of 15 questions pertaining to the attractiveness of the product package (e.g., "The design of the package's front side is appealing," "The information on the package's front side is credible").

After completion of the paper-and-pencil package evaluation, we removed the materials from the cubicles and invited all participants to take part in an unrelated, blind chocolate taste test. Thus, respondents believed that they were to test the chocolate of an unknown foreign company, whose chocolate was part of its range of regular chocolates available in that country. These instructions ensured that participants in the treatment and in the control condition did not infer that the chocolate they were to taste was the same as the chocolate they evaluated the package for. Within the blind taste test, all participants received two transparent bowls of chocolate (one bowl containing dark chocolate pearls $(700 \mathrm{~g})$, the other containing milk chocolate pearls $(700 \mathrm{~g})$ ) and they evaluated the product on several seven-point "agree-disagree" items relating to their taste, color, and structure. After completing the taste test and following a short filler task, participants responded to a brief personality questionnaire designed to collect data on demographics (age, gender, nationality, weight, height).

\subsubsection{Results}

Consumption. After the taste test and unbeknownst to the participants, the experimenter weighed how many grams of the chocolate pearls had been consumed by each participant. We created a summated variable for the consumption of the milk and dark chocolate pearls. To test our hypothesis of reduced consumption of regular category members as a consequence of spillover of conflict-induced states of aversion, an ANCOVA on the consumption of the chocolate was run with condition ("treatment", "control", or "baseline control") as between-subject factor and hunger as a covariate. 
Results revealed a significant main effect of condition $(\mathrm{F}(2,84)=12.05, p<.05)$, with less of the regular chocolate being consumed in the treatment condition $(\mathrm{M}=8.81, \mathrm{SE}=$ 2.65) compared to the control $(\mathrm{M}=23.19, \mathrm{SE}=2.44)$ and the baseline control condition $(\mathrm{M}=25.53, \mathrm{SE}=2.55)$. The latter two conditions did not differ from each other with respect to consumption $(\mathrm{F}(1,84)<1)$. Controlling for participants body mass index $\left(\mathrm{BMI}=\right.$ weight $/$ height $\left.^{2}\right)$, as well as gender and taste did not have any effects on the results. An overview of the findings is presented in Figure 6.

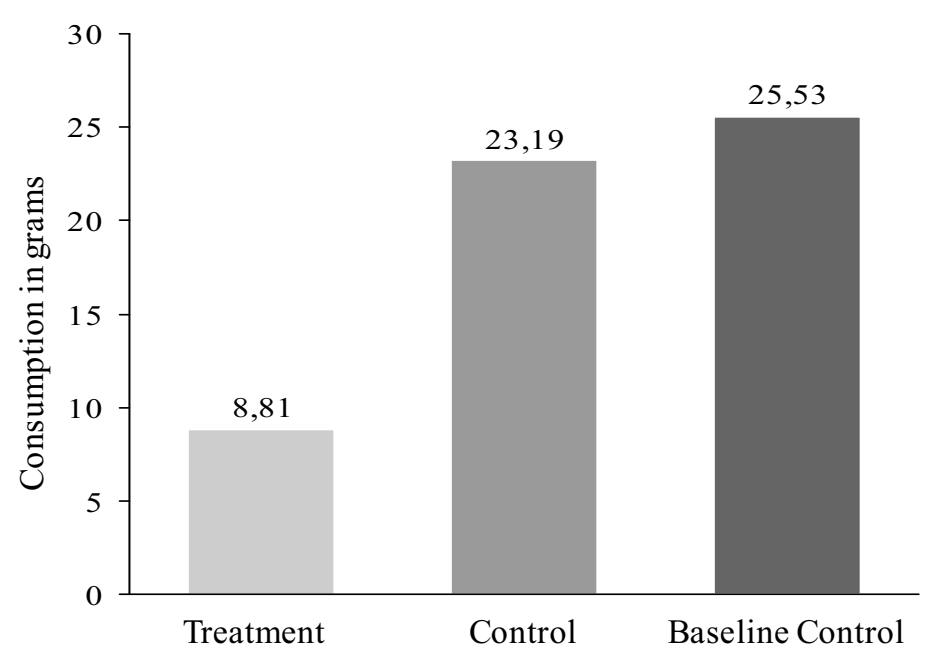

Figure 6: Consumption of Regular Chocolate across Conditions

\subsubsection{Discussion}

The primary aim of the first experiment was to test for potential spillover effects of conflict-induced states of aversion triggered by an indulgence making a functional health claim to food category members not causing the conflict. Drawing on associative network theory (e.g., Collins and Loftus 1975; Keller 1993; Morrin 1999) and prior work on affective and behavioral traces of goal conflict (Bailis et al. 2011), we argued that negative states of aversion induced by the origin indulgence spread through the entire network of mental associations, thereby affecting behavior towards regular product category members as they are cognitively linked to the origin. This hypothesis was supported, as we found decreased consumption of the regular chocolates after 
exposure to the chocolate carrying a functional health claim relative to a control and a baseline control condition. Importantly, the non-significant difference in consumption between the control and the baseline control condition implies that elaboration on the chocolate package in the control condition did not trigger conflict per se. If such elaboration would induce conflict, we should have observed lower consumption in the control condition relative to the baseline control condition.

These results provide some first evidence that in addition to the welldocumented phenomenon of spillover of perceptions and associations (e.g., Roehm and Tybout 2006) also affective states can spill over to affect behavior towards objects which are related to the origin via consumers' associative networks. In order to test the robustness of this effect, we conducted a replication study using a different product category. Moreover, we wished to explore the extent to which consumers' health perceptions of regular category members are subject to change in the event of experiencing aversion triggered by conflict-inducing functional health claims attached to indulgent foods.

\subsection{Experiment 2}

The objective of the second experiment was two-fold. First, we aimed to replicate the spillover effect identified in experiment 1 within a different product category. To further challenge our previous results, we switched from the category of foods to the category of beverages. In particular, we selected soft drinks as a beverage category because soft drinks such as coke and lemonade are typically perceived as sweet and tasty, yet simultaneously as unhealthy due to the high amount of sugar and empty calories ${ }^{6}$. We expected to find reduced consumption of a regular soft drink not making health claims after being exposed to a soft drink making a functional health claim relative to a control condition in which participants are exposed to the same stimulus without any health-related cues.

\footnotetext{
${ }^{6}$ Empty calories are a measurement of the energy present in indulgent high-energy foods with poor nutritional profiles, with most of the energy typically coming from processed carbohydrates, fats, or ethanol (see also National Institute of Health).
} 
Second, we wished to explore to what extent consumers' health perceptions of the regular soft drink are subject to change after being exposed to a soft drink carrying a functional health claim. In the event of spillover of aversion leading to decreased consumption of the regular soft drink, it is conceivable that also consumers' health perceptions of that soft drink go down. This would be in line with prior literature indicating that current emotional states can bias perceptions of contextual stimuli relevant to the currently experienced emotions (e.g., Bailis et al. 2011; Balcetis and Dunning 2006; Bruner and Goodman 1947; McGinnies 1949; Vogt et al. 2011). Hence, an additional aim of our second experiment was to explore to what extent spillover of negative states of aversion induced by a functional health claim influences consumers' health perceptions of regular category members.

\subsubsection{Method}

Participants. Fifty-two students (22 men, 30 women) from a medium-sized Dutch University participated in the experiment in exchange for course credit. From the participants, the majority was German $(63.5 .0 \%)$ or Dutch $(21.2 \%)$, with an average age of 22 years.

Design and procedure. We randomly assigned participants to one of two conditions ("treatment" and "control"). In the treatment condition, we presented participants with a print ad we developed, depicting a new version of $7 \mathrm{Up}{ }^{\circledR}$ featuring the following health-related information: "7Up Cherry Antioxidants - Healthy Happy Life" (see Appendix B). For the control condition, we removed the health-related information, resulting in a print image of a regular version of $7 \mathrm{Up}$ Cherry with no further cues regarding its healthiness (“7Up Cherry- Happy Life”).

Similar to the procedure used in experiment 1 , the experiment consisted of two separate tasks. The instructions emphasized that the tasks were initiated by different manufacturers and were thus independent. To lend further credibility to the claim that the two tasks were initiated by different manufacturers, we again used different layouts for the questionnaires of the two tasks. In the first task, we asked participants to evaluate the design and appearance of the advertisement by responding to several ninepoint "agree-disagree" statements including an item asking whether they perceived the 
information provided in the ad as credible ("I think the information provided in the advertisement is credible") and one inquiring about the likeability of the advertisement ("I like the advertisement"). In the second task, we invited respondents to participate in an unrelated soft drink taste test of a foreign soda manufacturer who, ostensibly, requested to remain anonymous. The instructions informed participants that the company was considering introducing its regular soft drinks also in the market of the country where this study was run and for which the blind taste test was designed.

We provided the beverage in large transparent cups filled with $500 \mathrm{ml}$ of soda. The cups were closed with a lid and participants were provided with $\varnothing 8 \mathrm{~mm}$ straws. This presentation of the soft drink was chosen to enhance realism as soft drinks are typically sold in this format in various out-of-home stores and snack locations. During the taste test, participants filled in an online questionnaire asking about their opinion on the taste and appearance of the soft drink, using nine-point Likert scales anchored at 1 $=$ totally disagree to $9=$ totally agree. To control for people generally avoiding soda, we included an item assessing participants' general likeability of soft drinks ("How much do you like soft drinks in general?"). In order not to bias participant's soft drink consumption during the taste test, we inquired about the regular soft drinks healthiness only at the end of the questionnaire, using the item "How healthy do you perceive this soft drink to be?"( 1 = very unhealthy and $9=$ very healthy). Unbeknownst to the participants, we measured how much of the soft drink was consumed, by comparing pre-and post-weighs of the cups after each experimental session.

\subsubsection{Results}

First, we tested whether participants in both conditions perceived the information provided in the advertisements as equally credible. Results of an ANOVA on information credibility with condition as between-subject factor revealed no difference between the two groups $\left(\mathrm{M}_{\text {Treatment }}=4.62, \mathrm{SD}=1.98, \mathrm{M}_{\mathrm{Control}}=5.08, \mathrm{SD}=\right.$ 2.07; $\mathrm{F}(1,50)<1)$. This finding implies that the presence of the functional health claim did not make the advertisement be perceived as less credible. Furthermore, we tested for differences in ad likeability and thirst, yet the results of two additional ANOVAs on advertisement likeability/thirst with condition as between-subject factor did not reveal 
significant differences between the groups (ad likeability: $\mathrm{M}_{\text {Treatment }}=4.62, \mathrm{SE}=1.89$, $\mathrm{M}_{\text {Control }}=5.08, \mathrm{SE}=2.07 ; \mathrm{F}(1,50)<1$; thirst: $\mathrm{M}_{\text {Treatment }}=5.46, \mathrm{SD}=2.12, \mathrm{M}_{\text {Control }}=$ $5.58, \mathrm{SD}=2.21 ; \mathrm{F}(1,50)<1)$.

Consumption. In line with our expectation, an ANCOVA on consumption with condition as between-subject factor and general liking of soft drinks as a covariate revealed a significant main effect $(F(1,49)=5.43, p<.05)$. Participants in the treatment condition consumed significantly less of the soft drink compared to those in the control condition $\left(\mathrm{M}_{\text {Treatment }}=96.15, \mathrm{SE}=14.47 ; \mathrm{M}_{\text {Control }}=143.96, \mathrm{SE}=14.47\right)$. That is, after seeing the $7 \mathrm{Up}$ advertisement featuring the conflict-inducing functional health claim, participants consumed significantly less of a regular soft drink, providing additional support for our prediction of conflict-induced spillover of aversive states. An additional ANOVA on taste perceptions of the regular soft drink revealed no differences between conditions $\left(\mathrm{M}_{\text {Treatment }}=5.16, \mathrm{SD}=1.78 ; \mathrm{M}_{\text {Control }}=5.29, \mathrm{SD}=2.17 ; \mathrm{F}(1,50)<1\right)$, and controlling for taste perceptions in the analysis on consumption did not change the pattern of results (i.e., all significant effects remained and no non-significant effects became significant). An overview of the findings is presented in Figure 7.

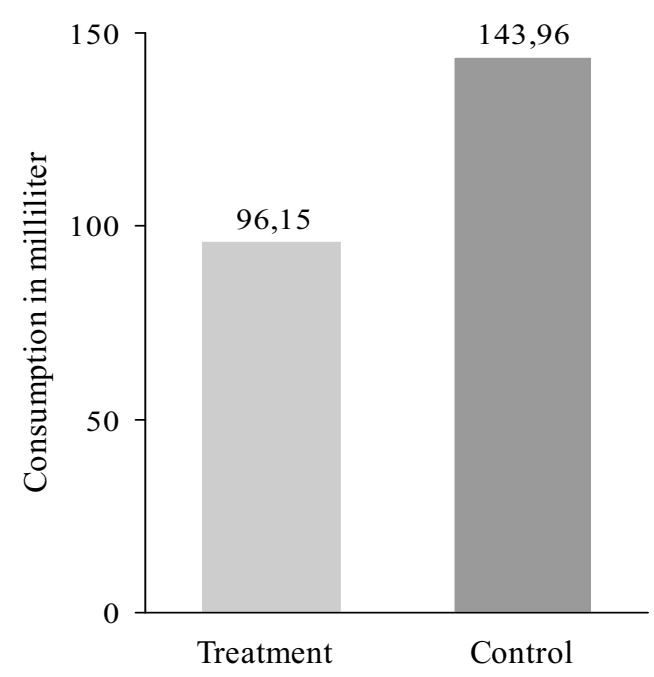

Figure 7: Consumption of the Regular Soft Drink across Conditions 
Health perceptions. In order to examine to what extent participants' health perceptions of the regular soft drink were affected by experienced aversion, we conducted an ANOVA on perceived healthiness of the regular soft drink with condition as between-subject factor. Interestingly, results revealed that participants in the treatment condition perceived the regular soft drink as significantly less unhealthy than those in the control condition $\left(\mathrm{M}_{\text {Treatment }}=2.50, \mathrm{SD}=1.44 ; \mathrm{M}_{\text {Control }}=1.77, \mathrm{SD}=1.07\right.$; $\mathrm{F}(1,50)=4.27 ; \mathrm{p}<.05)$. That is, health perceptions of the regular soft drink were not affected negatively by experiencing negative states of aversion. On the contrary, the regular soft drink was perceived as significantly less unhealthy ${ }^{7}$ by participants in the treatment condition relative to those in the control group, suggesting that a different mechanism than that of aversion was at work.

\subsubsection{Discussion}

First and foremost, the results of our second experiment replicated the finding of spillover of conflict-induced aversive states established in experiment 1. Specifically, we showed that after exposure to a conflict-inducing indulgence, the same decrease in consumption of a regular category member is observed when switching from an indulgent food to an indulgent beverage category. In addition, we explored the extent to which consumers' health perceptions of the regular soft drink are subject to change after being exposed to a healthy soft drink alternative. Results revealed that rather than a downgrading of the regular category member's perceived healthiness - which would be in line with the pattern of reduced consumption - we find participants in the treatment condition rating the regular soft drink as significantly less unhealthy than those in the control condition. This finding appears to suggest that the health perceptions of the regular soft drink provided by participants in the treatment condition are unlikely a direct consequence of spillover of conflict-induced aversive states, but instead might be the result of a separate health claim-induced perception spillover of positive health information.

\footnotetext{
${ }^{7}$ One could also frame this result as participants in the treatment condition perceiving the regular soft drink as more healthy instead of less unhealthy. However, considering the still very low mean of 2.5 on a nine-point scale, we do not think that speaking of increased healthiness ratings is appropriate.
} 


\subsection{General Discussion}

Indulgences using functional health claims to position themselves as better, more wholesome alternatives relative to other indulgences in a given product category, are increasingly prominent in the market. Despite the growing interest in, and availability of, healthy indulgences, little is known about their specific effects on food intake. In chapter 2 of this dissertation, we studied how different types of health claims attached to indulgences influence how much of the healthy indulgence is eventually consumed. Our results supported the counterintuitive idea that indulgences making functional health claims result in a previously unidentified "backfire" effect in that consumers responded to such health claims with reduced consumption relative to a control group. We attributed this decrease in food intake to high experienced goal conflict, which consumers resolve by avoiding the object causing the conflict. In light of the notion of cognitive relatedness of objects (e.g., Lei et al. 2008), the question of how the presence of such conflict-inducing indulgences in a given product category might affect related category members becomes highly relevant.

The results of the present research reveal that also consumption of regular category members decreases when consumers are confronted with an indulgence making a functional health claim prior to consumption. We argue that this decrease in food intake of regular category members is a result of spillover of negative states of aversion as a direct consequence of experienced goal conflict. This, in itself, is intriguing, in that the negative affective state was evoked by essentially positive health information. Our findings extend the work of Bailis et al. (2011) by providing evidence of goal conflict-induced spreading of avoidance behavior to objects that are cognitively related to the conflict origin. The current data also complements the results obtained in our previous study by demonstrating that a brief exposure to goal-conflict inducing indulgences might result in a similar "backfire" effect regarding consumption of regular category members as identified for consumption of the healthy indulgences themselves. Our primary contribution thus lies in exemplifying the power of claim-induced goal conflict in not only affecting consumption of the food causing the conflict, but also consumption of objects not causing the conflict, but being related to the conflict origin via consumers' associative networks. 
Furthermore, in experiment 2 of the present study we sought to explore to what extent consumers' health perceptions of regular category members are subject to change after being exposed to a healthy alternative. Specifically, we wished to investigate whether and how consumers' perceptions regarding regular category members' healthiness are affected by spillover of states of aversion. Our finding of less unhealthy healthiness ratings of the regular soft drink that was consumed suggests that rather than being negatively affected by aversion, an aversion-independent process of health association transfer from the brand presented in the first task (i.e., the healthy indulgence) to the unknown brand consumed in the second task of the experiment was at work. This finding is somewhat surprising given that prior literature has indicated that positively valenced information about products or brands is usually less influential than negatively valenced information in forming evaluations and decision making (e.g., Skowronski and Carlston 1989). Despite this well-accepted negativity bias, however, concerns have been raised in the literature as to whether it is really the informational valence determining the magnitude of spillover effects. For example, Scott and Tybout (1981) suggested that negative cues are not given more weight than positive cues because of their actual negative valence, but because such information is either statistically or contextually rare (i.e., one is less likely to come across negative information than positive information in daily life or a negative cue is presented amidst several positive cues in a particular context), or because such information is non-modal or extreme (i.e., the property of being "bad" on an attribute when almost all other similar objects are "good" on that attribute).

By and large, health claims attached to indulgences appear to communicate positive information about the food. Their suggestion of potential health benefits likely experienced by consuming the food in an environment which is dominated by associations of unhealthiness might be considered as rare in context and possibly even as non-modal or extreme (i.e., indulgences carrying a health claim position themselves as being "good" on an attribute about which presumably all other indulgences are "bad"). Given that information that is rare in context, non-modal or extreme is informative as it discriminates between objects (Scott and Tybout 1981), the positive information communicated through health claims might be subject to spillover effects as well. 
At this point, however, it is crucial to keep in mind how health claims are typically processed in order not to be misled by too early predictions and generalizations for claim-induced health perception spillover. In fact, rather than being processed as a whole, as is suggested in the previous paragraph, we have argued in chapter 2 of this dissertation that primacy is given to the affirmation (i.e., the attribute) communicated in a claim. With functional health claims, this results in the activation of health-related schemata and associations. If an attribute that is considered as beneficial for one's health is emphasized in a claim (e.g., antioxidants), the accessed health-related associations are likely positive. If, however, an attribute stressed in a health claim is regarded as detrimental for one's health (e.g., cholesterol), then the accessed healthrelated associations are likely negative. As noted by Scott and Tybout (1981), rather than information valence, the necessary condition for spillover to occur is accessibility to information that is either statistically or contextually rare, non-modal or extreme. Communicating the presence of antioxidants in chocolates or soda is, next to being positive information, also contextually rare/non-modal. Hence, spillover of such positive health associations triggered by the health claim is likely. We therefore argue that the "higher" healthiness ratings of the regular soft drink provided by participants in the treatment condition in experiment 2 are the result of positive health association spillover. Note, however, that the effect should flip when a negative health-related attribute is emphasized that meets at least one of the conditions defined by Scott and Tybout (1981). That is, stressing the reduced amount of cholesterol would likely result in negative health association transfer if that information is contextually rare, non-modal or extreme. Assuming positive health perception spillover for all health claims attached to indulgent foods would thus be a too simplistic generalization.

\subsubsection{Theoretical Implications}

Together, the results of the present study indicate that the presence of indulgences making functional health claims in a given product category can potentially result in spillover processes involving both conflict-induced spillover of affective states of aversion, as well as claim-induced transfers of health information. These findings advance our knowledge on spillover effects in two important ways. First, by measuring consumption as a direct outcome of experienced states of aversion, we provide initial 
evidence of spillover of negative affective states triggered by conflict-inducing positive health information attached to indulgences. Although we showed this effect only for a functional health claim featuring antioxidants, the effect presumably holds for any other functional health claim attached to indulgences as well: from a theoretical perspective, spillover of negative states of aversion to objects cognitively linked to the origin is expected to take place as long as the indulgent source induces conflict and thus aversion. Given that all functional health claims attached to indulgences, regardless of whether they stress positive or negative health-related attributes, are expected to evoke conflict, they should all result in the same reduced consumption of related objects. Second, our data appears to support the prediction of Scott and Tybout (1981), that rather than informational valence, its statistical/contextual rareness, distinctiveness, or non-modal/extreme characteristics determine whether associations are subject to spill over. That is, while spillover of negative affective states of aversion is expected to be observed for any functional health claim attached to indulgences, spillover of claimrelated associations only occurs when the information provided by the claim is rare, non-modal or extreme. If this condition is met, the valence of the attribute emphasized in a claim determines the direction of association transfer (i.e., an attribute regarded as beneficial for one's health results in increased health ratings of related objects; an attribute regarded as detrimental for one's health results in decreased health ratings of related objects).

\subsubsection{Managerial Implications}

From a managerial perspective, our findings are of relevance in that we highlight the potential 'backfire' effect of functional health claims attached to indulgences not only with respect to the consumption of the healthy indulgences themselves (cf. chapter 2 of this dissertation), but also regarding category members not making such claims. That is, if one brand in a given product category uses conflictinducing functional health claims to differentiate itself from competitors, negative repercussion regarding the consumption of products in that same category are likely when consumers are confronted with, or exposed to, the healthy version of the indulgence. Two ramifications follow this observation. First, such spillover of negative states of aversion is not limited to competitors in that product category, but can certainly 
also affect brands of the brand portfolio to which the conflict-inducing brand belongs. Here, depending on whether relatedness between brands in the portfolio has been cultivated (Lei et al. 2008), spillover effects are possible even to brands operating in different product categories (e.g., launching a Nestlé KitKat dark chocolate bar claiming to be low in sodium might negatively affect consumption of Nestlé's Nesquik drinks as well as their perceived healthiness).

Second, our findings are of relevance also for companies' strategic placement of indulgences featuring functional health claims on supermarket shelves. Typically, products belonging to the same product category are positioned in close proximity to each other in supermarkets. So would we find the healthy versions of Liga cookies (e.g., Liga Continue ${ }^{\circledR}$ Vitamins \& Minerals Cookies; Liga Continue ${ }^{\circledR}$ Cholesterol-reducing Cookies) next to the regular, standard versions of cookies from various other brands. In light of our finding of reduced food intake of regular category members following exposure to conflict-inducing indulgences, it might prove beneficial to increase the physical distance between regular and healthy versions of indulgent foods to avoid negative repercussions for the standard versions. For example, one could think about placing foods not in terms of their general product category membership, but instead regarding their specific benefits fulfilling specific consumer needs (e.g., placing the Liga ${ }^{\circledR}$ Continue healthy cookies adjacent to other snacks that are positioned as healthy alternatives of regular versions). Thereby, although probably not entirely eliminated, adjacency-caused spillover effects might get minimized.

On the other hand, following such a shelf-placement strategy would simultaneously minimize also the identified positive health perception transfers from the healthy indulgences to regular category members. Yet, as outlined above and assuming contextual rareness or non-modality, such effects are only positive if the attribute emphasized in a health claim is regarded as beneficial for one's health. If a claim stresses attributes primarily associated with negative health effects, the respective spillover of health-related associations is likely to be negative. As such, Liga's Continue ${ }^{\circledR}$ Cholesterol-reducing cookies are likely to reduce consumers' health perceptions of other cookies. Notwithstanding such transfers of claim-induced associations, the behavioral implications of potential spillover processes triggered by 
indulgences making functional health claims are more impactful and should thus guide managers in their decisions about whether and how to use such claims.

For public policy makers, our results exemplify once more the supremacy of functional health claims to stimulate more healthy eating patterns within entire product categories. Hence, in an effort to reduce an increase in waistlines of consumers in western societies, it might prove effective to encourage or even enforce health claims attached to indulgence to be framed in functional terms.

\subsubsection{Limitations and Future Research}

We acknowledge that our research is subject to several limitations which need to be taken into account when interpreting the results. Despite the limited external validity resulting from experimental lab research in general, it is important to realize that we did not explicitly measure goal conflict again in the present study. Rather, we built on the findings of our previous study and used stimuli which we have shown to trigger conflict between health and indulgence goals ${ }^{8}$. Thus, we are confident that also in the present research the functional health claim resulted in conflict between health and indulgence goals. Moreover, we included a baseline control group (i.e., a condition in which participants evaluated a non-food product prior to consumption) in our first experiment of this research to empirically verify that conflict has not been induced by participants' evaluations of a chocolate package not carrying a functional health claim (i.e., in the control condition). If that was the case, we would have observed lower consumption in the control condition relative to the baseline control condition. Future research using different claims or conflict-triggering stimuli, however, should verify the presence of conflict by explicitly measuring it. A related limitation pertains to the fact that instead of measuring negative states of aversion directly (e.g., how saliently someone experiences aversion), we employed consumption data indicative for how effectively experienced aversion influences behavior. We strongly encourage future research to measure aversion or any other affective states of interest directly in order to provide more sound empirical evidence for spillover of affective states.

\footnotetext{
${ }^{8}$ In the context of indulgences, we showed that using a functional health claim emphasizing an extra amount of antioxidants has resulted in conflict between health and indulgence goals (experiment 3 in chapter 2 of this dissertation).
} 
Second, although we took great care in differentiating the product evaluation task from the actual taste test (e.g., the instructions emphasized that the two tasks were initiated by different companies and were thus independent; the layout and design of the respective questionnaires was different; the taste test was described as being initiated by a foreign manufacturer who considered introducing its foods/beverages in the country in which the taste test was run), we do not have explicit data verifying that participants in the treatment condition did not infer that the food they tasted was the healthy version they evaluated the package for. However, we included a question at the very end of the final questionnaire asking whether participants had read the instructions carefully (dichotomous "yes/no" question), whereby we emphasized that we relied on their honest answer and that a negative answer (e.g., admitting that they did not read the instructions carefully) would not have any consequences for them. All participants indicated that they read the instructions carefully, which enhances our confidence that our data did not suffer from such inferences. Nevertheless, we acknowledge that a stronger 'manipulation' check would have been valuable and should be implemented in future research.

Third, we would like to stress that our findings only represent an initial first step in exploring goal-conflict induced spillover involved with tempting foods, as we demonstrated spillover only within product categories to foods/beverages sharing substantial feature overlap with the origin indulgence, thus being strongly linked to the origin via consumers' associative networks. More research is necessary to test the robustness of our findings within other product categories, and especially across product categories. For example, would we obtain the same results if participants were to consume, say, potato chips, cheese crackers, or some sort of cake after being exposed to healthy chocolate featuring functional health claims? Theoretically, those foods are all indulgent foods, which should thus all be linked to the origin indulgence in an associative network. However, given the finding that the strength of retrieval of nodes is a function of the strength of the associative linkages between nodes (Lei et al. 2008), we might expect cake to be affected more strongly because it shares more associations with the origin indulgence (e.g., a similar texture, a similar perception of richness, or simply the fact that there is many versions of chocolate cakes) than chips and crackers. 
Furthermore, it would be interesting to examine such spillover on a brandspecific level (e.g., how conflict induced by a parent brand affects its sub-brands or vice versa, or to what extent affective states might spill over from category leaders to competing follower brands). The finding that asymmetric associations result in asymmetric spillover between brands (Lei et al. 2008) suggests that, for example, aversive states induced by category leaders might spill over more strongly to follower brands than vice versa, and that this effect is enhanced the fewer nodes are actually retrieved (e.g., Anderson 1983). Being able to formulate specific predictions as to when other brands might be affected most by an object causing goal conflict would be very valuable for managers in their efforts to manage their brands successfully.

Finally, this paper has dealt exclusively with spillover effects triggered by functional health claims attached to indulgences. It would be interesting to examine to what extent also hedonic health claims can be sources for spillover effects. In contrast to functional health claims, hedonic health claims do not evoke goal conflict, but instead are expected to result in an increased hedonic orientation towards foods (cf. chapter 2 of this dissertation). Applying the finding of spillover of negative affective states to cognitively related objects, it is conceivable that also positive affective states such as increased hedonic orientations (e.g., increased experienced pleasure associated with consuming a food) are subject to spillover effects. This would be expected to result in increased food intake of, for example, regular category members following exposure to indulgences claiming to be low in fat or low in sugar (e.g., Liga ${ }^{\circledR}$ Continue Reduced Sugar). Future research might verify this prediction in an effort to equip managers with an optimal decision background for managing their brands and retail settings. 



\section{CHAPTER 4}

\section{Conclusion}

The overall aim of this dissertation was to study the effects of healthy indulgences on consumers' ability to control their food intake. Specifically, we sought to examine when and why people over-consume versus regulate food intake in response to health claims attached to indulgent foods. In this chapter, we conclude this dissertation by summarizing the key findings of our empirical investigations and by discussing the resulting implications. We end this chapter by offering some general directions for future research in the domain of healthy indulgences and food temptation management. 


\subsection{Introduction}

The objective of this dissertation was to investigate when and why people overconsume versus regulate food intake in response to health claims attached to indulgent foods. Despite the growing interest in the concept of healthy indulgences among marketers, scholars, and public policy makers, few scientific research exists that comprehensively studies how consumers' respond to health claims attached to indulgent foods. The few studies that have started to investigate the topic have pushed beliefs about the effects of healthy indulgences in the direction that they might uniformly lead to increased food intake, thus fueling instead of diminishing the prevalent societal problem of increasing waistlines and obesity in western societies. Drawing on literature in the field of consumer behavior, marketing, and psychology, we show that healthy indulgences can be a blessing or a curse, depending on whether health claims feature functional or hedonic food attributes, and on whether one views our findings through the lens of food manufacturers or public policy makers.

In the following sections, we present the key findings of our empirical investigations and discuss the relevance of our results for managers and public policy makers. We conclude by offering a promising set of future research directions, which we believe will further advance our understanding of the conditions under which consumers benefit versus lose from consuming healthy indulgences.

\subsection{Synopsis}

It is hard to ignore the significant change the landscape of indulgent food has undergone during the past decade. Inspired by consumers' increasing demand for foods enabling them to pursue hedonism, satisfy cravings, and to splurge on special occasions without compromising convenience, taste, and health (Today's Dietitian 2008), foodproducing companies have flooded the market with a variety of "smart-snacking alternatives" offering health benefits as well as indulgence at the same time. This dissertation set out to investigate the effects of such healthy indulgences on consumers' ability to control their food intake. We defined healthy indulgences as foods typically perceived as unhealthy but consumed primarily for reasons of taste, pleasure, and 
indulgence, all carrying a claim or label either explicitly or implicitly suggesting that the food is a healthier alternative relative to a conventional version. In order to examine to what extent consumers really benefit from such food options, the following problem statement has been formulated in the first chapter of this dissertation and has guided the development and execution of the studies reported in manuscript I (chapter 2) and manuscript II (chapter 3):

\section{When and why do people over-consume versus regulate food intake in response to health claims attached to indulgent foods?}

Prior literature has provided some conflicting predictions as to how health claims affect consumption of the indulgences they are attached to. The most prominent (and intuitively appealing) view suggests that health-related nutrition-based claims stimulate food intake because they result in consumers making inappropriate generalizations of attributes not substantially related to the attributes emphasized in the claims. False inferences of fewer calories in foods labeled as low in fat (e.g., Wansink and Chandon 2006), or expectations of lower amounts of fat in foods claiming to be low in cholesterol (e.g., Andrews et al. 1998) have been argued to create misleading "health halos" providing consumers with an implicit license to eat, as consumption of such foods becomes easier to justify relative to conventional versions not making any claims. This perspective is supported by research demonstrating the consumption-increasing effects of low-fat health claims (Wansink and Chandon 2006), illustrating a worrisome increase in food intake by up to $50 \%$. Following the literature on overgeneralizations of nutrient-based claims, and taking into account the demonstration of substantial overconsumption when foods are labeled as lower in fat, one might be tempted to conclude that all nutrition-based health claims attached to indulgent foods would provide similar ease of justification, thereby stimulating food intake rather than triggering self-control.

Alternatively, one might argue that in light of an inverse relationship between functional and hedonic attributes potentially making indulgences being perceived as less enjoyable the healthier they are portrayed (Raghunathan et al. 2006), health claims are likely to result in decreased consumption of the indulgent foods they are attached to. As 
such, these two theoretical perspectives predict opposite consumption patterns of indulgences carrying health-related claims, strongly amplifying the relevance of a more thorough examination of the subject for academics, marketers and public policy makers alike.

In manuscript I we provide converging evidence that, in fact, neither of the previously discussed theories uniformly predict consumers' behavioral responses to different types of health claims. Drawing on literature documenting primacy of affirmation (Jung et al. 2004), we present a more nuanced perspective than is offered by previous literature on nutrition-based claims to identify the conditions under which people over-consume versus regulate food intake in response to health claims and to shed light on the underlying processes. The results of our empirical investigation reveal that the extent of consumption of indulgences framed as healthy depends on the nature of the attributes the claims emphasize (i.e., functional versus hedonic). Breaking up health claims into tags (e.g., "low", "extra") and affirmations (i.e., the attributes stressed in the claims; for instance, "fat", "cholesterol", "antioxidants") and applying the notion of primacy of affirmation to such linguistic constructions, we suggest that only the attributes emphasized in health claims are accessed to render a judgment, while the respective tags are being ignored (e.g., Jung et al. 2004; Mayo et al. 2004). Given that typically, health claims highlight either functional food attributes with a strong connotation to the concept of health (e.g., antioxidants, vitamins), or hedonic attributes primarily associated with the indulgent aspects of the food (e.g., fat, sugar $=$ taste), we hypothesize that two very different schemata, namely health-related or indulgencerelated schemata, are activated upon exposure to either type of claim (Jung et al. 2004).

In support of this prediction, our results show that functional health claims trigger activation of health-related goals, which, together with already salient indulgence goals triggered by the hedonic nature of the indulgent foods themselves (Dhar and Simonson 1999; Fedoroff, Polivy, and Herman 2003; Raghunathan et al. 2006; Shiv and Fedorikhin 1999; Tepper and Trail 1998), create a situation of conflict between competing health and indulgence goals. Using two different examples of health claims featuring functional food attributes (i.e., one highlighting the reduced amount of an attribute perceived as detrimental for one's health and the other highlighting the 
presence of an attribute regarded as beneficial for one's health), we demonstrate that in an effort to resolve the experienced conflict and corresponding aversive state (Festinger 1956; Ramanathan and Williams 2007), consumers decrease their consumption of the indulgence causing the conflict. Thus, functional health claims attached to indulgences enhance consumers' ability to control their food intake.

Health claims featuring hedonic attributes, on the other hand, result in increased consumption of the healthy indulgence relative to a control group. We argue that the primacy granted to the hedonic affirmation renders health goals less accessible in favor of an accentuated hedonic orientation to food, thereby stimulating increasing food intake. Although in our process-measuring study an accentuated hedonic orientation involved with hedonic health claims is not reflected in further enhanced indulgence goal accessibility (cf. chapter 2, experiment 3), results of a study contrasting a hedonic health claim (i.e., "low-fat") with a purely hedonic claim (i.e., "extra-creamy" as a representative of "high-fat"; experiment $2 b$ ) further support the notion of hedonic attributes accentuating a focus on the pleasure dimensions of the food, as we find increased consumption irrespective of how the overall meaning of the claim is interpreted. The previously adopted ease-of-justification perspective (Wansink and Chandon 2006) would suggest that the low-fat claim would be processed in its entirety, resulting in consumers perceiving the food carrying the claim to be less "bad" and thus easier to justify relative to a conventional version of the food. Following this logic, a high-fat or extra-creamy claim should make the respective food appear more "bad" and hence more difficult to justify relative to a standard version. This should then lead to decreased consumption relative to that of the standard version. Our finding of increased consumption of both the food carrying the low-fat claim and the food carrying the extracreamy claim rules out an ease-of-justification mechanism, while bolstering the suggested primacy of affirmation account. Importantly, however, we stress that our data does not provide an explicit process-measure of an increased hedonic orientation; it only captures the consequences of a mindset in which hedonic schemata are highly salient. We therefore emphasize that a more direct test of this mechanism is needed to empirically verify that an accentuated hedonic orientation is driving increased food intake when consumers are exposed to indulgences making hedonic health claims. 
In manuscript II (cf. chapter 3), we continue with investigating further consequences of attribute-induced goal conflict triggered by exposure to indulgences making functional health claims. From a manufacturer perspective, the reduced consumption of indulgences making functional health claims identified in manuscript I represents a worrisome "backfire" effect of using functional health claims. In light of the cognitive relatedness between brands making them subject to potential spillover effects (e.g., Lei et al. 2008; Meyers-Levy and Tybout 1989), a central question that arises pertains to the extent to which regular category members might be affected by the presence of such conflict-inducing indulgences in that category. Hence, we examine in our second manuscript whether functional health claim-induced states of aversion can spill over to affect consumption of conventional category members not causing the experienced conflict.

The results of two experimental studies demonstrate that aversive states accompanying goal conflict do not appear to be limited to affect the object initially causing the conflict (i.e., the healthy indulgence), but instead spill over to affect consumption of objects related to the origin indulgence via consumers' associative networks. By measuring consumption as a proxy for how experienced aversion affects behavior, we show that both indulgent foods (e.g., chocolates) as well as indulgent beverages (e.g., soft drinks) are affected negatively by the presence of healthy alternatives making functional health claims in a given product category. Given that spillover of negative affective states reflects consumers' reactions to initially positively valenced information, our data redirects attention away from the extent to which informational valence determines spillover of associations and perceptions (see Scott and Tybout 1981 for a detailed discussion), to consumers' affective reactions to information irrespective of its valence and the behavioral consequences.

In addition, the second experiment in manuscript II also provides some indication for a simultaneous, yet independent spillover effect of claim-related health perceptions. Participants who, in the first experimental task, have been exposed to a conflict-inducing soft drink advertisement (i.e., a soft drink featuring a claim referring to antioxidants), rated a regular soft drink not making health claims that was subsequently consumed in a second experimental task as significantly less unhealthy 
relative to a control group. This finding suggests that rather than being negatively affected by states of aversion, an aversion-independent process of health association transfer from the brand presented in the first task (i.e., the healthy indulgence) to the unknown brand consumed in the second task of the experiment was at work.

Together, the findings obtained in the present research offer unique insights into when and why people over-consume versus regulate food intake in response to health claims attached to indulgent foods. Thereby, our work contributes a piece to the overall puzzle of understanding the dynamics of consumers' self-regulatory processes in the context of food temptations and, importantly, the conditions under which selfcontrol is enhanced or reduced by health-related environmental cues.

\subsection{Implications}

The findings of the studies reported in manuscript I and II put forward that the concept of healthy indulgences is much more complex than one would intuitively expect, with interesting theoretical insights and far-reaching implications and consequences for food-producing companies and public policy makers.

Overall, we show that healthy indulgences indeed significantly influence consumers' consumption patterns. Yet, rather than deriving at a one-fits-all conclusion, which would follow the common wisdom that all health claims are created equal, our results suggest that it is crucial to distinguish between hedonic and functional health claims to predict how much food is eventually consumed. Empirically demonstrating the specific conditions under which consumers' self-control with food intake is enhanced or reduced provides an important contribution to the current debate on whether healthy indulgences are beneficial or detrimental in triggering more healthy eating patterns. As implied by the combined results of the two manuscripts, any governmental "black or white" decisions regarding the support or impediment of the market penetration of healthy indulgences would represent a too simplistic action. Our research offers specific recommendations as to the extent to which people should be shielded from indulgences making health-related claims. On the one hand, and following the findings of manuscript I, it would be important to reduce consumers' exposure to indulgences featuring hedonic health claims. Such claims strongly tempt 
people to consume more of the healthy indulgence than they otherwise would of the regular counterparts. Notwithstanding the detrimental effects of hedonic health claims attached to indulgent foods, however, the efforts of food-producing companies to offer indulgences containing fewer amounts of fat or sugar should be acknowledged. We therefore propose that the health benefits communicated through hedonic health claims should be reframed in functional terms to more effectively fight over-consumption and to help consumers remain on track with following a balanced diet. Healthy indulgences featuring functional health claims, on the other hand, have been shown to help control food intake on a relatively broad scale. As we observed in manuscript I, claims emphasizing functional, health-related food attributes, result in reduced consumption of the food to which they are attached without limiting consumers' taste perceptions or intentions to purchase the indulgence. Moreover, the findings of manuscript II suggest that such claims also lead to reduced food intake of regular food category members. Assuming that such reduced consumption translates into less absolute calorie intake while simultaneously satisfying consumers craving for indulgence, indulgences featuring functional health claims appear to offer many opportunities to combat the societal issues of obesity and increasing waistlines in the long-run.

Importantly, the above implications reflect a perspective typically employed by public policy makers and, possibly, also consumers themselves. Considering our findings from a manufacturer perspective provides quite different conclusions. In fact, for manufacturers our findings strongly suggest withdrawing from using functional health claims in combination with indulgent foods, while an increasing use of claims emphasizing hedonic, indulgence-related aspects appears profitable. Although our data does not offer indications of changes in consumers' intentions to purchase indulgences making either functional or hedonic health claims, the respective decreased (increased) consumption triggered by functional (hedonic) health claims implies delayed (earlier) repurchase patterns for such foods. For companies, product sales and profit numbers are central performance indicators often used to determine the products' future in a given brand portfolio. If the reduced consumption of indulgences featuring functional health claims indeed translates into unsatisfactory sales data in the long-run, brand managers would have a hard time justifying the use of such claims. As such and as already 
mentioned previously, whether healthy indulgences should be considered a blessing or a curse strongly depends on the perspective one takes on in interpreting our results.

\subsection{Suggestions for Future Research}

While we have provided specific suggestions for future research at the end of each empirical study (manuscript I and II), the following sections are devoted to an in depth theoretical discussion on some general directions for future research in the domain of healthy indulgences.

First, we would like to encourage research examining the extent to which individual differences might influence our pattern of results. For example, it would be important to investigate to what extent food-specific individual differences such as being a restrained (versus unrestrained) eater might affect our findings.

\subsubsection{Restraint Eating}

Living in an obesogenic, "toxic" environment characterized by a multitude of unhealthy, easily accessible food temptations (Hill and Peters 1998; Wadden, Brownell and Foster 2002), it is not surprising that many consumers experience difficulties in controlling how much of the alluring foods they eventually consume. A large body of research examining eating-related self-regulation upon exposure to tempting food cues has documented differences between people categorized as restrained versus unrestrained eaters (Fedoroff et al. 1997, 2003; Herman and Polivy 1980; Stroebe et al. 2008). The theory of restraint eating describes the - mostly unsuccessful - attempts of chronic dieters to regulate their food intake by overriding internal cues such as hunger signals (Papies et al. 2008). More formally, restraint eating is defined as "the deliberate effort to combat the physiologically-based urge to eat in order to lose weight or maintain a reduced weight" (Fedoroff et al. 1997, p.34). Individuals categorized as restrained eaters are thus said to experience greater difficulty in controlling their food intake relative to unrestrained eaters, as they are highly influenced by the enjoyment anticipated with food intake. Papies and colleagues (2007), for example, have shown that in contrast to unrestrained eaters, restrained eaters have a strong hedonic orientation towards foods reflected in an activation of hedonic thoughts when confronted with 
tempting food cues. Subsequent work by Stroebe et al. (2008) revealed that a primed goal of eating enjoyment inhibits a weight or diet-related goal in restrained, but not in unrestrained eaters. Together, these findings suggest that restrained eaters' overconsumption of palatable foods is driven by an attentional bias towards hedonically relevant food cues and a simultaneous inhibition of eating control thoughts needed for regulating food intake.

This perspective appears to be in conflict with the theory of temptation-elicited goal activation (Fishbach et al. 2003), according to which exposure to tempting food cues activates rather than inhibits weight control goals for dieters who repeatedly exerted self-control with food intake. Hence, the question arises whether chronic dieters such as restrained eaters can actually diet successfully. Papies, Stroebe and Arts (2008) suggest that it is necessary to distinguish between successful and unsuccessful dieters. They show that for dieters who are unsuccessful in controlling their food intake, exposure to palatable food inhibits a diet goal in favor of a focus on eating enjoyment, while for dieters who are successful in controlling how much to eat, exposure to tempting food activates a diet or weight-control goal (Papies et al. 2008).

The previous discussion inevitably raises the question as to how restrained eaters would respond to exposure to healthy indulgences. Most likely, healthy indulgences are particularly appealing to individuals continuously aware of their eating behavior, in that such foods appear to suggest guilt-free food enjoyment. Transferring the general findings of how successful and unsuccessful dieters react to tempting food cues to the specific context of healthy indulgences leads us to expect the following:

Exposing successful dieters to indulgences making functional health claims should result in highly accessible diet goals (Fishbach et al. 2003; Papies et al. 2008), as well as in highly accessible health goals (cf. chapter 2), both translating into even more conflict between long-term health and weight-control goals and short-term indulgence goals. Consequently, we would expect the identified decreased consumption following functional health claims to be more pronounced for successful dieters relative to nondieters. Exposing unsuccessful dieters to the same type of healthy indulgences likely results in their initial focus on eating enjoyment (Papies et al. 2008) getting offset by 
highly accessible health goals, leading to similar decreased consumption patterns as we would expect to observe for non-dieters.

A slightly different picture emerges for the event of exposing restrained eaters differing in their self-regulatory success in food intake to indulgences making hedonic health claims. Exposing successful dieters to indulgences making hedonic health claims might result in their initial focus on controlling their food intake (Fishbach et al. 2003; Papies et al. 2008) getting offset by an accentuated focus on food enjoyment, eventually resulting in similar consumption patterns as one would expect for non-dieters. Note that this would imply that a potentially activated diet goal must be overruled by the strong focus on the pleasures associated with consuming the food. Given that successful attempts to control one's food intake, however, have been found to result in weakened associations between hedonic thoughts about food and a desire to eat, but strengthened associations between hedonic thoughts about food and weight-control goals (Bargh 1990; Bargh and Gollwitzer 1994), it is more likely that a diet goal gets activated for successful dieters when being exposed to indulgences making hedonic health claims. Together with a highly accessible indulgence goal, this likely creates a situation of goal conflict, eventually resulting in decreased consumption not only relative to non-dieters, but also relative to a control group. Finally, exposing unsuccessful dieters to indulgences making hedonic health claims likely strengthens an already strong focus on food enjoyment, resulting in the identified increased consumption following hedonic health claims to be more pronounced for unsuccessful dieters relative to their nondieting counterparts.

Finding evidence for the predicted effects discussed above would imply that functional health claims uniformly lead to more controlled food intake among both groups of restrained eaters as well as for unrestrained eaters, whereas interestingly, hedonic health claims might actually enhance self-control for successful dieters, while leading to over-consumption for unsuccessful dieters as well as non-dieters. Hence, studying the moderating role of restraint eating in the context of healthy indulgences provides an important and relevant avenue for future research. 


\subsubsection{The Role of Need for Cognitive Closure}

Second, and in addition to investigating the moderating effects of restraint eating, it would be interesting to examine how individual differences related to people's motivation to attain cognitive closure might affect our results. As Shah, Friedman, and Kruglanski (2002, p. 1263) note, "goals are not pursued within a motivational or emotional vacuum", implying that specific individual or situational differences in motivational and emotional states may influence how goals affect behavior. The concept of need for cognitive closure (hereafter referred to as NFCL; Kruglanski and Freund 1983) describes a motivational tendency to desire clear, definite, and unambiguous knowledge as opposed to confusion and ambiguity (Kruglanski 1989; see also Vermeier (2003) for a review on the concept of NFCL) ${ }^{9}$. In other words, NFCL refers to how people approach and reduce cognitive uncertainty (Golec and Federico 2004).

Considering our finding of functional health claims triggering goal conflict, emotional ambiguity and epistemic confusion (e.g., Ramanathan and Williams 2007; Shah et al. 2002), it would be important to study how people differing in their predispositional level of NFCL respond to such conflict-inducing indulgences. People characterized as high in NFCL (as opposed to those low in NFCL) typically experience negative feelings when closure is threatened and show a strong motivation to avoid such feelings by reducing discomfort associated with ambiguity as quickly as possible (Golec and Federico 2004; Kruglanski and Webster 1996). Further, when exposed to ambiguous or conflicting information, people high in NFCL tend to seize and freeze on information and cognitive cues appearing early in a sequence and subsequently base their judgment on concepts most accessible at that particular moment in an effort to achieve and perpetuate clarity (Ford and Kruglanski 1995; Thompson et al. 1994). Thus, people high in NFCL tend to rely largely on prototypical information or currently

\footnotetext{
${ }^{9}$ Note, that when we use the term "need for cognitive closure" (NFCL), we refer to a need for nonspecific closure rather than a need for specific closure (Kruglanski 1989). Need for nonspecific closure describes a desire to get any answer as opposed to no answer, whereas need for specific closure requires a specific answer (Kruglanski 1989). Also note, that need for cognitive closure is conceptually different from need for cognition (NFC), in that the latter is largely process oriented, whereas the former is primarily result or goal oriented (e.g., Vermeier 2003). That is, a person high in NFC views the act of thinking or engaging in complex cognitive tasks as a desired end-state, whereas someone high in NFCL enjoys the end-state of thinking (i.e., reaching closure).
} 
accessible constructs and are therefore easily influenced by stereotypes. In contrast, people low in NFCL are much more tolerant of ambiguity and confusion and, other than people high in NFCL, people low in NFCL generally continue searching for diagnostic information that helps them distinguish between categories, making them more open to new information and less reliant on temporarily accessible constructs.

The previous discussion appears to suggest that people differing in their predispositional level of NFCL might respond differently to conflict-inducing indulgences featuring functional health claims. Specifically, it seems reasonable to expect that the effect of reduced food intake as a result of experienced goal conflict is more pronounced for people high in NFCL relative to those low NFCL. Although exposure to a functional health claim should induce conflict among both groups of people, those high in NFCL who generally shun ambiguity and conflicting situations, might show greater conflict avoidance behavior than their low NFCL counterparts. These patterns of behavior are expected to transfer also to situations in which exposure to a conflict-inducing indulgence is followed by a consumption incidence of a conventional category member not responsible for the experienced state of aversion (cf. chapter 3). That is, spillover of experienced states of aversion is likely to affect consumption of regular category members more strongly for individuals high in NFCL than for those low in NFCL.

Regarding potential claim-induced perception spillover effects, however, prior literature on NFCL would suggest that health-related association transfer is likely to occur only for people high in NFCL. Recall that people high in need for cognitive closure tend to seize and freeze on information appearing early in a sequence, making them base their subsequent judgment on concepts most accessible at that particular moment to achieve and perpetuate clarity (Ford and Kruglanski 1995; Thompson et al. 1994). Such overutilization of early cues and accessible concepts results in people high in NFCL becoming impervious to subsequent information (Kruglanski and Webster 1996), which should facilitate spillover of claim-induced health perceptions to other, related foods. People low in NFCL, on the other hand, are expected to process new information independent of what they were processing previously, thus blocking early cues to affect their judgments and decision making in a subsequent task. As such, it is 
possible that for people low in NFCL, no health-perception spillover would be observed.

Together, the previous discussion suggests that the behavioral effects identified in the current set of studies involving functional health claims might be more pronounced for people with a high pre-dispositional level of NFCL relative to their low NFCL counterparts, irrespective of whether consumption of the healthy indulgence itself or of a related category member is in the focus of attention. With respect to spillover of claim-induced health perceptions from an indulgence making a functional health claim to related category members, however, people's pre-dispositional level of NFCL might serve as a 'gatekeeper' in associative networks, enabling healthperceptions to spill over to destination nodes when NFCL is high, but not (or to a much lesser extent) when NFCL is low.

\subsubsection{Subtle Health Cues, Presentation Format, and Size}

An additional avenue for future research pertains to the question as of whether cues other than explicit health claims might help consumers to control their consumption of indulgent foods. The findings of our current set of studies strongly suggest that consumers might actually benefit from health claims which are framed in functional rather than in hedonic terms. Although studying the effects of health claims on consumers' food intake control represents a timely and relevant research subject, it would be valuable to investigate to what extent other, more subtle health-related cues might prove effective in triggering more healthy eating patterns.

A common, yet very subtle way of manipulating the perceived healthiness of indulgences is to attach small amounts of fruits to the tempting food options. Consider, for example, the common ways in which desserts are presented to consumers (see Figure 8). Typically, desserts such as cake, mousse au chocolat, pudding, and ice cream are served on a plate or in a bowl to which a small amount of fruits is added. Fruits such as raspberries and strawberries are either put next to the indulgence in a decorative manner, or they represent a more "integral" part of the temptation in that they are placed on top of the indulgence. 

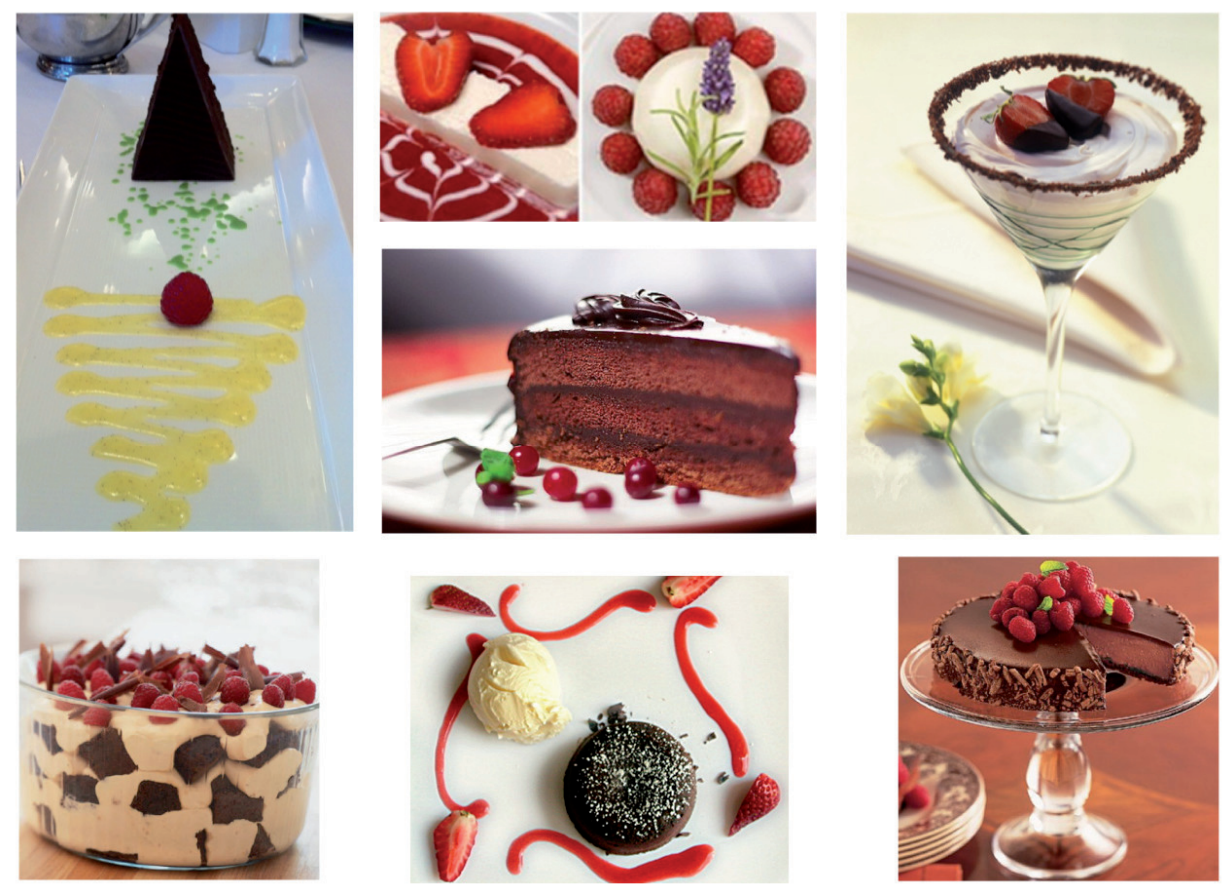

Figure 8: Desserts Presentation with Fruits as Decoration

This raises a couple of interesting theoretical questions, as prior literature has looked only at choices between vices and virtues, in which the virtue was presented as a 'full alternative' to the vice. Examining the effects of bundles of virtues and vices wherein the virtue represents an addition to the vice may provide some interesting insights into whether and how such food presentations will influence consumers' food intake. For example, would the addition of virtuous cues (i.e., fruits) to a vice (e.g., cake) stimulate food intake, thereby taking on a similar function as the addition of hedonic health claims to indulgent foods? Or would the fruits function as health cues triggering accessibility of health goals in addition to indulgence goals triggered by the cake itself? As suggested by the results of our first manuscript, if fruits would be construed as health cues, this would result in goal conflict and should trigger enhanced self-control reflected in reduced consumption of the dessert relative to a control group that is presented with cake and no fruits. Yet, whether the combination of vices and virtues indeed evokes a situation of goal conflict necessary for self-control to be enhanced might depend on several factors. In light of the finding that a single prime can 
activate different schemata depending on the unique and personal associations people have with the primed construct (Wheeler and Berger 2007), it is possible that fruits trigger health-related schemata only for some people, while for others, they evoke more hedonic concepts and associations. Moreover, the presentation format (presenting fruits next to, vs. as part of, the cake) might matter as well. Research by Fishbach and Zhang (2008) has shown that presenting items pertaining to temptations and goals together or apart influences the relative value and preference for these items. For example, when healthy items (e.g., a bunch of strawberries) are presented in the same picture with an unhealthy item (e.g., coke), participants valued and preferred the unhealthy item more. When both items were presented in separate pictures, however, consumers valued and preferred the healthy item relative to the unhealthy item. Do these findings imply that fruits would function as virtuous health cues necessary for conflict to arise only if they are presented next to, and thus separate from, the indulgence? More generally, under which conditions are bundles of virtues and vices construed as two separate entities and when are they perceived as one hedonic entity (i.e., a dessert)? Answering these questions would enable specific predictions as to whether and how more subtle health cues might help consumers in their attempts to live a balanced, healthy diet.

A related issue worthwhile investigating in future research pertains to the influence the size (or quantity) of indulgences positioned as healthy might have on food intake control. Research has shown that larger packages/food sizes bias consumption by at least 20 percent, while consumers falsely assume that they are unaffected by this phenomenon (e.g., those that ate from larger plates ate more compared to those that ate from smaller plates without being aware of this effect and feeling equally satiated; Wansink 1996a). This phenomenon has been labeled 'unit bias' and posits that within a reasonable range of size or quantity, consumers have a sense that any given entity (large or small) is the appropriate amount to consume (Geier et al. 2006). Thus, it seems that when the amount of food on a plate or bowl increases, so does actual consumption because it influences consumption norms, thereby lessening one's reliance on selfmonitoring. The difficulty of monitoring precisely how much one consumes makes people rely heavily on visual consumption cues (Pudel and Oetting 1977; Wansink, Painter, and North 2005). Although health claims attached to indulgent foods do not represent visual consumption cues per se, we have shown that functional health claims 
trigger long-term health goals for which it is likely that the size or quantity of an indulgence matters (i.e., a lot of unhealthy food is bad for reaching a health goal; just a little of unhealthy food is not so bad, as an external control represented by the limited quantity is already imposed (Argo and White 2011). It would be interesting to find out whether the activation of goals relevant for size or quantity would make size salient, thereby moderating the effect of the functional health claim on consumption. Specifically, it might be possible that the activation of the health goal draws attention to the quantity of the food. If the consumer is presented with only a small amount of "bad" food, s/he might experience less conflict because the maximum amount possible to eat is limited. Hence, the reduced consumption evoked by functional health claims might be more pronounced for large, relative to small amounts of indulgence foods. 



\section{REFERENCES}

Aaker, David A. and Erich Joachimsthaler (2000), "The Brand Relationship Spectrum: The Key to the Brand Architecture Challenge," California Management Review, 42 (Summer), 8-23.

Advertising Age (2000), "Firestone Woes Create Opportunity,” Vol. 2011.

Ahluwalia, Rohini, H. Roa Unnava and Robert E. Burnkrant (2001), “The Moderating Role of Commitment on the Spillover Effect of Marketing Communication," Journal of Marketing Research, 38 (November), 458-70.

Anderson, John R. (1983), “A Spreading Activation Theory of Memory,” Journal of Verbal Learning and Verbal Behavior, 22 (3), 261-95.

Andrews, Craig J., Richard G. Netemeyer, and Scott Burton (1998), "Consumer Generalization of Nutrient Content Claims in Advertising," Journal of Marketing, 62 (October), 62-75.

Argo, Jennifer J. and Katherine White (2011), "When Do Consumers Eat More? The Role of Appearance Self-Esteem and Food Packaging Cues," Journal of Marketing, ahead of print, 1-14.

Bailis, Daniel S., Tara M. Thacher, Nathan C.A. Aird and Lisa J. Lipschitz (2011), "Affective and Behavioral Traces of Goal Conflict With Physical Activity," Basic and Applied Social Psychology, 33 (2), 128-44.

Balachander, Subramanian and Sanjoy Ghose (2003), "Reciprocal Spillover Effects: A Strategic Benefit of Brand Extensions," Journal of Marketing, 67 (January), 414.

Balcetis, Emily and David Dunning (2006), "See What You Want to See: Motivational Influences on Visual Perception," Journal of Personality and Social Psychology, 91 (4), 612-25. 
Bargh, John A. (1990), “Auto-Motives: Preconscious Determinants of Social Interaction," In E. T. Higgins \& R. M. Sorrentino (Eds.), Handbook of motivation and cognition: Foundations of social behavior, 2, 93-130, New York: Guilford.

Bargh, John. A. and Peter M. Gollwitzer (1994), "Environmental Control of GoalDirected Action: Automatic and Strategic Contingencies between Situations and Behavior," In W. D. Spaulding (Ed.), Integrative Views of Motivation, Cognition, and Emotion, Nebraska Symposium on Motivation (41, 71-124), Lincoln: University of Nebraska Press.

Bargh, John A. and Tanya L. Chartrand (1999), "The Unbearable Automaticity of Being," American Psychologist, 54, 462-79.

Bargh, John A. and Tanya L. Chartrand (2000), "The Mind in the Middle: A Practical Guide to Priming and Automaticity Research," in Handbook of Research Methods in Social and Personality Psychology, Reis T. and C.M. Judd, Eds. New York: Cambridge University Press.

Barsalou, Lawrence and Daniel Sewell (1985), "Contrasting the Representation of Scripts and Categories," Journal of Memory and Language, 24 (6), 646-65.

Baumeister, Roy F. (2002), "Yielding to Temptation: Self-Control Failure, Impulsive Purchasing, and Consumer Behavior," Journal of Consumer Research, 28 (4), 670-76.

Berman, Mark, and Risa Lavizzo-Mourey (2008), "Obesity Prevention in the Information Age: Caloric Information at the Point of Purchase," Journal of the American Medical Association, 300, 433-435.

Bruner, Jerome S. and Cecile C. Goodman (1947), "Value and Need as Organizing Factors in Perception," Journal of Abnormal Social Psychology, 42, 33-44.

Caballero, B. (2007), “The Global Epidemic of Obesity: An Overview," Epidemiologic Reviews, 29 (1), 1. 
Center for Consumer Freedom (2007), “CCF Report: New Perspective on Obesity,” http://www.consumerfreedom.com/2007/12/3507-ccf-report-new-perspectiveon-obesity/.

CDC, Centers for Disease Control and Prevention (2011), “Overweight and Obesity, Economic Consequences," http://www.cdc.gov/obesity/causes/economics.html.

Chandon, Pierre and Brian Wansink (2007), "The Biasing Health Halos of Fast-Food Restaurant Health Claims: Lower Calorie Estimates and Higher Side-Dish Consumption Intentions," Journal of Consumer Research, 34 (October), 301 14.

Chernev, Alexander and David Gal (2010), "Categorization Effects in Value Judgments: Averaging Biases in Evaluating Combinations of Vices and Virtues," Journal of Marketing Research, 47 (August), 738-47.

Chernev, Alexander (2011), The Dieter's Paradox: Why Dieting makes us Fat, Advance Copy, Cerebellum Press.

Chernev, Alexander (2011a), "The Dieter's Paradox," Journal of Consumer Psychology, 21 (April), 178-83.

Chitturi, Ravindra, Rajagopal Raghunathan, and Vijay Mahajan (2007), "Form versus Function: How the Intensities of Specific Emotions Evoked in Functional versus Hedonic Trade-offs Mediate Product Preferences," Journal of Marketing Research, 44, 702-14.

Cleeren, Kathleen, Harald van Heerde and Marnik Dekimpe (2010), "Rising from the Ashes: How Brands and Categories can Overcome Product Harm Crises," working paper.

Collins, Allan M. and Elizabeth F. Loftus (1975), “A Spreading-Activation Theory of Semantic Processing," Psychological Bulletin, 82 (6), 407-28.

Critser, Greg (2003), "Fat Land: How Americans became the fattest People in the World," New York: Mariner/Houghton Mifflin. 
Cutler, David M., Edward L. Glaeser and Jesse M. Shapiro (2003), "Why Have Americans Become More Obese?” Journal of Economic Perspectives, 17 (3), 93-118.

Consumer Reports on Health (2006), “Why You Can’t Just Eat One,” 18 (3), 10.

Dahlen, Micael and Frederik Lange (2006), "A Disaster is Contagious: How a Brand in Crisis Affects Other Brands," Journal of Advertising Research, (December), 388-97.

Dhar, Ravi and Itamar Simonson (1999), "Making Complementary Choices in Consumption Episodes: Highlighting versus Balancing," Journal of Marketing Research, 36 (1), 29-44.

Dawar, Niraj and Madan M. Pillutla (2000), "Impact of Product-Harm Crises on Brand Equity: The Moderating Role of Consumer Expectations," Journal of Marketing Research, 37 (May), 215-26.

Epstein, Leonhard H. and J. Leddy (2006), "Food Reinforcement," Appetite, 46 (1), 225.

Fazio, Russell H. (1990), "A Practical Guide to the Use of Response Latencies in Social Psychological Research," in Review of Personality and Social Psychology, Vol. 11, C. Hendrick and M.S. Clark, eds. Newbury Park, CA: Sage, 74-97.

Fedoroff, Ingrid, Janet Polivy and Peter C. Herman (1997), "The Effect of Pre-Exposure to Food Cues on the Eating Behavior of Restrained and Unrestrained Eaters," Appetite, 28 (1), 33-47.

Fedoroff, Ingrid, Janet Polivy and Peter C. Herman (2003), “The Specificity of Restraint versus Unrestraint Eaters' Responses to Food Cues: General Desire to Eat, or Craving for the Cued Food?" Appetite, 41 (1), 7-13.

Festinger, Leon (1957), “A Theory of Cognitive Dissonance,” Stanford, CA: Stanford University Press.

Finkelstein, Stacey R. and Ayelet Fishbach (2010), "When Healthy Food Makes You Hungry," Journal of Consumer Research, 37 (3), 357-67. 
Fishbach, Ayelet, Ronald S. Friedman, and Arie W. Kruglanski (2003), "Leading Us Not Unto Temptation: Momentary Allurements Elicit Overriding Goal Activation,” Journal of Personality and Social Psychology, 84, 296-309.

Fishbach, Ayelet and Ying Zhang (2008), "Together or Apart: When Goals and Temptations Complement Versus Compete," Journal of Personality and Social Psychology, 94, 547-59.

Fishbach, Ayelet and K. Myrseth (forthcoming), “The Dieter's Dilemma: Identifying When and How to Control Consumption," in L. Dube (Ed.) Obesity Prevention: The Role of Society and Brain on Individual Behavior, Elsevier.

Food and Agriculture Organization (2002), “The Developing World's New Burden: Obesity," http://www.fao.org/FOCUS/E/obesity/obes1.htm.

Ford, Thomas E. and Arie W. Kruglanski (1995), "Effects of Epistemic Motivations on the Use of Accessible Constructs in Social Judgment," Personality and Social Psychology Bulletin, 21, 950-62.

Fujita, Kentaro, Yaakov Trope, Nira Liberman and Maya Levin-Sagi (2006), “Construal Levels and Self-Control," Journal of Personality and Social Psychology, 90 (3), 351-67.

Geier, Andrew B., Paul Rozin and Gheorghe Doros (2006), "Unit Bias: A New Heuristic That Helps Explain the Effect of Portion Size on Food Intake," Psychological Science, 17 (6), 521-25.

Geyskens, Kelly, Siegfried Dewitte, Mario Pandelaere, and Luk Warlop (2008), “Tempt Me Just a Little Bit More: The Effects of Prior Food Temptation Actionability on Goal Activation and Consumption," Journal of Consumer Research, 35 (December), 600-10.

Golec, Agnieszka and Christopher M. Federico (2004), "Understanding Responses to Political Conflict: Interactive Effects of the Need for Closure and Salient Conflict Schemas," Journal of Personality and Social Psychology, 87, 750-62. 
Grunert, Klaus G. and Josephine M. Wills (2007), “A Review of European Research on Consumer Response to Nutrition Information on Food Labels," Journal of Public Health, 15, 385-99.

Hale, Todd (2010), "Food: The Social Network of the Ages," NielsenWire, http://blog.nielsen.com/nielsenwire/consumer/food-the-social-network-of-theages/.

Heatherton, Todd F., Janet Polivy, and C. Peter. Herman (1990), "Dietary Restraint: Some Current Findings and Speculations," Psychology of Addictive Behaviors, 4, 100-6.

Herman, C. Peter and Janet Polivy (1980), "Restraint Eating," in A.J. Stunkard (Ed.), Obesity, (208-25), Philadelphia: Saunders.

Hill, James O. and John C. Peters (1998), "Environmental Contributions to the Obesity Epidemic," Science, 280, 1371-74.

Hoch, Stephen J. and George F. Loewenstein (1991), “Time-Inconsistent Preferences and Consumer Self-Control," Journal of Consumer Research, 17 (4), 492-507.

John, Deborah Roedder, Barbara Loken and Christopher Joiner (1998), "The Negative Impact of Extensions: Can Flagship Products be Diluted?" Journal of Marketing, 62 (January), 19-32.

Jung, Grant Susan, Prashant Malaviya, and Brian Sternthal (2004), "The Influence of Negation on Product Evaluations," Journal of Consumer Research, 31 (3), 583-91.

Kahneman, Daniel and Amos Tversky (1979), "Prospect Theory: An Analysis of Decision under Risk”, Econometrica, 47 (2), 263-92.

Kanouse, David E. and L. Reid Jr. Hanson (1972), "Negativity in Evaluations," in Attribution: Perceiving the Causes of Behavior, E.E Jones et al., Ed. Morristown, NJ: General Learning Press.

Keller, Kevin Lane (1993), “Conceptualizing, Measuring, and Managing CustomerBased Brand Equity,” Journal of Marketing, 57 (January), 1-22. 
Khan, Uzma and Ravi Dhar (2006), "Licensing Effect in Consumer Choice," Journal of Marketing Research, 43 (May), 259-66.

Kivetz, Ran and Itamar Simonson (2002), "Earning the Right to Indulge: Effort as a Determinant of Customer Preferences Toward Frequency Program Rewards," Journal of Marketing Research, 39 (2), 155-70.

Kruglanski, Arie W. and T Freund (1983), “The Freezing and Un-Freezing of LayInferences: Effects on Impressional Primacy, Ethic Stereotyping and Numerical Anchoring," Journal of Experimental Social Psychology, 19, 44868.

Kruglanski, Arie W. (1989), "Lay Epistemics and Human Knowledge: Cognitive and Motivational Bases," New York: Plenum.

Kruglanski, Arie W. and Donna Webster (1996), "Motivated Closing of the Mind: Seizing and Freezing," Psychological Review, 103, 263-83.

Kurzbard, Gary and George J. Siomkos (1992), “Crafting a Damage Control Plan: Lessons from Perrier,” Journal of Business Strategy, 13 (March/April), 39-43.

Labroo, Aparna A. and Angela Y. Lee (2006), "Between Two Brands: A Goal Fluency Approach of Brand Evaluation," Journal of Marketing Research, 43 (August), 967-84.

Lei, Jing, Niraj Dawar and Jos Lemmink (2008), "Negative Spillover in Brand Portfolios: Exploring the Antecedents of Asymmetric Effects," Journal of Marketing, 72 (May), 111-23.

Levin, Irwin and Gary Gaeth (1988), "How Consumers are Affected by the Framing of Attribute Information Before and After Consuming the Product," Journal of Consumer Research, 15 (December), 374-78.

Livingstone, M. Barbara E. and Alison E. Black (2003), "Markers of the validity of reported energy Intake," The Journal of Nutrition, 133 (3), 895-920.

Loewenstein, George F. (1996), “Out of Control: Visceral Influences on Behavior,” Organizational Behavior and Human Decision Processes, 65, 272-92. 
Lopez-Walters, Kim and Larry Wu (2007), "Healthy Indulgent vs. Indulgent Health: Avoiding the Confusion," Vol. November: IconCulture Point of View.

Lutz, Richard J. (1975), "Changing Brand Attitudes Through Modification of Cognitive Structure," Journal of Consumer Research, 1, 49-59.

Lynch, John (1982), "On the External Validity of Experiments in Consumer research," Journal of Consumer Research, 9 (3), 225-39.

Mayo, Ruth, Yaakov Schul and Eugene Burnstein (2004), "I am Not Guilty vs. I am Innocent: Successful Negation May Depend on the Schema Used for Its Encoding,” Journal of Experimental Social Psychology, 40 (July), 433-49.

McGinnies, Elliot (1949), "Emotionality and Perceptual Defense," Psychological Review, 56, 244-51.

Medin, Douglas L. and Edward E. Smith (1984), "Concepts and Concept Formation," Annual Review of Psychology, 35, 115-38.

Metcalfe, Janet and Walter Mischel (1999), “A Hot/Cool-System Analysis of Delay of Gratification: Dynamics of Willpower," Psychological Review, 106, 3-19.

Meyers-Levy, Joan and Alice M. Tybout (1989), "Schema Incongruity as a Basis for Product Evaluation," Journal of Consumer Research, 16 (1), 39-54.

Monsivais, Pablo and Adam Drewsnowski (2007), "The Rising Costs of Low-EnergyDensity Food”, Journal of the American Dietetic Association, 107 (12), 20716.

Morrin, Maureen (1999), “The Impact of Brand Extensions on Parent Brand Memory Structures and Retrieval Processes," Journal of Marketing Research, 36 (November), 517-25.

Nestle, Marion (2002), "Food Politics: How the Food Industry Influences Nutrition and Health," Berkley: University of California Press.

Nielsen, Samara J. and Barry M. Popkin (2003), "Patterns and Trends in Food Portion Sizes, 1977-1998," Journal of the American Medical Association, 289 (4), 45053. 
Ogden, Jane (1995), “Cognitive and Motivational Consequences of Dieting," European Eating Disorder Review, 24, 228-41.

Okada, Erica Mina (2005), "Justification Effects on Consumer Choice of Hedonic and Utilitarian Goods," Journal of Marketing Research, 42 (February), 43-53.

Palmer, Sharon (2008), "Healthy Indulgence: A Best of Both Worlds Approach to Eating," Today's Dietitian, 10 (September), 62.

Papies, Esther K., Wolfgang Stroebe and Henk Aarts (2007), "Pleasure in the Mind: Restraint Eating and Spontaneous Hedonic Thoughts about Food," Journal of Experimental Social Psychology, 43 (5), 810-17.

Papies, Esther K., Wolfgang Stroebe and Henk Aarts (2008), "Healthy Cognition: Processes of Self-Regulatory Success in Restrained Eating," Personality and Social Psychology Bulletin, 34 (9), 1290-300.

Payne, John W. and James R. Bettman (2000), "Preferential Choice and Adaptive Strategy Use," in Bounded Rationality: The Adaptive Toolbox, G. Gigerenzer and R. Selten eds., MIT Press.

Polivy, Janet, C. Peter Herman, Rick Hackett and Irka Kuleshnyk (1986), “The Effects of Self-Attention and Public Attention on Eating in Restrained and Unrestrained Subjects," Journal of Personality and Social Psychology, 50, 1253-60.

Pudel, V.E. and M. Oetting (1977), "Eating in the Laboratory: Behavioral Effects of the Positive Energy Balance," International Journal of Obesity, 1 (4), 369-86.

Raghunathan, Rajagopal, Rebecca Walker Naylor, and Wayne D. Hoyer (2006), "The Unhealthy = Tasty Intuition and its Effects on Taste Inferences, Enjoyment, and Choice of Food Products," Journal of Marketing, 70 (October), 170-84.

Raghunathan, Rajagopal (2007), "Silver Clouds, Dark Linings: The "More Hedonic = Less Functional" Intuition and Its Implications for Consumption Decisions," Presentation held at the University of Leven, Belgium. 
Ramanathan, Suresh and Patti Williams (2007), "Immediate and Delayed Emotional Consequences of Indulgence: The Moderating Influence of Personality Type on Mixed Emotions," Journal of Consumer Research, 34 (August), 212-23.

Raynor, Hollie A. and Leonard H. Epstein (2001), "Dietary Variety, Energy Regulation, and Obesity," Psychological Bulletin, 127, 325-41.

Roehm, Michelle and Alice M. Tybout (2006), "When Will a Brand Scandal Spillover and How Should Competitors Respond?" Journal of Marketing Research, 43 (August), 366-73.

Rook, Dennis W. (1987), "The Buying Impulse," Journal of Consumer Research, 14 (September), 189-99.

Schuldt, Jonathan P. and Norbert Schwarz (2010), "The 'Organic' Path to Obesity? Organic Claims Influence Calorie Judgments and Exercise Recommendations,” Judgment and Decision Making, 5 (June), 144-50.

Scott, Carol A. and Alice M. Tybout (1981), “Theoretical Perspectives on the Impact of Negative Information: Does Valence Matter?" in Advances in Consumer Research, Vol. 8, Kent B. Monroe, ed. Ann Arbor, MI: Association for Consumer Research, 408-409.

Shah, James Y., Ron Friedman and Arie W. Kruglanski (2002), "Forgetting All Else: On the Antecedents and Consequences of Goal Shielding," Journal of Personality and Social Psychology, 83 (6), 1261-80.

Shiv, Baba and Alexander Fedorikhin (1999), "Heart and Mind in Conflict: The Interplay of Affect and Cognition in Consumer Decision Making," Journal of Consumer Research, 26 (3), 278-92.

Skowronski, John T. and Donald E. Carlston (1989), "Social Judgment and Social Memory: The Role of Cue Diagnosticity in Negativity, Positivity, and Extremity Biases," Journal of Personality and Social Psychology, 52 (4), 68999.

Spencer, Stephen J., Mark P. Zanna, and Geoffrey T. Fong (2005), "Establishing A Causal Chain: Why Experiments Are Often More Effective Than Mediation 
Analyses in Examining Psychological Processes," Journal of Personality and Social Psychology, 89 (6), 845-51.

Stroebe, Wolfgang, Wendy Mensink, Henk Aarts, Henk Schut and Arie W. Kruglanski (2008), "Why Dieters Fail: Testing the Goal Conflict Model of Eating," Journal of Experimental Social Psychology, 44, 26-36.

Tepper, Beverly and Amy Trail (1998), "Taste or Health: A Study on Consumer Acceptance of Corn Chips," Food Quality and Preference, 9 (4), 267-72.

Thompson, Erik P., Robert J. Roman, Gordon B. Moskowitz, Shelly Chaiken and John A. Bargh (1994), “Accuracy Motivation Attenuates Covert Priming Effects: The Systematic Reprocessing of Social Information," Journal of Personality and Social Psychology, 66, 474-89.

Vermeier, Iris (2003), "The Influence of Need for Closure on Consumer Choice Behavior," Doctoral Dissertation, University of Ghent.

Vogt, Julia, Ljubica Lozo, Ernst H. W. Koster, and Jan D. Houwer (2011), “On the Role of Goal Relevance in Emotional Attention: Disgust Evokes Early Attention to Cleanliness," Cognition and Emotion, 25 (3), 466-77.

Wadden, Thomas A., Kelly D. Brownell and Gary D. Foster (2002), "Obesity: Responding to the Global Epidemic," Journal of Consulting and Clinical Psychology, 70, 510-25.

Wansink, Brian (1996), “Can Package Size Accelerate Usage Volume?” Journal of Marketing, 60 (3), 1-14.

Wansink, Brian (1996a), "Mindless Eating: Why We Eat More Than We Think," New York, NY: Bantam Books.

Wansink, Brian (2004), "Environmental Factors that Increase the Food Intake and Consumption Volume of Unknowing Consumers," Annual Review of Nutrition, $24,455-79$. 
Wansink, Brian, James E. Painter and Jill North (2005), "Bottomless Bowls: Why Visual Cues of Portion Size May Influence Intake," Obesity Research, 13, 93100.

Wansink, Brian and Pierre Chandon (2006), "Can 'Low-Fat' Nutrition Labels Lead to Obesity?" Journal of Marketing Research, 43 (November), 605-17.

Ward, Andrew and Tracy Mann (2000), “Don’t Mind if I Do: Disinhibited Eating under Cognitive Load," Journal of Personality and Social Psychology, 78 (4), 75363.

Wertenbroch, Klaus (1998), “Consumption Self-Control via Purchase Quantity Rationing," Marketing Science, 17 (4), 317-37.

Wheeler, Christian S. and Jonah Berger (2007), "When the Same Prime Leads to Different Effects," Journal of Consumer Research, 34 (3), 357-68.

Wilcox, Keith, Lauren Block, Gavan Fitzsimons and Beth Vallen (2009), "Vicarious Goal Fulfillment: When the Mere Presence of a Healthy Option Leads to an Ironically Indulgent Decision," Journal of Consumer Research, 36 (October), 380-93.

Willmer, Karen (2007), "Guilt-Free Indulgence is What Consumers Want, Says Datamonitor," http://www.bakeryandsnacks.com/Markets/Guilt-freeindulgence-is-what-consumers-want-says-Datamonitor.

Wolf, Anne M. and Graham A. Colditz (1998), "Current Estimates of the Economic Cost of Obesity in the United States," Obesity Research, 6 (2), 97-106.

Wright, Peter (1974), “The Harassed Decision Maker: Time Pressure, Distractions, and the Use of Evidence," Journal of Applied Psychology, 59, 555-61.

WHO, World Health Organization (2008), "Controlling the Global Obesity Epidemic," Nutrition Topics, http://www.who.int/nutrition/topics/obesity/en/.

WHO, World Health Organization (2011), "Obesity and Overweight," Fact Sheet No. 311, http://www.who.int/mediacentre/factsheets/fs311/en/. 
Zou, Ning Ning and Jill Hobbs (2006), "Modeling Functional Food Choice and Health Care Impacts: A Literature Review," Consumer and Market Demand Agricultural Policy Research Network, Project Report CMD-06-02. 

APPENDIX A 


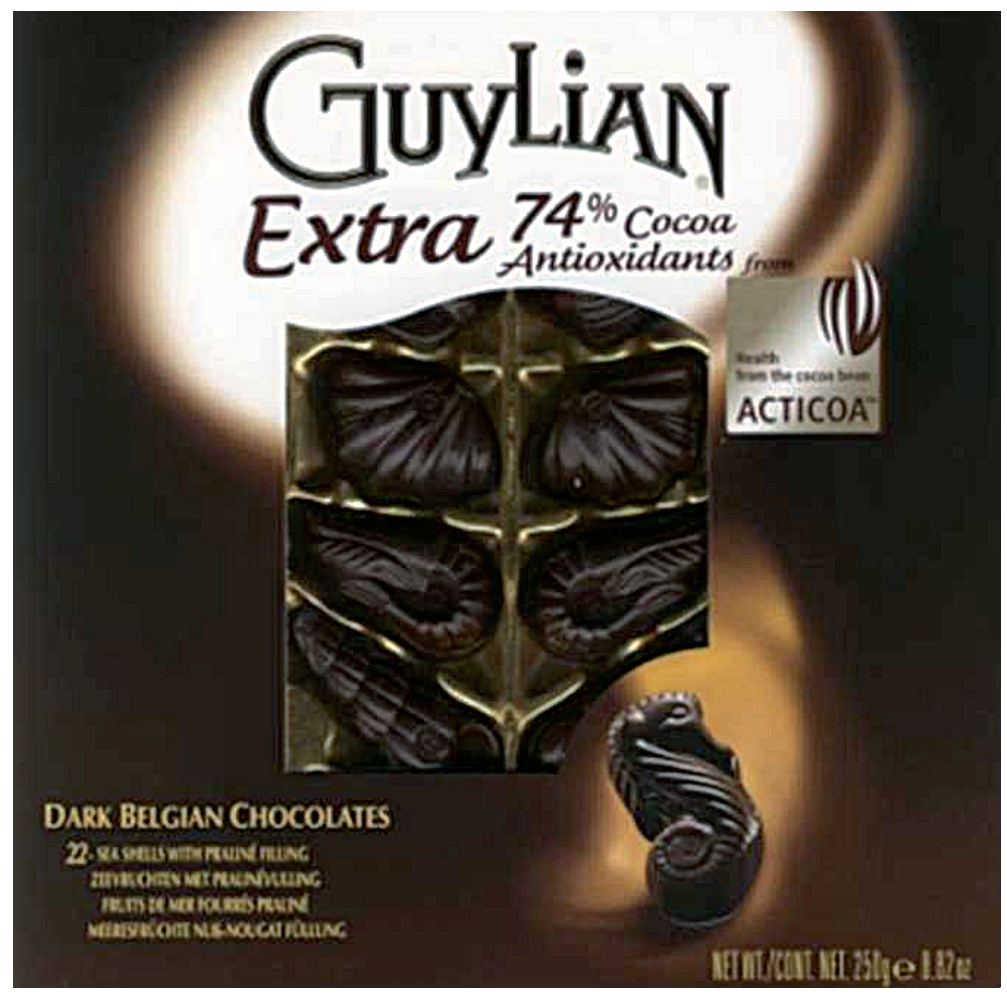




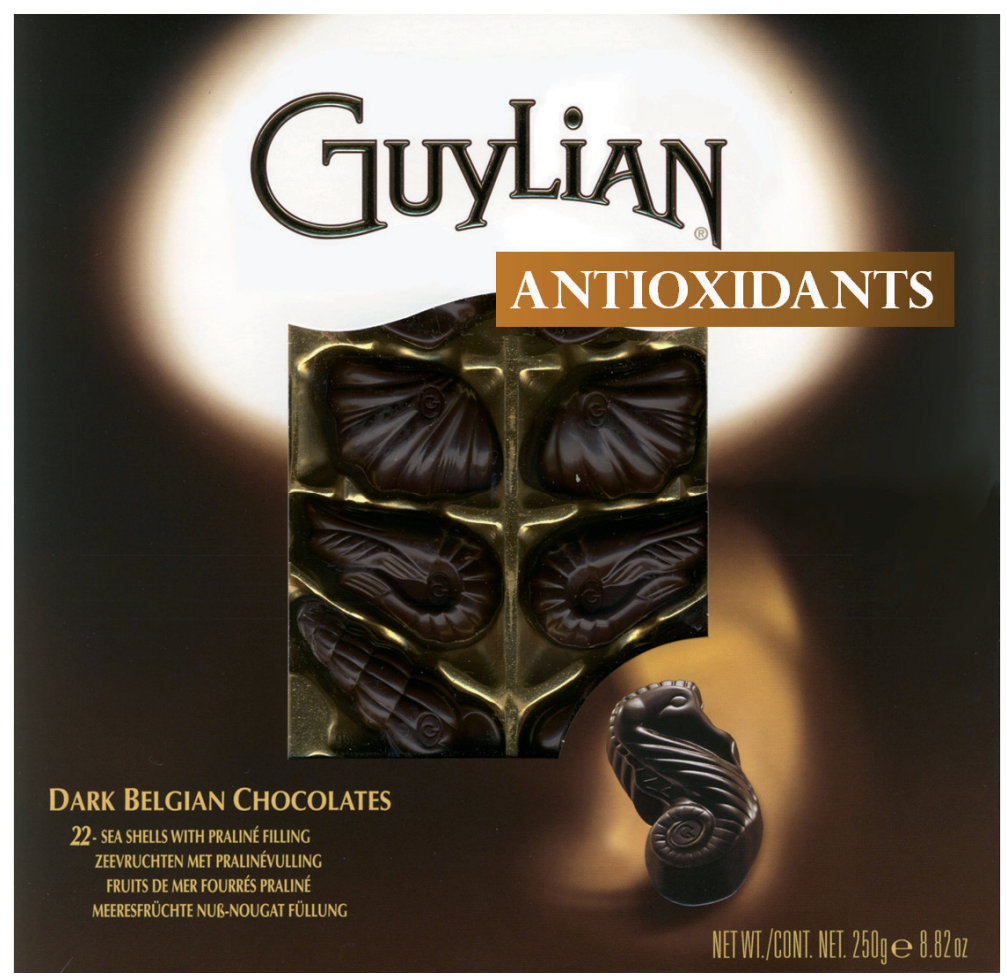




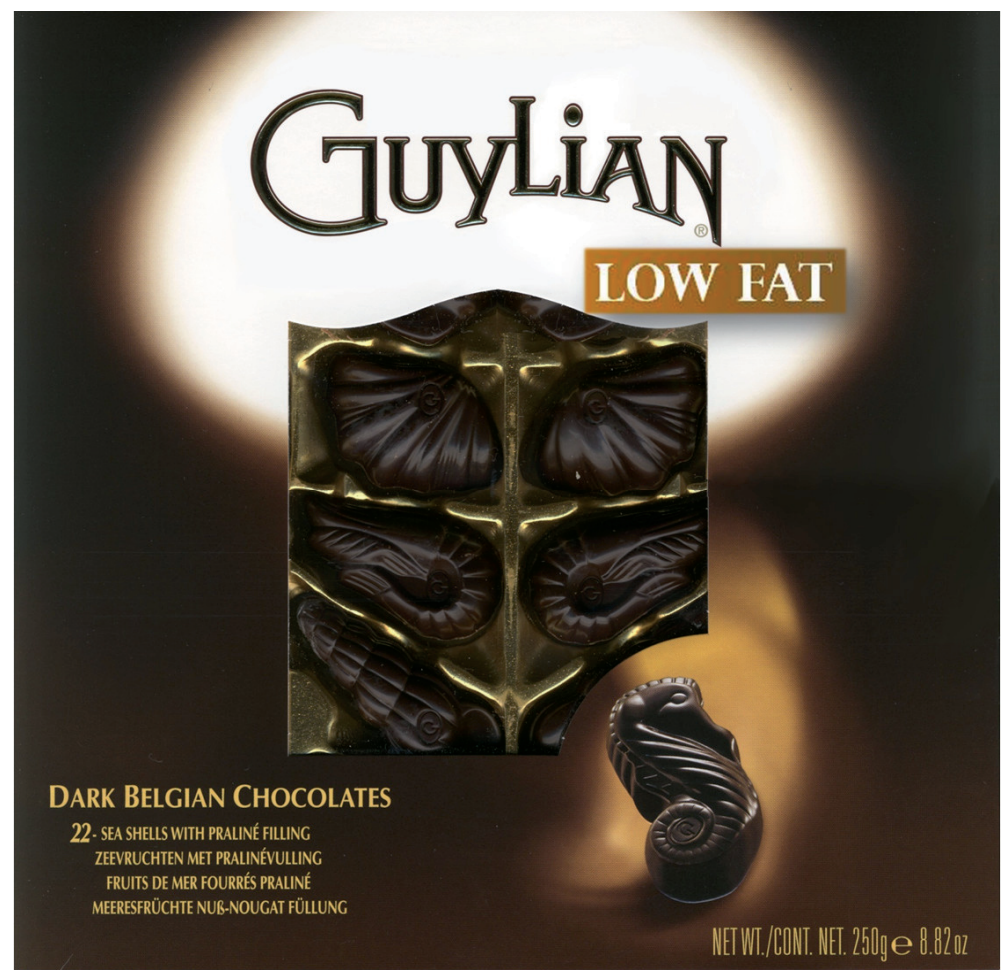




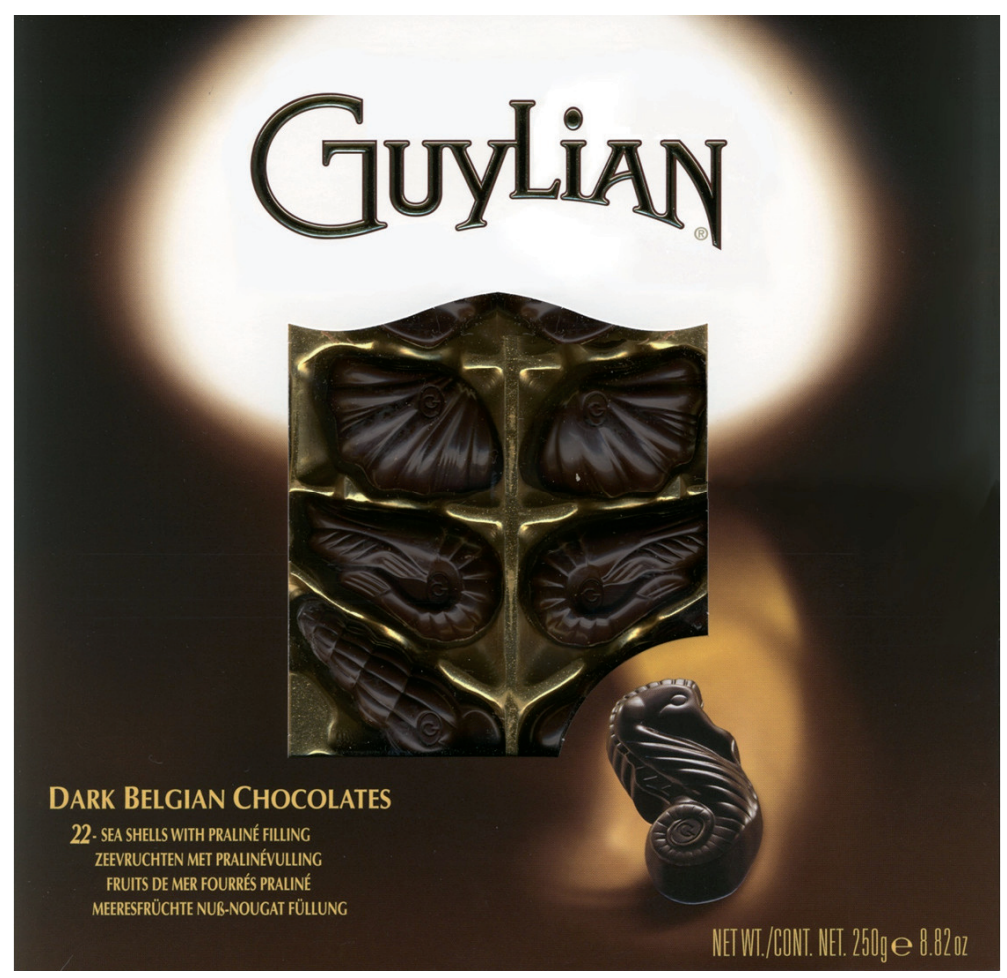




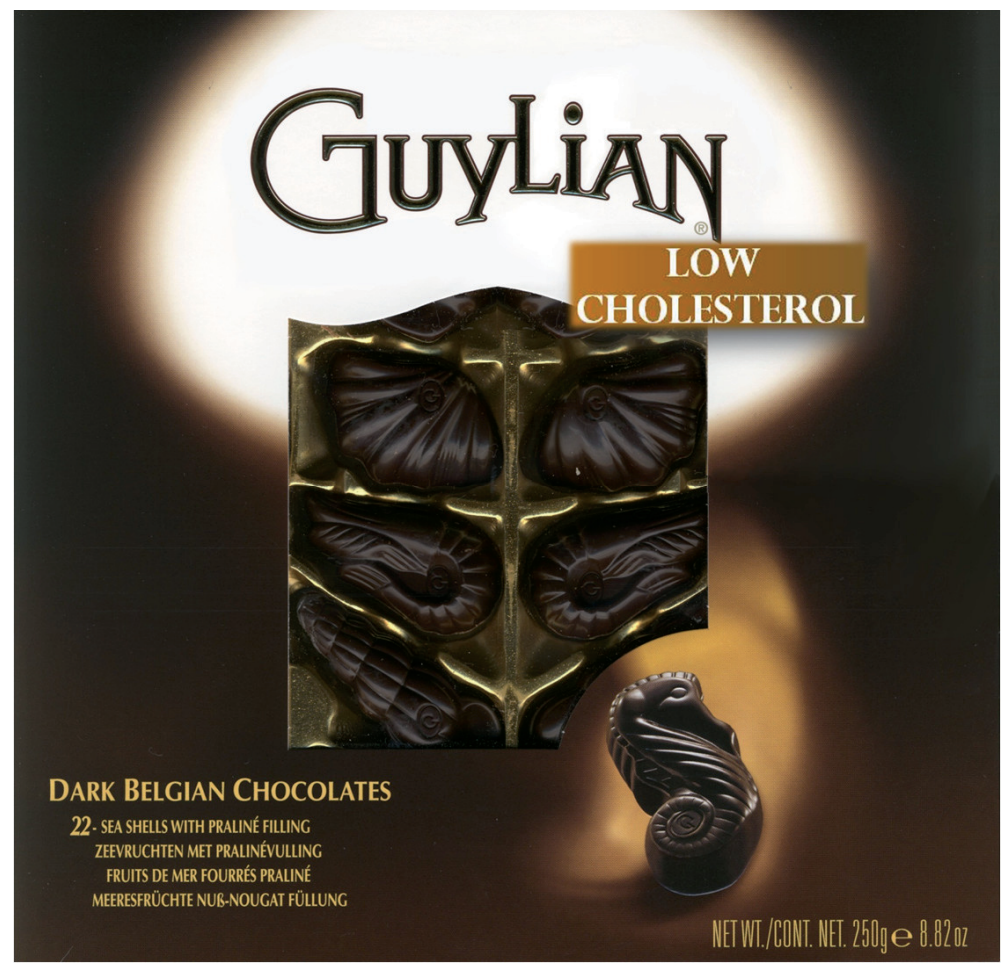


APPENDIX B 


\section{Healthy. Happy. Life.}

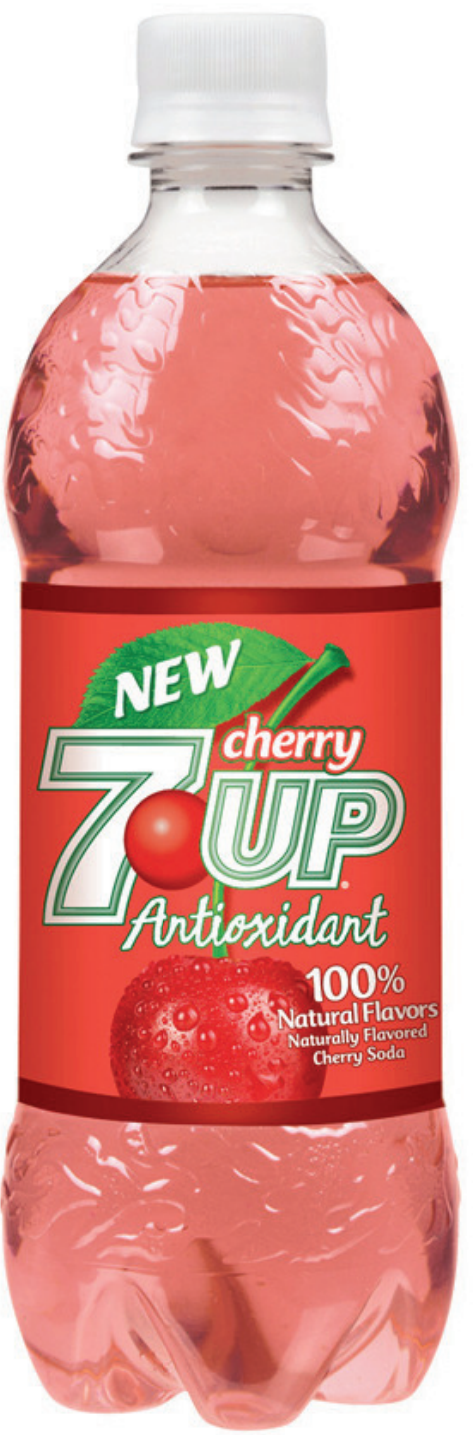




\section{Happy. Life.}

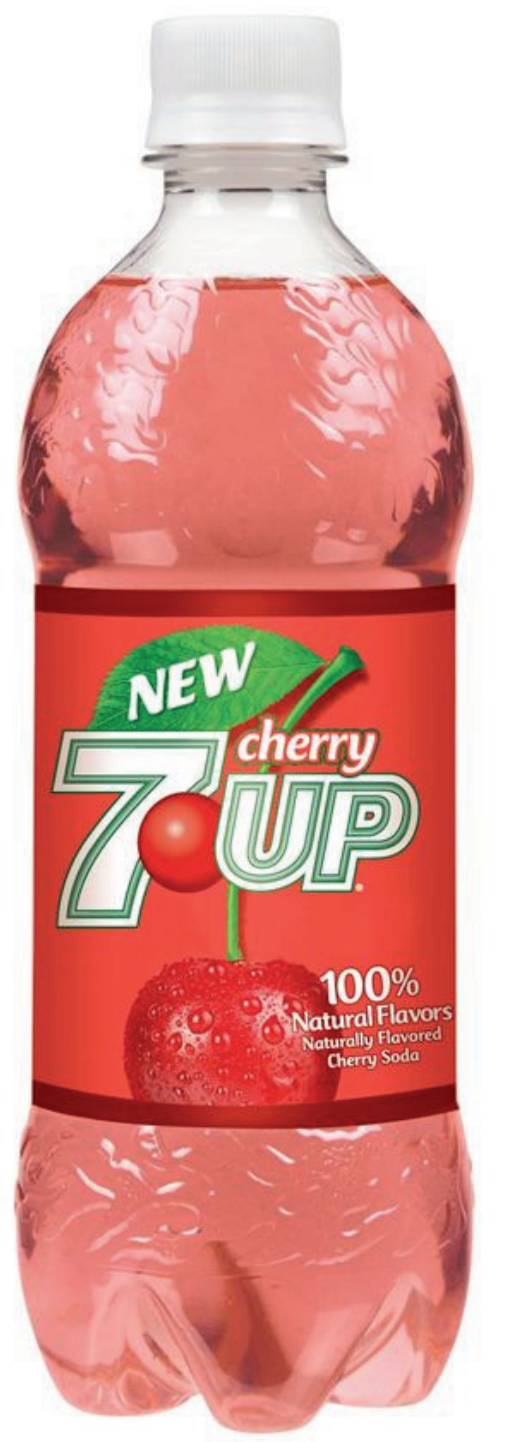





\section{CURRICULUM VITAE}

Nina Belei was born on January 1st 1980 in Aachen, Germany. From 1990 till 1999, she attended secondary school at the Anne-Frank Gymnasium in Aachen. As part of her secondary education, Nina was a visiting student at Richland High School in Dallas, TX, USA for seven months in 1996. After receiving her high school degree (Abitur) in 1999, Nina participated in a two-year apprenticeship program at the Stadtsparkasse Düsseldorf in Germany and became a certified banker in 2002. In the following four years, Nina studied International Business at Maastricht University in the Netherlands with a major in marketing. As part of her undergraduate studies, Nina spent one semester as a visiting student at the University St. Gallen in Switzerland in 2004. In 2007, Nina graduated with distinction (cum laude) and received her Master of Science Degree in International Business. She then worked as a Junior Lecturer for two months, before she joined the Department of Marketing \& Supply Chain Management at Maastricht University as a doctoral candidate. In the course of her doctoral studies, Nina conducted research in the field of consumer behavior and taught several courses in the general field of marketing. As the coordinator of the course 'Brand Management' and together with its teaching staff, Nina was awarded the annual UM Education Prize 2009 for outstanding contribution to education at Maastricht University. In 2010/2011, Nina spent seven months as a visiting Ph.D. student at the Kellogg School of Management at Northwestern University in Evanston, IL, USA; a stay sponsored by Professor Dr. Brian Sternthal and Professor Dr. Nidhi Agrawal. During that time, parts of her research studies were carried out also at the University of Chicago (Chicago, IL, USA) in collaboration with Professor Dr. Suresh Ramanathan. As of August 2012, Nina will start a position as Assistant Professor of Marketing at Radboud University, Nijmegen School of Management, the Netherlands. 